\title{
Sexual dimorphism in the Arachnid orders
}

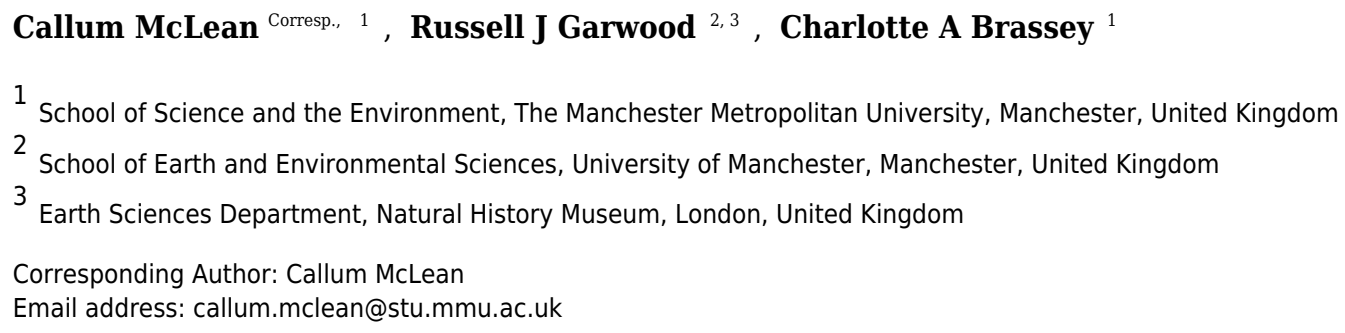

Sexual differences in size and shape are common across the animal kingdom. The study of sexual dimorphism can provide insight into the sexual- and natural-selection pressures experienced by males and females in different species. Arachnids are diverse, comprising over 100,000 species, and exhibit some of the more extreme forms of sexual dimorphism in the animal kingdom, with the males and females of some species differing dramatically in body shape and/or size. Despite this, research on arachnid sexual dimorphism has primarily focused on specific clades as opposed to observing traits across arachnid orders, the smallest of which have received comparatively little attention. This review provides an overview of the research to date on the trends and potential evolutionary drivers for sexual dimorphism and sexual size dimorphism (SSD) in individual arachnid orders, and across arachnids as a whole. The most common trends across Arachnida are female-biased SSD in total body size, male-biased SSD in relative leg length, and sexual dimorphism in pedipalp length and shape. However, the evolution of sexually dimorphic traits within the group is difficult to elucidate due to uncertainty in arachnid phylogenetic relationships. Based on the dataset we gathered here we highlight gaps in our current understanding and suggest areas for future research. 
$4{ }^{1}$ School of Science and the Environment, Manchester Metropolitan University, M1 5GD

$5{ }^{2}$ School of Earth and Environmental Sciences, University of Manchester, M13 9PT

$6 \quad{ }^{3}$ Earth Sciences Department, Natural History Museum, London SW7 5BD, UK

$7 \quad$ *Corresponding author: callum.mclean@stu.mmu.ac.uk 


\section{Abstract}

10 Sexual differences in size and shape are common across the animal kingdom. The study of

11 sexual dimorphism can provide insight into the sexual- and natural-selection pressures

12 experienced by males and females in different species. Arachnids are diverse, comprising over

13100,000 species, and exhibit some of the more extreme forms of sexual dimorphism in the

14 animal kingdom, with the males and females of some species differing dramatically in body

15 shape and/or size. Despite this, research on arachnid sexual dimorphism has primarily focused on

16 specific clades as opposed to observing traits across arachnid orders, the smallest of which have

17 received comparatively little attention. This review provides an overview of the research to date

18 on the trends and potential evolutionary drivers for sexual dimorphism and sexual size

19 dimorphism (SSD) in individual arachnid orders, and across arachnids as a whole. The most

20 common trends across Arachnida are female-biased SSD in total body size, male-biased SSD in

21 relative leg length, and sexual dimorphism in pedipalp length and shape. However, the evolution

22 of sexually dimorphic traits within the group is difficult to elucidate due to uncertainty in

23 arachnid phylogenetic relationships. Based on the dataset we gathered here we highlight gaps in

24 our current understanding and suggest areas for future research. 


\section{Introduction}

27 Sexual dimorphism (SD), the difference in morphological, physiological and behavioural traits

28 between males and females, is ubiquitous in nature. Common hypotheses to explain sex-specific

29 divergence in body size and shape relate to sexual selection, intraspecific niche divergence and

30 female fecundity pressures (Shine, 1989; Andersson, 1994). The first major step to understand

31 the evolution of SD, however, is to document and describe the occurrence of sexually dimorphic

32 traits in a wide range of species. Amongst vertebrates, for instance, the occurrence of SD is well

33 documented. In mammals, it has been quantified in 1370 species, representing around $30 \%$ of

34 known mammalian species (Lindenfors, Gittleman \& Jones, 2007). Datasets of similar size have

35 been used to quantify SD in reptiles (1341 species, Cox et al., 2007) and birds (Owens \&

36 Hartley, 1998). In contrast, the SD literature pertaining to invertebrates is more fragmented

37 (Abouheif \& Fairbairn, 1997), particularly within arachnids. Whilst a limited number of studies

38 include large interspecific datasets their taxonomic breadth, relative to size of the group, pales in

39 comparison to those in the vertebrate literature. Although such studies can highlight trends

40 within specific groups, they provide only limited insight into trends across arachnids as a whole,

41 primarily due to its diversity: the group comprises over 100,000 species (Cracraft \& Donoghue, 42 2004).

Research into arachnid SD to date has largely focused on the spiders (Arachnida:

44 Araneae). This is driven by interest in their conspicuous sexual size dimorphism (SSD), a subset of SD, which pertains solely to size differences in segments or body size between sexes. Interest

46 in SSD in spiders stems from orb weaving spiders, which have the largest proportional weight

47 difference between females and males of all studied land animals (Foellmer \& Moya-Larano, 48 2007). Hence, research has probed the causes of this size disparity, and in particular the degree to 
49 which spiders follow Rensch's Rule, which states that if SSD is male-biased within a group, SSD

50 will increase with the increased body size of a species; the converse is also true if SSD is female-

51 biased in a group (Rensch, 1950). A focus on this question and group has left other arachnid

52 orders relatively understudied, in terms of both SSD or SD in general.

The lack of study is unfortunate, as arachnids constitute an interesting group for learning more about SD, due to their wide range of morphologies, habitats and life histories. Indeed, SD is present in numerous forms throughout the arachnids, including the occurrence of exaggerated weapons (Santos, Ferreira \& Buzatto, 2013), asymmetry (Proctor, 2003), extreme size dimorphism and other forms of polymorphism (e.g. Opiliones, Schizomida, and Acari). The wide range of potential causes and expressions of dimorphism allow the influence of sexual selection and niche partitioning within the group to be assessed in great depth.

Recent advances make a review of SD in arachnids timely and important. Rigorous statistical testing has become commonplace in the last decade, with recent papers not only commenting on sexual differences, but also quantifying their significance (e.g. Foellmer \& Moya-Larano, 2007; Zatz et al., 2011; Santos et al., 2013). Furthermore, high-resolution imaging has facilitated the study of smaller organisms, and the adoption of geometric morphometric techniques has allowed for sexual shape dimorphism to be quantified across a number of groups (e.g. humans, Franklin et al., 2007; reptiles, Kaliontzopoulou et al., 2007; spiders Fernández-

67 Montraveta \& Marugán-Lobón, 2017). Advances in phylogenetic methods have also made it possible to reconstruct the plesiomorphic state of sexually dimorphic traits, and the order of 69 character acquisition in their evolution, thus providing novel data to help understand the drivers of SD (e.g. Hormiga et al., 2000; Baker \& Wilkinson, 2001; Emlen et al., 2005). 
In light of these new approaches, here we present the first review of SD across

Arachnida. In particular, we have focused on collating data on the smaller arachnid orders, for which there is no pre-existing synthesis of sexual dimorphism. We begin by considering common methodological issues encountered throughout the arachnid SD literature. We move on to chart both SSD and shape dimorphism across eleven living orders, and touch on potential drivers in the evolution of sexually dimorphic arachnid traits. We conclude with a discussion of shared patterns in SD across Arachnida, and make suggestions for the direction of future research. As this review is of general interest to all researchers interested in the development of SD and morphology, all arachnid specific terms are defined or described as fully as possible.

\section{Considerations when studying sexual dimorphism in arachnids}

Across the animal kingdom, metrics for quantifying SSD differ considerably between groups. In mammals, SSD is synonymous with dimorphism in body mass (e.g. Weckerly, 1998; Lindenfors et al., 2007). In contrast, in reptiles and fish SSD is often studied using body length (e.g. Cox et al., 2007; Halvorsen et al., 2016), in amphibians using snout-vent length (e.g. Kupfer, 2007), and in birds using wing or tarsus length (e.g. Székely et al., 2007). Mass is infrequently reported for arachnids. A primary challenge when reporting arachnid SSD is therefore identifying a linear reference character which reliably represents 'overall' body size in both sexes. Body length inclusive of opisthosoma, for example, may increase with feeding and is, to some degree, a measure of hunting success (as further outlined in sections 'Araneae' and 'Solifugae' below). As a result, total body size in arachnids is often taken as carapace length or width (e.g. Weygoldt, 2000; Legrande \& Morse, 2000; Pinto-da-Rocha et al., 2007; Zeh, 1987a). However, carapace metrics can still be confounded by other shape variables (e.g. Vasconcelos et al., 2014; 
94 Fernández-Montraveta \& Marugán-Lobón, 2017). For instance, the presence of unusual gland

95 features in males of some spiders certainly modifies the shape of the carapace (Heinemann \&

96 Uhl, 2000). A number of potentially problematic reference characters are highlighted in the

97 following review.

$\mathrm{SD}$ in arachnids is often considered within the context of allometric scaling and support,

99 or lack thereof, for Rensch's rule. Once a suitable reference character has been identified,

100 advanced statistics can clarify when allometry is present, yet the choice of regression type bears

101 consideration. Type-I (ordinary least squares) regression is recommended when variation in the

102 dependent variable is more than three times that of the independent variable (Legrende, 1998),

103 yet allometric studies of organismal morphology frequently do not meet this criterion. Applying

104 Type-I models in instances where variance in the dependent and independent variables are

105 similar can result in an underestimation of the regression coefficient (e.g. Costa-Schmidt \&

106 Araújo, 2008) and potentially hide allometric growth. Yet in situations when measurement error

107 is low and measurement repeatability is very high, this underestimation is found to be negligible

108 (e.g. Kilmer \& Rodríguex, 2017). Furthermore, whilst many sexually dimorphic traits show

109 positive allometry, sole focus on allometric scaling should be avoided. Bonduriansky (2007)

110 found that many such characters (even those used as weapons in competition) scale

111 isometrically, or with negative allometry, across a range of bird, fish and insect taxa. An

112 emphasis on recording shape and overall size as opposed to just allometry is thus critical in

113 determining the presence of SD.

114 When addressing the evolutionary drivers behind sexually dimorphic traits, it is important

115 to avoid framing hypotheses around one sex (Weygoldt, 2000). For example, when studying SSD

116 in orb-weaving spiders, the bulk of recent research has focused on the benefits of small body size 
117 in males (e.g. Moya-Laraño et al., 2002; Foellmer \& Moya-Larano, 2007; Grossi \& Canals,

118 2015). However, within a broader phylogenetic context, female gigantism is often considered

119 more important in the development of size disparity (Hormiga, Scharff \& Coddington, 2000). It

120 is thus important to consider the advantages of differing morphologies from the perspective of

121 both sexes.

122 Taxonomy may also be problematic, most notably when considering male polymorphism,

123 as present in a number of arachnid groups (Clark \& Uetz, 1993; Gaud \& Atyeo, 1996; Santos et

124 al., 2013; Buzatto \& Machado, 2014). Assigning multiple male morphs to the corresponding

125 female is challenging. Indeed, male polymorphism is likely to be more common than reported,

126 but remains due to the difficulties of placing differing morphs into the same species. This may

127 further complicate the study of sexual dimorphism, particularly if sexes exhibit niche

128 partitioning.

Finally, we note that caution is required due the inconsistent application of terminology

130 within arachnology. Terms such as setae (referring to a stiff hair or bristle) and flagellum (a

131 slender 'whip-like' appendage or body tagma) are used throughout arachnid literature to refer

132 non-homologous structures. For example, the flagellum refers to a cheliceral appendage in

133 solifuges and to a structure on the posterior opisthosoma in schizomids (Harvey, 2003).

134 Conversely, homologous structures may be given different names across arachnids. The

135 segments of the leg often carry different names between groups despite being homologous, and

136 in the case of Amblypygi, homologous pedipalp segments are assigned differing names

137 depending on author (Weygoldt, 2000). Where ambiguity in terminology exists, we provide

138 descriptions of body segments where terminology alone may not describe position and form. 


\section{Aim and survey methodology}

141 A literature survey was conducted in Google Scholar using the scientific name of an arachnid

142 order (for example "Uropygi”) and all common names (“whip scorpion”, "vinegaroon”) and

143 derivatives, with AND (the Boolean operator indicating that returned results should contain this

144 and the subsequent term) then "sexual dimorphism". Google Scholar was chosen over other

145 literature databases (e.g. Web of Science or Scopus) as the specified search terms may occur

146 anywhere within the text, as opposed to only the title, abstract and keywords. Each returned

147 paper was examined to determine if it contained pertinent information. Particular effort was

148 made to identify and incorporate studies that quantified sexual dimorphism, especially those with

149 statistical support. If no evidence of sexual dimorphism was provided, but a further citation was

150 given, that citation was assessed. Additionally, arachnologists' personal paper collections were

151 used to access further documents that did not appear in Google Scholar or citations. A full list of

152 papers included, the form of dimorphism illustrated, and the type of reporting used (qualitative

153 vs. quantitative) is provided in the Supplementary Material. We highlight here that "sexual

154 dimorphism" refers to the condition in which males and females differ in their characteristics

155 beyond primary sexual organs. The morphology of intromitent organs (penis in harvestmen and

156 some mites, or pedipalps in spiders) and spermatophores, for example, is beyond the scope of

157 this review.

\section{Standard figure abbreviations}

160 Each section is accompanied with a figure charting general trends of SSD within the order.

161 Figures follow a standard configuration: body parts coloured red indicate male-biased SSD,

162 green indicates a female bias, and purple mixed sex bias. Legs are numbered 1-4, chelicerae are 
163 marked "C" and pedipalps are marked "P"; male ( $\left({ }^{\Uparrow}\right)$ or female () symbols denote SSD in

164 overall body size. Other specific abbreviations are defined in figure captions. A plate of all SSD

165 trend figures, for comparison across orders, is placed in the supplementary material.

167 Acari

168 Description and phylogeny

169 Acari, the subclass that contains mites and ticks, is the most speciose arachnid group with around

17055,000 reported species (Zhang, 2011), although it is thought that this represents only a small

171 fraction of a potential 1 million extant species (Walter \& Proctor, 1999). Acari have colonised

172 almost all terrestrial and marine environments and have also adopted modes of life including

173 herbivory, predation, parasitism and scavengry (Vacante, 2015). Morphologically, Acari are

174 distinct from the rest of the arachnids through their tagmosis, and the presence of a gnathosoma,

175 a structure formed by the chelicerae, pedipalps, and mouth, which form a functional unit

176 separated from the rest of the body by a region of flexible cuticle. There are two major clades

177 within Acari, the Parasitiformes and the Acariformes. They are differentiated morphologically by

178 the stigmata arrangements; in Parasitiformes there are 1-4 dorsolateral or ventrolateral stigmata

179 behind the coxa of leg II, which are absent in Acariformes (Vacante, 2015).

180 There is debate about monophyly of Acari, and multiple recent analyses have suggested

181 that the two major clades are split making Acari polyphyletic. For example, Garwood et al.'s

182 (2017) morphological phylogeny places Parasitiformes as the sister group to a clade including

183 Acariformes and solifuges, and molecular phylogenies elsewhere agree with these results

184 (Pepato, da Rocha \& Dunlop, 2010). However, other molecular studies place Acariformes as the 
185 sister group to pseudoscorpions, with this clade being the sister group to all other arachnids

186 including Parasitiformes (Sharma et al., 2014). Earlier morphological phylogenies have also

187 placed Acari as a sister group to Ricinulei (Lindquist, 1984; Shultz, 2007).

188

189 Sexual dimorphism and potential drivers

190 The majority of literature concerning the SD in Acari focuses on the major acariform group

191 Oribatida (e.g. Behan-Pelletier \& Eamer, 2010; Behan-Pelletier, 2015a,b). SD in feather mites

192 has also been explored (Proctor, 2003). Within Orbatida, secondary sexual characters are

193 generally considered rare (Behan-Pelletier \& Eamer, 2010). SSD in overall body length is

194 typically present but not pronounced in Orbatida: females are larger (Figure 1), but male and

195 female often overlap in size (Behan-Pelletier \& Eamer, 2010). The most commonly SD is found

196 in the dermal gland system (Behan-Pelletier \& Eamer, 2010), with markedly different

197 arrangements of the dermal porose areas reported between sexes (Norton \& Alberti, 1997;

198 Bernini \& Avanzati, 1983). These structures are used to spread sex hormones (Norton \& Alberti,

199 1997) and male dermal glands can be associated with integumental structures on the carapace

200 such as raised tubercles (Behan-Pelletier \& Eamer, 2010).

201 Body shape dimorphism is reported in some mite species. In Cryptoribatula euaensis, the

202 female carapace takes the semicircular form typical of the family Oripodidae, whereas the male

203 carapace is pear shaped (Behan-Pelletier \& Eamer, 2010). The arrangements of plates

204 comprising the exoskeleton can also differ between sexes in Oribatida, as can the occurrence of

205 setae and other integumental structures (Behan-Pelletier \& Eamer, 2010; Behan-Pelletier and

206 Eamer, 2015b). In extreme cases, the idostoma, the body segment that attaches to the legs, can

207 even be bifurcated (Proctor, 2003). In several groups of feather mites, body shape is non- 
208 symmetrical across the sagittal plane in males (Protor, 2003; Proctor \& Knee, 2018). In those

209 taxa characterised by male polymorphism (where males occur in multiple morphotypes, often

210 reflecting different mating strategies; e.g. Radwan, 1993; Ra'Anan \& Sagi, 1985; Tsubaki,

211 2003), males can be both symmetrical and asymmetrical (Proctor, 2003).

212 The evidence for SSD in leg length is limited, and appears to favour males. In two

213 species of Ameronothrus, leg length exceeds body width in males, whilst the opposite is true for

214 females (Søvik et al., 2004; Behan-Pelletier \& Eamer, 2010). This may not represent true SSD in

215 leg length as females also have a larger body size in this species (Søvik et al., 2004). Male-bias

216 SSD in the third leg length has also been documented (Gaud \& Atyeo, 1996). Furthermore, male

217 legs are often modified with flanges, lobes, leg clamps, adanal discs, or pincers (Proctor, 2003).

218 Setal arrangement also varies between sexes, with male orbatids having modified setae on the

219 legs that are absent in females (Behan-Pelletier \& Eamer, 2010; Behan-Pelletier, 2015b). Within

220 the gnathosoma, male pedipalps are enlarged relative to female conspecifics. In some species of 221 Astigmata, males also have pedipalp branches unseen in females of the same species, and in the

222 most extreme cases the pedipalps appear antler-like (Proctor, 2003). Chelicerae are also enlarged

223 in some male feather mite species (Proctor, 2003). There are a number of prodorsal

224 modifications present exclusively in males of some acarid species, which are hypothesised to

225 help the male push female towards their spermatophore (Behan-Pelleiter \& Eamer, 2015b). This

226 suggest the influence of sexual selection acting through a form of sexual coercion.

Potential drivers for dimorphism in Acari are difficult to determine given the relative lack

228 of information on life history. A correlation between habitat and SD has been discussed in

229 Oribatida, as the majority of sexually dimorphic species occur in non-soil environments (Behan-

230 Pelletier \& Eamer, 2010), despite Acari as a whole being more speciose in the soil (Behan- 
231 Pelletier \& Eamer, 2010). Likewise, SD in the glandular system has been linked to habitat, as sex

232 pheromones emitted from dermal glands are potentially more important for attracting a mate in

233 drier environments (Norton \& Alberti, 1997). Dimorphism in the nymphs of Kiwi bird (Aves:

234 Apterygiformes) mites has also been attributed to their environment, with males living in

235 feathers and females living in cutaneous pores, being one of the few unequivocal examples of

236 niche partitioning between species in arachnids (Gaud \& Atyeo, 1996).

237 Mating has been hypothesised to play a role in the elaboration of the third legs of male

238 feather mites. The lobes, flanges and setae on the legs potentially help males to align with the

239 female spermaduct opening (Gaud \& Atyeo, 1979), and sexual selection could drive the

240 development of these modifications. Elsewhere, heteromorphic 'fighter' males of Caloglyphus

241 berlesei use their enlarged third legs to kill rival males (Radwan, 1993) and monopolise females.

242 In contrast, non-fighter males, which do not kill off rival males, are more successful in larger

243 colonies under laboratory conditions (Radwan, 1993); factors such as population density may

244 therefore influence mating behaviour and thus sexual- and male-dimorphic morphology.

245 Research into SD among mites and ticks has thus far been limited in taxonomic scope.

246 Advances in high-resolution 3D imaging could assist future research into SD in smaller mites.

247 We believe mites present an interesting study organism for interrogating the interplay between

248 morphology and mating strategies. For example, many oribatid mites can and do reproduce via

249 parthenogenesis (Behan-Pelletier \& Eamer, 2010); the extent to which species that reproduce in

250 this manner exhibit SD is as yet unknown. 


\section{Description and phylogeny}

254 Amblypygi, or whip spiders, are an arachnid order comprising ca. 220 species (McArthur et al.,

255 2018). Amblypygids live in tropical regions, preferring rainforests and caves, and are obligate

256 predators (Weygoldt, 2003). Members of the order have a distinct morphology, their most

257 recognisable trait being raptorial pedipalps exceeding twice the individual's body length in some 258 taxa (Weygoldt, 2000). Amblypygids also possess antenniform first legs known colloquially as

259 whips, which bear sensory devices thought to allow mechano- and chemoreception (Igelmund, 260 1987). Amblypygi also lack a terminal flagellum, which differentiates them from the other two 261 orders that comprise the clade Thelyphonida, Uropygi and Schizomida (following the

262 International Society of Arachnology). Recent morphological and molecular phylogenies

263 consistently place amblypygids in a clade with thelyphonids (Shultz, 2007; Garwood \& Dunlop, 264 2014; Sharma et al., 2014; Garwood et al., 2017).

\section{Sexual dimorphism and potential drivers}

267 Female-biased SSD in overall body size, as measured by carapace width, is common across

Amblypygi (McArthur et al., 2018), potentially relating an increased capacity for egg production

269 at larger body sizes (Armas, 2005) via fecundity selection. Male-biased SSD in pedipalps is

270 widespread across the group, but the level of dimorphism varies greatly between species

271 (McArthur et al., 2018; Figure 2). In Damon variegatus and D. gracilis, pedipalpal tibia length

272 scales similarly in males and females across early instars. However, after the fourth nymphal

273 stage, the pedipalpal tibia displays greater positive allometry relative to carapace length in males

274 (Weygoldt, 2000; Figure 3). A similar growth pattern has been identified in the pedipalpal tibia

275 of Phrynichus deflersi arabicus (Weygoldt, 2003), Phrynus marginemaculatus and 
276

277

278

279

280

281

282

283

284

285

286

287

288

289

290

291

292

293

294

295

296

297

298

Heterophrynus batesii (McArthur et al., 2018). Male-bias SSD in pedipalpal length has also been observed in adults of several other species (e.g. Charinus mysticus and Sarax huberi), albeit with smaller sample sizes (e.g. Vasconcelos et al., 2014; Seiter et al., 2015). Pedipalpal spines may also be sexually dimorphic in Amblypygi. Both male and female adult Euphrynichus bacillifer possess spines transformed into rounded apophyses, yet these are both larger and carry more glandular pores in males. Phrynichus exophthalmus also has a blunt apophasis on the pedipalp in males but not in females (Weygoldt, 2000). The function of the apophyses and their associated glandular pores remains unclear (Weygoldt, 2000). SD in the number of pedipalpal spines has also been reported in Charinus jibaossu (Vasconcelos et al., 2014).

Recent work has suggested that territorial contest could be a driving force behind pedipalp SSD in amblypygids. Field observations of Phrynus longipes have found that the majority of territorial contests $(82.8 \%$ in trials) are decided purely via display (Chapin \& ReedGuy, 2017). In these trials, the winner was always the individual with the longest pedipalpal femur length, creating a selective pressure for longer pedipalps. However, investment in pedipalps is a high-risk strategy, as in those interactions that escalate to contest and cannibalism, the winner is best predicted by body size (Chapin \& Reed-Guy, 2017). A recent study has also reported that the level of SSD across amblypygid species decreases with distance from the equator (McArthur et al., 2018). This may indicate climatic controls on mating strategy, as has been demonstrated in Opiliones (Machado et al., 2016), but further research is required.

The antenniform first pair of legs has also been observed to be dimorphic in a number of species across the group, and statistically demonstrated in P. marginemaculatus and H. batesii (McArthur et al., 2018). Male-male confrontation follows a common pattern across Amblypygi: initially, males 'fence' by turning side-on to one another and repeatedly touching antenniform 
299 legs, before unfolding their pedipalps, turning face on and charging (Weygoldt, 2000). Males

300 also use whips to display to females and touch the female's body before mating (Weygoldt,

301 2000). Whip legs are also thought to have chemoreceptive functions (Weygoldt, 2000) that could

302 hypothetically aid in mate search, although no link has yet been draw between whips and the

303 ability to locate potential mates. It would therefore appear that SSD in whip length is driven by

304 sexual selection though male contest and potentially female mate choice via pre-copulatory 305 courtship.

Body segments can also show dimorphism, although it is rare in the group (Weygoldt,

307 2000). Shape dimorphism can be observed in C. jibaossu, with the male having wider carapace

308 relative to length than females (Vasconcelos et al., 2014). McArthur et al. (2018) also reported

309 widespread female biased dimorphism in carapace width, although it was being considered a

310 proxy for overall body size. In Damon medius and D. variegatus, females possess a pleural fold

311 along the ventrolateral and posterior opisthosomal margins; in ovigerous females, this fold

312 surrounds the eggs to form a brood pouch (Weygoldt, 2000). On the underside of the

313 opisthosoma, females of some species in the family Phrynichidae possess an area of red-gold

314 hair around the posterior margin of the genital opening that is otherwise absent in males

315 (Weygoldt, 2000).

316 SD in amblypygids is understudied relative to the larger arachnid orders. Several

317 publications report little or no dimorphism within species (e.g. Rahmadi et al., 2010; Giupponi \&

318 Kury, 2013). By necessity, these rely on small sample sizes: amblypygids are seldom seen in

319 large numbers in the wild and are thus difficult to collect (Weygoldt, 2000). As a result,

320 quantitative tests are either not possible, or low in statistical power. Furthermore, subtle sexual

321 character dimorphism (e.g. differences in pedipalpal dentition) are easily overlooked in studies 
322 that rely on linear metrics. Future work will benefit from revisiting existing amblypygid 323 collections, and utilising advances in imaging and 3D morphometrics. 
325 Araneae

326 Description and phylogeny

327 Araneae — or spiders — are the archetypal arachnid, and the order comprises over 47,500

328 species (World Spider Catalogue, 2018). Spiders are found in almost all terrestrial habitats. They

329 are always predatory and possess weapons that are absent in other arachnids, such as the ability

330 to administer venom via the chelicerae, and the ability to spin silk using opisthosomal spinnerets.

331 Araneae are members of a clade containing Amblypygi and Uropygi; their sister group is thought

332 to be either Amblypygi (Wheeler \& Hayashi, 1998) or Pedipalpi as a whole (a clade comprising

333 Amblypygi, Uropygi and Schizomida; Shultz, 2007; Sharma et al., 2014; Garwood et al., 2017).

334

335 Sexual dimorphism and potential drivers

336 Spiders are typically characterised by female-biased SSD, with females outweighing male

337 conspecifics by up to two orders of magnitude (Figure 4; Foellmer \& Moya-Larano, 2007). In

338 web-building spiders, female body length frequently exceeds that of males (e.g. Head, 1995;

339 Vollrath, 1998), and can be twice that of males (e.g. Hormiga, Scharff \& Coddington, 2000).

340 Extreme female-biased SSD is particularly prevalent in the families Thomisidae and Araneidae

341 (Hormiga, Scharff \& Coddington, 2000). The bulk of research concerning SD in spiders has

342 concentrated on the prevalence of female-bias SSD and the potential driving factors underlying

343 such extremes in total body size. The so-called 'giant females vs. dwarf males' controversy

344 (Coddington, Hormiga \& Scharff, 1997) has been discussed in detail elsewhere (see Moya-

345 Larano et al., 2002; Foellmer \& Moya-Larano, 2007), and is not covered further in the present

346 review. Likewise, the degree to which total body size SSD in Araneae is consistent with the 
347 predictions of Rensch's rule has been the subject of considerable study. The current consensus

348 appears to be that SSD actually increases with body size in spiders characterised by female-bias

349 SSD (Abouheif \& Fairbairn, 1997; Prenter et al., 1999) counter to Rensch's rule, with male and

350 female body size showing relatively uncorrelated evolution (Foellmar \& Moya-Laraño, 2007).

351 Furthermore, interesting exceptions to female-biased SSD do exist; for example, the aquatic

352 spider Argyroneta aquatica displays male-bias SSD in total body length (Schütz \& Taborsky,

353 2003). Linyphia triangularis also subverts the general trend with males having wider

354 cephalothoraxes than females (Lang, 2001), and male of the wolf spider Allocosa brasiliensis are

355 larger than females in cephalothorax length (Aisenberg et al., 2007).

It should be noted that the above studies consider body size SSD within the context of

357 body length (e.g. Head, 1995; Elgar, 1991). Body length is subject to change based on hunting

358 success, resulting in potential overestimation of female body size in particular, as they tend to

359 feed more over their life span (Legrand \& Morse, 2000). Carapace width is unaffected, however,

360 and remains roughly constant within an instar stage (Legrand \& Morse, 2000), and may therefore

361 become the preferred metric in future studies of SSD in spiders. However, the use of carapace

362 width as a predictor of body size can also be problematic in instances when the prosoma itself

363 shows SD. In Donacosa merlini (Lycosidae), geometric morphometric analysis found the male

364 carapace to be statistically wider and more anteriorly protruding than that of the female relative

365 to overall size (Fernández-Montraveta \& Marugán-Lobón, 2017). The authors also report

366 differences in the relative sizes of the prosoma and opisthosoma, which is suggested to result

367 from the larger female opisthosoma creating a fecundity advantage by stowing more eggs, with

368 other studies finding strong correlation between female carapace size and clutch size (e.g. Pekár,

369 2011; Legrande \& Morse, 2000). Statistically significant SSD in carapace width and height is 
370 also present in the linyphiid Oedothorax gibbosus (Heinemann \& Uhl, 2000). This results from a

371 large gland located within the male cephalothorax that supplies a nuptial secretion to females

372 during courtship (Vanacker et al., 2003). The presence of this gland is also male dimorphic, and

373 males of the morph that lacks the gland have a smaller carapace. This likely indicates a

374 divergence in male mating behaviour (Heinemann \& Uhl, 2000).

SD in the pedipalps of spiders must be considered with caution. Within Araneae, the male pedipalp is principally adapted to transfer spermatophores to the female reproductive tract. As such, they effectively function as genitalia, and sex-based differences are examples of 'primary' sexual dimorphism. Unlike other arachnid groups, secondary SD in the pedipalps is rare in spiders. However, males of some burrowing wolf spiders, namely Allocosa alticeps and $A$. brasiliensis, possess palpal spines that are absent in conspecific females (Aisenberg et al., 2010).

381 Contrary to other burrowing wolf spider taxa, males of these two species burrow while females

382 engage in active mate search, and modifications to male pedipalps are thought to improve

383 burrowing performance (Aisenberg et al., 2010).

385 (Foellmer \& Moya-Larano, 2007). Hypotheses for its adaptive significance fall into two broad categories: locomotion and display. Increased leg length has been linked to a theoretical increase

387 in climbing and bridging speed (Grossi \& Canals, 2015), whilst other authors have argued for the 388 role of sexual cannibalism in imposing a selective pressure towards longer legs to aid in escape

389 (Elgar et al., 1990). Male-bias SSD in leg length has also been correlated with active mate

390 searching, because male wolf spiders involved in active mate searching possess longer legs

391 relative to those of females (Framenau, 2005). Interestingly, in wolf spider taxa in which females 
392 actively search for mates, female-biased SSD in leg length becomes common, though examples

393 of this reverse in SSD bias are thought to be uncommon (Aisenberg et al., 2010).

394 In contrast, the legs of male salticids (jumping spiders) are commonly elongated and

395 ornamented with setae for the purpose of display. Male peacock spiders possess elongated third

396 legs relative to females, which are used in a ritualised courtship dance, often tipped with white

397 bristles (Girard \& Endler, 2014). Males of Diolenius phrynoides also show extreme lengthening

398 of the first legs, which are adorned with ridges of setae on the tibia unlike those of the female;

399 again for use in display (Peckham \& Peckham, 1889). Elongation of the forelegs in male wolf

400 spiders has likewise been related to courtship (Kronestedt, 1990), supported by the presence of

401 heavily pigmented bristles in the male Schizocosa ocreata (Scheffer et al., 1996). This species

402 displays 'drumming' behaviour, where males beat their legs against the ground in order to attract

403 prospective mates. In situations where the substrate hinders the transmission of the drumming,

404 females prefer males with intact bristles, providing evidence they also play a visual role in

405 courtship displays (Scheffer et al., 1996). Intersexual contest could also drive dimorphism in the

406 legs of some species. Fighting behaviour using the legs as weaponry has been observed between

407 males in the genera Modisimus and Blechroscelis, with males typically using their legs to push

408 against the opponent (Eberhard \& Briceno, 1985).

409 Spider chelicerae are also characterised by SSD, although the direction of dimorphism is

410 less consistent than in the pedipalps or legs. Unlike isometric females, male Zygoballus rufipes

411 chelicerae exhibit positive allometric growth in length relative to carapace length, with the

412 resultant enlarged chelicerae in adult males thought to be involved in courtship display (Faber,

413 1983). Taxa in which males present nuptial gifts to prospective mates are also characterised by

414 male-bias SSD in absolute cheliceral size, although the structures do scale with isometry (Costa- 
415 Schmidt \& Araújo, 2008). In wolf spiders though, female chelicerae have been reported to be

416 statistically larger than males (Walker \& Rypstra, 2002). Increased dentition on the chelicera

417 base is also seen in males of some species (Peckham \& Peckham, 1889), but the purpose of this

418 is unclear. Given that chelicerae are used in male-male competition and that fighting success is a

419 good predictor of mating success in spiders (e.g. Rovner, 1968; Watson, 1990), intrasexual

420 selection may also underlie the hyper-allometric growth of male chelicerae (Funke \& Huber, 421 2005).

Alternatively, SSD in Myrmarachne palataleoides chelicerae has been attributed to

423 differing forms of prey capture between males and females, in which the relatively longer

424 chelicerae of males are used to spear and dispatch prey in the absence of venom, which appears

425 only in female conspecifics (Pollard, 1994). Dimorphism in some wolf spider chelicerae has also

426 been correlated to dietary differences between the sexes, in turn relating to their respective

427 reproductive roles. Females are known to catch significantly more prey items, and show

428 statistically significant female-biased dimorphism in cheliceral paturon (the segment housing

429 chelicerae muscles, adjacent to the fang) length, width and fang width (Walker \& Rypstra, 2002).

430 Little evidence of habitat niche divergence between sexes exists, indicating female-biased SSD

431 in chelicerae was likely a response to increased feeding induced by the energetic cost of rearing

432 young (Walker \& Rypstra, 2002). Female-biased SSD in chelicerae in the ant-eating spider

433 Zodarion jozefienae also appears to be related to trophic niche partitioning. Due to the increased

434 energetic demands of fecundity, females prey on larger morphs of Messor barbarous ants than

435 males (Pekár et al., 2011).

436 Sexual body character dimorphism in ornamentation, patterning and colouration are also

437 common across Araneae. Female orb-weaving spiders have a highly ornamented carapace 
438 comprising spines and bright colours, which are otherwise lacking in males (Peckham \&

439 Peckham, 1889). In the spiny orb-weaving genera Micrathena and Chaetacis, elongate

440 abdominal spines have evolved independently in females on eight separate occasions, and may

441 exist as anti-predator structures for the usually larger and thus more conspicuous females

442 (Magalhães \& Santos, 2012). In salticids, however, males are characterised by increased

443 colouration. Male Habronattus decorus, for example, possess a purple opisthosoma and brighter

444 colours on the legs and prosoma than their black and white female counterparts do (Peckham \&

445 Peckham, 1889). Further SD is visible when some taxa are viewed under ultraviolet (UV) light.

446 For example, only male Cosmophasis umbratica have body parts that reflect UV light (Lim \&

$447 \mathrm{Li}, 2006$ ). Salticids are capable of detecting light well within the UV spectrum (Peaslee \&

448 Wilson, 1989), and female C. umbratica exhibit a preference for UV-reflecting mates as opposed

449 to those with UV-reflecting capabilities masked (Bulbert et al., 2015). Such research highlights

450 the importance of considering other potential modalities for dimorphism that are less obvious to

451 the human observer (Huber, 2005).

452

In Theraphosidae, commonly known as tarantulas, SD occurs in both the size and

453 composition of urticating setae, which are hairs expelled when the spider is threatened, causing

454 respiratory distress in vertebrates (Bertani \& Guadanucci, 2013). Longer urticating setae have

455 been reported in males compared to females of numerous species, and statistically significant

456 differences identified in Avicularia avicularia (Bertani \& Guadanucci, 2013). Setae composition

457 is also sexually dimorphic, with females of three different genera possessing only Type-I setae,

458 which are shorter hairs thought to defend against other invertebrates (Bertani \& Guadanucci,

459 2013). In contrast, males possess both Type-I and Type-III setae, the latter being a longer seta

460 used to ward off vertebrates. Differences in setal composition may relate to the males' 
461 requirement to search for mates, placing them at greater risk of encountering vertebrate predators

462 (Bertani \& Guadanucci, 2013).

463 Spiders are by far the most-studied arachnid order in terms of SD, and particularly SSD.

464 Research in this group has benefitted from a number of novel approaches, including advanced

465 imaging techniques (e.g. studies in UV reflectivity and histological sectioning), kinematics and

466 biomechanical testing. The application of such techniques to other arachnid orders may prove

467 useful in future research. Additionally, sample sizes are often far in excess of those generated on 468 non-Araneae arachnids.

469

470

\section{Palpigradi}

471

\section{Description and phylogeny}

472 Palpigradi, or micro-whip scorpions, are one of the least studied arachnid orders (see

473 Supplementary Table). There are 78 extant species that are primarily found in leaf litter and

474 caves across the tropics (Condé, 1996; Harvey, 2003). Diagnostic features include a long,

475 segmented terminal flagellum coupled with tri-segmented chelicerae (Harvey, 2003). Moreover,

476 all species are very small. and typically average $1-1.5 \mathrm{~mm}$ in total length $(\mathrm{Ax}, 2000)$. The order

477 Palpigradi has been placed in Tetrapulmonata with Amblypygi, Araneae, Uropygi and

478 Schizomida (Shultz, 1990; Wheeler \& Hayashi, 1998), but also as a sister group to different

479 groups, including Acariformes (Van der Hammen, 1989; Regier et al., 2010), solifuges (Giribet

480 et al., 2002) or the rest of Arachnida (Shultz, 2007). The most recent studies have placed

481 Palpigradi as the sister group to Parasitiformes (Sharma et al., 2014) or to the remaining

482 arachnids (Garwood \& Dunlop, 2014; Garwood et al., 2017). 
484 Sexual dimorphism and potential drivers

485 To date, SSD in overall body size has not been reported in Palpigradi (Figure 5), and expression 486 of SD occurs predominantly in setal arrangements. In Eukoenenia chilanga, males have more 487 setae on the opisthosomal sternites, ventral sclerotized plates making up opistosomal segments X 488 and XI (Montaño-Moreno \& Francke, 2013). The number of setae also differs on other 489 opistosomal segments, with male E. mirabilis possessing 31 setae on sternite VI compared to six 490 or seven in the female (Condé, 1991). Setae are generally thicker and more cylindrical in males

491 (Barranco \& Mayoral, 2007; Souza \& Ferreira, 2012).

492 Dimorphism in the palpigrade glandular systems have also been observed. In $E$.

493 lawrencei, females possess three large glandular masses that protrude under segment VII 494 compared to two glands in the males (Condé, 1991). The extra glands in females may play a role 495 in reproduction (Condé, 1991), though this is not elaborated on. The degree to which the above 496 differences are statistically significant remains untested, however, and previous studies are 497 limited by small sample sizes.

Further work is needed for the patterns and drivers of SD in Palpigradi to be understood.

499 As far as we are aware, the mating habits of Palpigradi have never been reported, and relatively

500 little is known of their ecology and behaviour. An improved understating of the mating and

501 courtship behaviors will prove important for identifying the potential drivers of observed 502 dimorphism. 


\section{Description and phylogeny}

506 Pseudoscorpions, occasionally referred to as book scorpions (or sometimes false scorpions), are

507 represented by over 3300 species (Garcia et al., 2016). Members of the order are found in a wide

508 range of terrestrial environments, typically in the tropics and subtropics, although occasionally as

509 far north as arctic Canada (Muchmore, 1990). Pseudoscorpions appear superficially similar to

510 scorpions, possessing pedipalpal claws and a segmented opisthosoma, although they lack the tail

511 and telson seen in true scorpions. They also differ from scorpions in size; the largest

512 pseudoscorpion reaches only $12 \mathrm{~mm}$ in total body length (Beier, 1961) yet most measure

513 approximately $1 \mathrm{~mm}$ (Schembri \& Baldacchino, 2011). Some morphological studies place

514 pseudoscorpions as the sister group to scorpions (Pepato, da Rocha \& Dunlop, 2010; Garwood \&

515 Dunlop, 2014; Garwood et al., 2017) and others to solifuges (Legg, Sutton, \& Edgecombe, 2013;

516 Giribet et al., 2002; Shultz, 2007). Molecular studies, in contrast, have placed them as the sister

517 group to acriform mites (Sharma et al., 2014).

\section{Sexual dimorphism and potential drivers}

520 Overall body size dimorphism is well documented in pseudoscorpions. In Cheiridioidea, a a

521 large superfamily containing the well-studied Chernetidae (Murienne et al., 2008), males are

522 consistently smaller than females, measured by carapace length (Zeh, 1987a). In fact, Zeh

523 (1987a) notes that male-biased SSD is rare in Chernetidae, finding just eight species that exhibit

524 reverse SSD in the 45 that were studied (Zeh, 1987a).

525 Sexual size dimorphism in pseudoscorpion pedipalps is present in a number of species.

526 Males in the family Chernetidae typically have larger pedipalpal claws than females (Figure 6; 
527 Zeh 1987a,b). This is highly variable however: male claw silhouette area ranges from $60-150 \%$

528 of that in females (Figure 7; Zeh, 1986). Furthermore, the direction and extent of dimorphism

529 can vary significantly within a genus. It is not uncommon to find both strong male-biased and

530 female-biased SSD in claw size within a genus (Figure 7; Zeh, 1987b). Regression analysis also

531 reveals that the SSD in male claws seems to increase relative to female body size (Zeh, 1986).

532 However, we note that this trend is not normalised to body size. Thus, whilst absolute difference 533 in claw size increases, this could be primarily due to changes in body size.

Several pseudoscorpion groups engage in 'pairing', a ritualised dance in which the male 535 grasps the female's pedipalpal claws before depositing a spermatophore (Weygoldt, 1966). Zeh

536 (1987a) has suggested pairing may be a major control on dimorphism, particularly in pedipalpal

537 claws. Furthermore, male-male aggression has been correlated to SSD in pedipalps. Male

538 pseudoscorpions often fight each other using the pedipalpal claws (Weygoldt, 1966; Thomas \&

539 Zeh, 1984), and experimental work suggests chela size, not body length, is a good predictor of

540 the victor in such contests. Notably, it has also been reported that males with larger chelae

541 produce more spermatophores than those with smaller chelae, suggesting they may have greater

542 mating success (Zeh, 1986). A weak but significant relationship between the level of SSD and

543 population density in Chernetidae has been reported. SSD was also found to be more pronounced

544 in specimens taken from nesting areas (Zeh, 1986).

SD in pseudoscorpions is therefore well documented. Studies have included extensive

546 statistical testing on morphometric characteristics, and the selective pressures driving SD are

547 comparatively well understood. SSD has been particularly well described in Chernetidae, yet

548 substantially less is known of other pseudoscorpion families. This is where significant gaps in

549 the current body of knowledge lie. 


\section{Opiliones}

\section{Description and phylogeny}

553 Opiliones, commonly known as harvestmen or daddy long-legs, are the third largest arachnid 554 order comprising over 6500 species (Kury, 2013). The greatest diversity of harvestmen is in the 555 tropics, though their range stretches into the high-latitudes (Pinto-da-Rocha, Machado \& 556 Giribet, 2007). A common characteristic of harvestmen is the second pair of legs, which carry 557 both mechano- and chemoreceptors (Willemart \& Chelini, 2007). Synapomorphies of the group

558 include the position of the gonopore, the presence of a penis or spermatopositor for direct 559 copulation, and the presence of repugnatorial glands (Pinto-da-Rocha et al., 2007). The majority 560 of recent phylogenetic analyses have placed Opiliones as the sister group to a clade comprising 561 pseudoscorpions and scorpions (Shultz, 2007; Pepato, da Rocha \& Dunlop, 2010; Garwood et

562 al., 2017). However, molecular analyses do not agree, placing Opiliones as the sister group to a 563 clade including spiders, Pedipalpi, scorpions, Ricinulei and Xiphosura, although the authors note 564 the impact of long branch attraction (Sharma et al., 2014).

\section{Sexual dimorphism and potential drivers}

567 'Total' body size in Opiliones is typically taken as the length of the dorsal scute, which

568 comprises the dorsal prosomal shield and the first abdominal segments (e.g. Willemart et al.,

569 2009; Zatz, 2010). While this is generally seen as a good metric for quantifying overall body

570 size, some publications report differences in body size based on a number of other

571 characteristics. SSD is reported in numerous harvestman groups. Females in the families 
572 Nipponopsalidiae, Sclerosomatidae and the genus Crosbycus are larger than males, although few

573 males are known in the latter (Pinto-da-Rocha et al., 2007). The metric used to quantify SD in

574 this instance is not clear, however. Larger body size in females has also been reported in

575 Longiperna concolor and Promitobates ornatus, based on dorsal scute length (Zatz, 2010).

576 Conversely, in Cranaidae and Oncopodidae the carapace is much larger in males than females

577 (Pinto-da-Rocha et al., 2007). Hence, whilst statistical testing is limited within the Opiliones, this

578 qualitative work suggests the direction of SSD might be variable across the group.

Modification of the tergites, sclerotized upper sections of arthropod segments, is

580 observed in a number of species. In Pettalidae, tergites around the anal region in males possess

581 grooves and ridges that are absent in females; in extreme cases tergites in this region become

582 divided (Pinto-da-Rocha et al., 2007). Levels of sclerotization can also differ between sexes, as

583 does body patternation (Pinto-da-Rocha et al., 2007; Taylor, 2004). The drivers behind this type

584 of dimorphism are unclear.

585 SD and SSD in specific appendages is more strongly supported within Opiliones. In

586 Longiperna concolor, for example, the fourth pair of legs displays male-bias SSD in length

587 (Figure 8, Zatz, 2010). Leg length is also bimodal in males of this species: males of the 'major'

588 morph show positive allometry, whilst males of th e'minor' morph are short-legged and display

589 isometry. Thus, 'minor' males that lack the exaggerated features of the 'major' males appear

590 more like females (Zatz et al., 2011). Such male dimorphism has been correlated to the presence

591 of intraspecific male fighting, with the fourth leg being used in contests between males of the

592 'major' morph. 'Minor' males, in contrast, avoid contests and employ a tactic of 'sneaking' into

593 harems in order to steal copulations (Zatz et al., 2011). Willemart et al. (2009) identify five

594 characters in N. maximus that show positive allometry in males, but not in females. All are 
595 involved in male-male contests. These include apophyses on the leg four coxae and trochanters,

596 and a dorsal-proximal spine on the femur of the fourth leg, all of which are involved with a phase

597 of fighting termed 'nipping' (Willemart et al., 2009). The apophyses take a much simpler form in

598 females (Willemart et al., 2009). The curvature and diameter of the males' fourth femur is also

599 characterised by positive allometry, potentially creating an advantage in the 'pushing' phase of

600 contest, in which males use their fourth legs to attempt to move their opponent (Willemart et al., 601 2009).

Similarly, SSD and male dimorphism co-occur in the second leg of Serracutisoma

603 proximum. In this species, males of the 'major' morph use the second leg to tap opponents in a

604 ritualised territorial contest (Buzatto \& Machado, 2008; Buzatto et al., 2011), with the winner of

605 such contests either holding, or taking over the contested territory and hypothetically increasing

606 their resource holding potential. Yet field observation, coupled with statistical testing, has

607 revealed no significant difference in second leg length or body size between the winners and

608 losers of territorial contests (Buzatto \& Machado, 2008). Males with longer second legs do

609 control larger harems, however, but do not hold preferential territories (Buzatto \& Machado,

610 2008).

611 Chemical communication has also been correlated to sex in Opiliones. Tegumental gland

612 openings located on the tarsus of the first, fourth and occasionally third leg, or the femur of leg

613 one, are present in males but not females (Willemart et al., 2010; Proud \& Felgenhauer, 2013; da

614 Silva Fernandes \& Willemart, 2014). Males rub the glandular pores on surfaces, and control the

615 flow of pheromones excreted (da Silva Fernandes \& Willemart, 2014; Murayama \& Willemart,

616 2015). Meanwhile, female Dicranopalpus ramosus possess greater numbers of sensory structures

617 (campaniform and falciform setae) on their tarsi relative to males (Wijnhoven, 2013), suggesting 
618 females may have an enhanced ability to detect chemical cues left by males. Males do however

619 possess sensilla chaetica, which are also thought to have a chemoreceptive function (e.g. Spicer,

620 1987; Kauri, 1989; Willemart et al., 2009), suggesting that chemical secretions may also play a

621 role in warding off rival males (da Silva Fernandes \& Willemart, 2014).

622

Male-bias SSD is also statistically supported in the pedipalpal length of Phalangium

623 opilio, and SD is observed through mechanoreceptors identified solely on the male appendage

624 (Willemart et al., 2006). Males of this species fight by pushing against each other and rapidly

625 tapping their pedipalps against the opponent. Pedipalp SSD is thought to determine the strength

626 and frequency of taps (Willemart et al., 2006). The appendages are also used to hold the legs of

627 females during copulation, suggesting male pedipalps have adaptations for multiple functions

628 (Willemart et al., 2006). Likewise, male-bias SSD is reported in the length of the chelicerae in

629 some families (e.g. Metasarcidae, Cranaidae and Oncopodidae; Pinto-da-Rocha et al. 2007). In

630 P. opilio, male chelicerae also have a horn-like projection protruding upwards in a dorsal

631 direction from the second cheliceral segment (Willemart et al., 2006). During contests, males

632 align their chelicerae and push against one another, with the 'horns' providing a surface for the

633 opponent to push against (Figure 9). Cheliceral horns are also placed over the female dorsum

634 post-copulation, again suggesting multiple functions (Willemart et al., 2006). In species

635 characterised by extreme male polymorphism, such as Pantopsalis cheliferoides, sexual

636 dimorphism is also reported in chelicerae length, with the smallest male morph typically

637 possessing reduced chelicerae relative to the female (Painting et al., 2015).

638 It is clear that male-male contests and differing mating strategies are a key control on SD

639 in harvestmen, yet recent work has suggested a more fundamental control on whether males aim

640 to hold territory or favour scramble competition, and thus the potential level of dimorphism 
641 observed. Harvestman breeding season length is best predicted by the number of months

642 experiencing favourable climatic conditions, particularly temperature (Machado et al., 2016). In

643 climates that consistently experience monthly mean temperatures of over $5^{\circ} \mathrm{C}$ along with the

644 requisite amount of precipitation, the breeding season is long and males usually hold

645 reproductive territories. In cooler climates the breeding season is much shorter, and scramble

646 competition is the main mating tactic (Machado et al., 2016). The greatly exaggerated contest

647 structures characterised by male-biased SSD are therefore typically only seen in warmer climates

648 (Machado et al., 2016).

649 It should also be noted that SD and male dimorphism often co-occurs in harvestmen,

650 having been attributed to similar selective pressures offset by intralocus sexual and tactical

651 conflict (Buzatto \& Machado, 2014 and references therein). Several studies have differentiated

652 between a 'major' male morph with exaggerated traits and more 'female-like' 'minor' morph.

653 Whilst such studies do not strictly quantify sexual dimorphism, information on male dimorphism

654 can still be informative with regard to alternative mating tactics and the morphological

655 differences between females and males of the 'major' morph. For further information on male

656 dimorphism, we refer readers to Buzatto \& Machado (2014), which details male dimorphism in

657 the group.

658 In conclusion, a male bias in the size of legs, chelicerae and other structures that appear

659 to be related to intrasexual selection are well supported in Opiliones. The common direction of

660 SSD in total body size remains unclear, however, due to ambiguous data with poor statistical

661 support, though it is possible that it varies across the order. Given the large number of studies

662 pointing towards male-male contest as a primary driver in SD in harvestmen it may be expected

663 that, like mammals that exhibit male-male contests, SSD is biased in the direction of males (e.g. 
664 Smuts \& Smuts, 1993). However, though contest is clearly a driver for the exaggerated

665 morphologies of 'major' males, comparatively little work appears to have been dedicated to how

666 'minor' males, where contest is not a factor, differ from females. Identifying a reliable proxy for

667 overall body size and statistically testing SSD should also be a priority.

668

669 Ricinulei

670 Description and phylogeny

671 Ricinulei, or hooded tick spiders, are the least speciose arachnid order comprising only 58

672 described species (Prendini, 2011). Ricinulei appear to inhabit damp tropical environments such

673 as wet leaf litter and caves (e.g. Gertsch, 1971; Cokendolpher \& Enríquez, 2004; Cooke, 1967;

674 Tourinho \& Azevedo, 2007). Features of the group include a locking ridge between the prosoma

675 and opisthosoma, and, uniquely, a hood that can cover the mouthparts. No consensus exists on

676 the placement of Ricinulei, which ranges between studies from being the sister group to a clade

677 including Acari and solifuges (Garwood et al., 2017), or a clade with Acari (Shultz, 2007;

678 Pepato, da Rocha \& Dunlop, 2010) to a sister group to Xiphosura (Sharma et al., 2014).

679

680

Sexual dimorphism and potential drivers

681 There is little evidence of SSD in overall body size in Ricinulei, although males of Pseudocellus

682 pachysoma have been found to possess a shorter and more granulated carapace than females

683 (Teruel \& Schramm, 2014). In Cryptocellus lampeli, the carapace is broader in females than it is

684 long, whilst the opposite is true in males (Cooke, 1967). Dimorphism is present in the third leg

685 across the group, where a copulatory organ is present in males (Legg, 1976). The organ derives 
686 from modified metatarsal and tarsal podomeres (Pittard \& Mitchell, 1972). Of particular note is

687 the close correspondence between the margins of the male metatarsal dorsum and a flange on the 688 female's IV coxae (Legg, 1976), which become attached during mating (Legg, 1977). It is

689 possible that the seemingly co-evolving leg structures could be an example of the 'lock and key'

690 hypothesis (Masley, 2012). Adaptations related to copulation in males are thought to be

691 taxonomically informative in the group (Tuxen, 1974), but whether these structures contribute to 692 reproductive isolation is yet to be tested. Cooke \& Shadab (1973) report that the shape of the 693 abdominal sclerites and the number of tubercles can also show significant SD, but do not expand 694 on these statements. SD is also expressed in arrangements of the tubercles found on the pedipalps 695 (Legg, 1976).

Male-biased SSD has also been documented in the legs of Ricinulei (Figure 10). Based 697 on a small sample size, Legg (1976) found all the legs of Ricinoides hanseni males to be longer 698 than those of females relative to body length. In the second leg, male femoral diameter can be 699 twice that of conspecific females, and the patella of males is also longer and more curved (Pittard 700 \& Mitchell, 1972). In P. pachysoma, the male first leg is thicker, and has a small conical spur 701 with a coarse granulated texture on its inner surface (Teruel \& Schramm, 2014). This pattern has 702 been correlated to the complex mating behaviour of Ricinulei, during which males may climb on 703 top of females (Cooke, 1967; Legg, 1976) and engage in an extended period of 'leg play', where 704 males rub and tap females with legs, before copulation occurs (Cooke, 1967; Legg, 1977). This 705 may indicate that female mate choice drives the elongation of male legs.

706 The retractable 'hood' (cucullus) covering the mouthparts and chelicerae also differs

707 between sexes. It is both wider and longer in male $C$. foedus than females, and is sometimes 708 more reflexed at its edges (Pittard, 1970). The cucullus is hypothesised to play a role in mating, 
709 the male cucullus acting as a wedge to help unlock the ridge between the prosoma and

710 opisthosoma in females, whilst Ricinoides afzeli females use the cucullus to stabilise eggs during

711 transport (Pittard, 1970). This suggests that female mate choice and differing reproductive roles

712 may drive cucullus dimorphism. The cucullus also has non-reproductive functions, aiding in

713 capturing prey and holding food during consumption (Pittard, 1970), and is therefore also likely

714 under the pressure of natural selection. Male-biased chelicerae SSD has also been reported, but

715 the driver of this dimorphism is unclear (Legg, 1976)

716 To date, most documented instances of SD in Ricinulei are qualitative, and little

717 morphometric data exists to provide statistical support of these conclusions. Future studies would

718 benefit from revisiting previously described collections (e.g. Cooke \& Shadab, 1973) and

719 applying morphometric analyses, allowing the occurrence/extent of SD to be more rigorously

720 quantified. 


\section{Schizomida}

\section{Description and phylogeny}

724 Schizomida, or short-tailed whip scorpions, comprise just over 230 described species (Reddell \&

725 Cokendolpher, 1995). Most species in the order are primarily tropical in distribution and tend to

726 be found away from bright light, with some species being troglodytes (Humphreys, Adams \&

727 Vine, 1989). Schizomids have been found in desert environments (Rowland \& Reddell, 1981)

728 and on the underside of ice and snow covered rocks (Reddell \& Cokendolpher, 1991), illustrating

729 their climatic range. Morphologically, schizomids resemble whip scorpions, except their

730 prosoma, which is divided into two regions (Barnes, 1982), and the lack of eyes. Due to these

731 morphological similarities, schizomids are almost universally thought to be the sister group of

732 Uropygi (Giribet et al., 2002; Shultz, 2007; Legg et al., 2013; Garwood \& Dunlop, 2014; Sharma

733 et al., 2014).

734

735 Sexual dimorphism and potential drivers

736 The most consistent sexually dimorphic trait within schizomids is the flagellum (a projection

737 from the terminal opisthosoma), which often varies in shape between sexes. The male flagellum

738 is generally enlarged and bulbous, whereas the female is typically elongate (Harvey, 2003). It

739 has been postulated that the flagellum plays a role in sex and species recognition during mating

740 (Sturm, 1958, 1973). Details of courtship and mating are limited to one species (Surazomus

741 sturmi), in which the female uses her mouthparts to grip the male flagellum during courtship

742 (Sturm, 1958, 1973). Given that many schizomids have secondarily lost their eyes (Harvey,

743 1992), it is certainly possible that the grasping of the male flagellum plays a role in both sex and 
744 species recognition during courtship. It has been noted, however, that flagellum dimorphism is

745 absent in other taxa (Rowland \& Reddell, 1980), with males of the family Protoschizomidae

746 often possessing an elongate flagellum similar to that of females (Rowland \& Reddell, 1979a).

747 Instead, Protoschizomidae species lacking dimorphism in the flagella tend to show narrowing of

748 the distal body segments in males; elongation is seen in pygidial segments X-XII and/or terminal

749 body segments V-XII (Rowland \& Reddell, 1979a).

750

SSD is also present in the schizomid pedipalp: males of many species have significantly

751 longer pedipalps than conspecific females (Figure 11; Harvey, 2001; Santos et al., 2013;

752 Monjaraz-Ruedas \& Francke, 2015). In dimorphic species, such as Rowlandius potiguar, male

753 pedipalp length is also highly variable relative to prosoma length compared to females (Figure

754 12; Santos et al., 2013). This has been attributed to the co-occurrence of male dimorphism,

755 where male morphs with either a long or a short pedipalp are present, the latter having pedipalps

756 similar in shape and size to the female (Santos et al., 2013). Male pedipalpal elongation occurs

757 largely in the femur, patella and tibia (Rowland \& Reddell, 1979a, 1981).

758

In contrast to Opiliones, where male dimorphism has been correlated with male-male

759 fighting (Buzatto et al., 2011; Zatz et al., 2011), evidence for direct combat in schizomids is

760 lacking. Furthermore, the male pedipalp does not play a direct role in copulation (Sturm, 1958,

761 1973). However, observations of the courtship of Hubbardia pentapeltis suggest that males

762 stretch out their pedipalps and use them to pick up small twigs before displaying them for

763 females (J.M. Rowland, pers. comm. from Santos et al., 2013). Further work is required to

764 confirm this within Rowlandius and other genera. If this behavioral information is confirmed, it

765 would suggest that female mate choice may be driving dimorphism. 

group (a clade defined by Rowland, 1975 containing members of the genus Schizomus) show both SD and male dimorphism: some males have a large pedipalp with a tibial spur, which is absent in males with smaller pedipalps and females (Rowland \& Reddell, 1980). genus level (Rowland \& Reddell, 1979a,b, 1980, 1981). Even within a single species the extent of SD varies in response to the environment. Cave dwelling individuals of Schizomus mexicanus are more strongly sexually dimorphic than those of epigean populations, for example (Rowland \& Reddell, 1980). Whilst compelling evidence has been put forward in support of sexual selection driving schizomid dimorphism (Santos et al., 2013), a paucity of behavioural data

776 limits further understanding. Future research on the potential pressures schizomids face in situ is 777 therefore necessary.

\section{Scorpiones}

\section{Description and phylogeny}

Scorpions are one of the more diverse arachnid orders comprising around 1750 described species

782 (Kovarik, 2009). They have colonised a wide range of terrestrial environments, with a northernmost occurrence of $50^{\circ} \mathrm{N}$ (Polis \& Sissom, 1990). Scorpions are unique amongst arachnids in possessing a long metasoma (tail) terminating in a venomous sting. Significant uncertainty exists regarding the placement of the group within the arachnid phylogeny. Recent morphological analyses have suggested they could be the sister group of harvestmen (Shultz,

787 2007), the sister group to a clade of solifuges and pseudoscopions (Wheeler \& Hayashi, 1998; 
788 Giribet et al., 2002), the sister group to Opiliones and pseudoscorpions (Garwood et al., 2017), or

789 the sister group to pseudoscorpions (Pepato, da Rocha \& Dunlop, 2010). Molecular phylogenies

790 variously place the order as closest to Ricinulei and Pedipalpi (Sharma et al., 2014), or as the

791 sister group to Pseudoscorpions, solifuges and harvestmen (Giribet et al., 2002). One placement

792 that has gained recent traction is Arachnopulmonata, a clade that includes scorpions and

793 pantetrapulmonata (spiders and pedipalpi). This clade has been recovered from molecular studies

794 (Sharma et al., 2014) and the groups within the clade seems to have morphological similarities in

795 their vascular systems (Klußmann-Fricke \& Wirkner, 2016; see also Giribet 2018).

796

797 Sexual dimorphism and potential drivers

798 SSD in scorpions is relatively consistent across the group (Figure 13). Females typically have a

799 larger carapace than males, which is thought to be a reliable indicator of overall body size (e.g.

800 Koch, 1977; Sánchez-Quirós et al., 2012). Nevertheless, the extent of SSD can vary

801 considerably. Australo-Papuan scorpions are characterised by extreme SSD, with the carapace of

802 females on average $40 \%$ longer than that of males. In contrast, some species show less than $1 \%$

803 difference in carapace length between sexes (Koch, 1977; Polis \& Sissom, 1990). Reverse SSD

804 is also occasionally observed in some scorpion clades. For example, male Liocheles australaisae

805 carapace length is on average $28 \%$ greater than that of females (Koch, 1977). Female-biased

806 SSD appears to be related to fecundity selection, with clutch size being strongly correlated with

807 maternal body size (e.g. Outeda-Jorge et al., 2009).

808 Scorpion SSD has also been reported based on total body length inclusive of tail.

809 Kjellsvig-Wearing (1966) found males of Tityus tritatis to be longer in overall body length than

810 females. We note that this length metric is likely a poor proxy for total body size, as the 
811 metasoma of male scorpions (segments comprising the tail exclusive of the telson) is often

812 elongated (Koch, 1977; Carlson et al., 2014; Fox et al., 2015); a trait most marked in the genera

813 Centruoides, Hadogenes, Isometrus and Hemiscorpius (Polis, 1990). This elongation is achieved

814 by lengthening of existing metasomal segments relative to females (Carlson et al., 2014), rather

815 than the addition of segments. As such, total body length performs worse than carapace length as

816 a predictor for body mass, due to the confounding factor of SSD in the tail. The telson itself is

817 not sexually dimorphic in the majority of species, but there are some exceptions (Polis \& Sissom,

818 1990). In Heterometrus laoticus the telson is longer in males (Booncham et al., 2007). Other

819 structural modifications can be found in males of Anuroctonus, Chaerilus, and Hemiscorpius

820 (Polis \& Sissom, 1990; Lourenço \& Duhem, 2010) and there is even some evidence of

821 dimorphism in venom glands in scorpions that exhibit sexual stinging (Sentenská et al., 2017).

822

The extent to which tail SSD is reflected in behavioural differences between male and

823 female scorpions remains unclear. Lengthening of the male metasoma has no impact on either

824 sprinting performance (by acting as a counterweight) or sting performance, defined as the

825 number of discrete stings when antagonised within a given time period (Carlson et al., 2014). It

826 may be that the increased length of the male metasoma is related to 'sexual stinging', in which

827 males sting their prospective mates (often in the arthrodial membrane adjacent to the pedipalpal

828 tibia) to stun the female and facilitate mating (Angermann, 1955, 1957; Francke, 1979;

829 Tallarovic et al., 2000). The male metasoma may also be used to 'club' or rub the female during

830 mating (e.g. Alexander, 1959; Polis \& Farley, 1979a).

831 The limbs of scorpions are also characterised by SSD, with male Centruroides vittatus

832 possessing significantly longer legs relative to total body size than females (Figure 14). This

833 translates to a 30\% sprint speed increase over females of the same body size (Carlson et al. 
834 2014). Limb elongation has therefore been linked to the documented male 'flight' versus female

835 'fight' response to predation (Carlson et al., 2014). Similar locomotory benefits could potentially

836 also apply to males seeking out sedentary females prior to mating. Finally, longer legs could also

837 aid 'leg play’ during mating (Polis, 1990).

838 In common with other arachnids (e.g. Schizomida and Amblypygi), marked dimorphism

839 is present in the pedipalps, which carry claws (chelae) in scorpions. Chelae in males are often

840 described as elongate or gracile compared to females, although the opposite is observed in some

841 genera (e.g. Buthus, Scorpio and some Titus; Polis, 1990). The degree to which male chelae

842 really are larger than females after controlling for body size remains a point of contention,

843 however. Whilst both the fixed and movable fingers of male chelae are longer and wider than

844 females in absolute terms across numerous species (e.g. Caraboctonus keyserlingi, Pandinus

845 imperator and Diplocentrus sp.; Carrera et al., 2009), no analyses normalise against body length.

846 This largely reflects the above difficulties (as discussed in above) in identifying a reliable

847 reference character for overall body size in Scorpions (Fox et al., 2015). In contrast, dimorphism

848 in chelae shape is more strongly supported. In a number of species, the movable finger of

849 females is more curved than that of the males (Carrera et al., 2009), and dentition (processes on

850 the inside surface of the chelae) differs between sexes in the family Buthidae (Maury, 1975).

851 Pedipalp dimorphism has previously been hypothesized to play a role in mating. During

852 courtship, many scorpions act in a 'courtship dance' involving the male and female grasping

853 chelae prior to mating (e.g. Alexander, 1959; Polis \& Farley, 1979a). Dimorphism in pedipalpal

854 chelae dentition, in particular, is thought to aid the male's grip of the female during mating

855 (Maury, 1975). 
857 dimorphism in the scorpion pedipalpal chelae and chelicerae (Carrera et al., 2009). Males are

858 more active during the mating season than females (Polis \& Sissom, 1990) and excavate burrows

859 more frequently than females (Carrera et al., 2009). In contrast, females build specialised

860 burrows for maternal care (Polis, 1990). Interspecific morphological differences associated with

861 burrowing are common (Polis, 1990; Prendini, 2001), but burrowing has yet to be systematically

862 investigated as a driver behind SD in scorpions.

863 Finally, marked sexual dimorphism is also observed in the pectines, a ventral wing-

864 shaped structure with numerous teeth, used a sensory organ. Females have smaller pectines than

865 males, and the angle between the two wings is greater (Polis, 1990). In an ontogenetic study of

866 Paruroctonus mesaensis, male pectines grew at a much faster rate when the animal reached

867 sexual maturity, potentially indicating the organ may be subject to sexual selection (Polis \&

868 Farley, 1979b). Multiple authors have also found statistically significant differences in pectine

869 length between species (Booncham et al., 2007; Fox et al., 2015). Pectines function as both

870 mechano- and chemoreceptors. It has been hypothesised that males use their larger structures to

871 track chemical trails left by females, and thus find mates (Melville, 2000). Several authors have

872 also suggested that males have more pectinal teeth than females (e.g. Alexander, 1959; Williams,

873 1980; Mattoni, 2005).

874

In summary, SSD is less extreme in scorpions than many other arachnid groups, yet

875 several anatomical regions do reliably exhibit sex differences. On average, females are larger in

876 total body size, whilst males possess longer legs, elongate and gracile chelae, a slender

877 metasoma, and enlarged pectines. Reverse SSD is present in the chelae and metasoma in some

878 groups (Polis \& Sissom, 1990). Future research should aim to map the phylogenetic distribution 
879 of such traits in order to better understand how life history and habitat use may result in

880 differential selection operating on males and females.

881

882 Solifugae

883 Description and phylogeny

884 Solifuges, known as camel spiders or sun spiders, comprise approximately 1000 species (Punzo, 885 1998a). The order is largely limited to arid environments, although some species are found in 886 rainforests and their margins (Harvey, 2003). The occurrence of sensory racquet organs on the

887 ventral surface of the coxae on leg IV differentiate Solifugae from other arachnids. Other notable 888 morphological features include enlarged chelicerae, elongate leg patellae relative to other 889 arachnids, and the presence of trachea instead of book lungs (Harvey, 2003). There is some 890 debate over their phylogenetic position within arachnids. Some studies report solifuges as the 891 sister group to pseudoscorpions (Shultz, 2007; Giribet et al., 2002) while others place them in a 892 clade with Acariformes (Pepato, da Rocha \& Dunlop, 2010, Garwood et al., 2017). Recent 893 molecular work has placed solifuges as the sister group to a clade including Xiphosura,

894 Ricinulei, Scorpiones, Pedipalpi, Araneae and Opiliones (Sharma et al., 2014).

895

\section{Sexual dimorphism and potential drivers}

897 Body length SSD is present in solifuges. Males are typically slightly smaller in body size, more

898 slender in form, and have longer limbs than females (Figure 15; Punzo, 1998b; Peretti \&

899 Willemart, 2007). Female-biased SSD likely relates to a fecundity advantage, with body size

900 tightly correlating to clutch size in Eremobates marathoni (Punzo, 1998a). It has been suggested 
901 that the longer legs of males in Solifugae could relate to extended mate searches or use in mating 902 (Wharton, 1986). Racquet organs are also larger in males (Peretti \& Willemart, 2007), and their

903 hypothesized function as chemoreceptors may increase male capacity to detect pheromones and 904 aid mate search (Punzo, 1998a). The fact that male pedipalps are used to 'massage' the female

905 during mating (Heymons, 1902; Junqua, 1962) may also explain why all male limbs are 906 elongated relative to overall body size.

Amongst arachnids, solifuges are best recognised by their large chelicerae. Numerous

908

909

910

911

912

913

914

915

916

917

918

919

920

921

922

923 studies report SD in the chelicerae (see Supplementary Material), yet often fail to distinguish the effects of shape and size dimorphism from one another. Indeed, a commonly reported metric of solifuge chelicerae is their aspect ratio, with male chelicerae characterised by a greater length:width ratio than those of females (Punzo, 1998a; Peretti \& Willemart, 2007). Whilst aspect ratio can itself be an important metric, often affecting function (e.g. Kruyt et al., 2014; Yeh \& Alexeev, 2016), the degree to which the 'slender' chelicerae of males are also dimorphic in total size is yet to be addressed in the literature. Calculations based on mean values presented by Punzo (1998a) do suggest female-biased dimorphism in cheliceral length and width, however. Quantifying the presence of SSD in chelicerae is further complicated by the lack of a reliable metric for total body size. Body length has been considered problematic, as the size of the abdomen is known to increase post-feeding (Brookhart \& Muma, 1981; Wharton, 1986). Elsewhere, the CP index, the combined length of the chelicerae and propeltidium (the prosomal dorsal shield in solifuges) has been preferred as a metric of solifuge total body size (Bird, 2015), further confusing the picture with regards to chelicerae length and overall SSD. is more widely accepted. Male chelicerae are straighter (Hrušková-Martišová et al., 2010), the 
924 fixed finger is less curved and the manus (a broad proximal section of the paturon which contains

925 the cheliceral muscles) is more gracile, i.e. narrower than in females (Bird, 2015). The dentition

926 of adult male chelicerae is also reduced in projection size (Bird, 2015). This is not universally

927 true however - though not quantified, there appears to be little to no difference in the size of the

928 primary and secondary teeth between sexes in Solpugiba lineata and some species of

929 Hemiblossia (Bird, 2015). Both are known to be termitophagous, thus Bird (2015) has

930 hypothesised that solifuge cheliceral dimorphism is linked to feeding behaviour. Males are

931 known to feed less often than females (Junqua, 1962; Wharton, 1986), and male chelicerae show

932 less dental wear (Fitcher, 1940). Sex differences in dietary preference have also been observed

933 under laboratory conditions, with female Gulvia dorsalis feeding on highly sclerotized beetles,

934 which are refused by males (Hrušková-Martišová et al., 2010). The increased depth of the manus

935 in female chelicerae may therefore facilitate an increase in muscle volume and enhanced bite

936 force and feeding efficiency (Bird, 2015). Such a pattern has previously been found

937 interspecifically: species characterised by chelicerae that are more robust are capable of

938 delivering a stronger bite force (van der Meijden et al., 2012).

939 Alternatively, dimorphism in solifuge chelicerae may arise from their function during

940 mating (van der Meijden et al., 2012). Male Galeodes caspius use their chelicerae to insert

941 spermatophores into the genital opening of the female (Hrušková-Martišová et al., 2010), often

942 inserting the fixed finger or occasionally the whole chelicera into the genital opening (Amitai et

943 al., 1962; Bird, 2015). After sperm transfer, the male may start a 'chewing' action; the precise

944 reason for this is unknown but is hypothesised to help force sperm into a storage area and/or

945 break up the spermatophore (Muma, 1966). The straighter shape of the male chelicerae may

946 assist with spermatophore insertion (Hrušková-Martišová et al., 2010), whilst reduced dentition 
947 could minimise damage during genital chewing (Bird, 2015). Sexually dimorphic setae are also

948 present on the base of the chelicerae, In Oltacola chacoensis, for instance, these are less

949 numerous in males, but larger and harder (Peretti \& Willemart, 2007). During mating, setae are

950 pressed up against the perigenital region of the female, indicating a potential role during mating

951 (Peretti \& Willemart, 2007).

952 SD is also present in the solifuge flagellum, an elongate structure protruding from the

953 fixed finger of the chelicerae. The flagellum occurs only in male solifugae (Punzo, 1998). There

954 is considerable interspecific variation in both the form of the flagellum (Lawrence, 1954; Punzo,

955 1998b) and in its articulation: it is fixed in some species and movable in others (Punzo, 1998b).

956 Lamoral (1975) suggested multiple potential functions for the flagellum, including as a

957 mechanoreceptor and being involved the storage and emission of exocrine secretions. Flagella

958 may also play a role in mating, being used by male Oltacola chacoensis to carry spermatophores

959 (Peretti \& Willemart, 2007), and being inserted into the genital opening during sperm transfer by

960 male Metasolpuga picta (Wharton, 1986).

961 To summarise, SSD is present to some degree in total body size and may be present in

962 chelicerae of solifuges, though shape dimorphism is better accepted. More work is required to

963 determine the relative importance of mating and feeding on cheliceral morphology. Bird (2015)

964 advocates a geometric morphometrics approach to quantifying the morphology of chelicerae, and

965 we concur that such a study including males and females from multiple, phylogenetically

966 disparate species would be an important advance in the field. Furthermore, life history

967 information pertaining to Solifugae is limited to a small number of species; mating, in particular,

968 has only been studied in three families (Hrušková-Martišová et al., 2010). Focusing basic

969 research onto lesser-studied groups may illuminate further trends in SD across the order. 
970

\section{Uropygi}

\section{Description and phylogeny}

973 Uropygi, known as whip scorpions or vinegaroons, are represented by 110 extant species (Zhang,

974 2011). The group is found in habitats limited to tropical and subtropical areas, preferring damp

975 and humid conditions, although Mastigoproctus giganteus is found in arid environments in the 976 southern United States (Kern \& Mitchell, 2011). As their common name suggests, uropygid

977 morphology bears some resemblance to that of scorpions, with palpal claws and a segmented

978 opisthosoma. However, whip scorpion anatomy differs from that of scorpions in having a 979 segmented terminal flagellum instead of a stinging tail. Furthermore, whip scorpions spray a 980 noxious mixture primarily composed of acetic acid from glands located near the pygidium as a 981 means of defence (Schmidt et al., 2000). There is consensus in the phylogenetic position of

982 Uropygi: they are widely regarded as the sister group to Schizomida, together forming

983 Thelyphonida, and being united with the Amblypygi to form the clade Pedipalpi (Giribet et al., 984 2002; Shultz, 2007; Sharma et al., 2014; Garwood et al., 2017).

\section{Sexual dimorphism and potential drivers}

987 SSD has been reported in whip scorpions, with males having a larger prosomal scutum, the 988 dorsal sclerotized prosomal plate (seen as a good indicator of body size) than females (Figure 16;

989 Weygoldt, 1988). Other minor structural modifications can also be seen in the opistisoma and

990 first leg of females (Huff \& Prendini, 2009). In the pedipalps, SD is present beyond the fourth 991 nymphal phase, which is the final nymphal stage before maturity. There is an increased positive 
992 allometric relationship in the length of the palpal femur and patella when regressed against

993 carapace length in adult male of the species Mastigoproctus gigantus that is unseen in females

994 (Weygoldt, 1971). SSD in the pedipalps is also seen in the genera Thelyphonellus and Typopelti,

995 and to a lesser degree Thelyphonus (Weygoldt, 1988). Male pedipalps have also been described

996 as "stronger" in these genera (Weygoldt, 1988), but there are no biomechanical analyses to

997 support this statement. Minor differences in structure between the male and female pedipalps are 998 also present. For example, the third spine on the female trochanter of Thelyphonus indicus is

999 much longer relative to other pedipalpal spines (Rajashekhar \& Bali, 1982), and the patella

1000 apophyses are thicker relative to length in females (Rajashekhar \& Bali, 1982).

1002 every group (Gravely, 1916). Where present, dimorphism is expressed through a larger tibial 1003 apophysis in males; this results, in males possessing a broader area on the tibia termed a 'palm',

1004 which is a consistent feature across Uropygi (Gravely, 1916; Weygoldt, 1971, 1972; Rajashekhar $1005 \&$ Bali, 1982). The tibial apophysis has a wide range of male morphologies across the group, 1006 ranging from a small projection to a suite of highly modified curved structures (Gravely, 1915).

1007 Similarly, the tarsus is characterised by sexually dimorphic projections in some species, with 1008 male T. indicus (Rajashekhar \& Bali, 1982) andcMastigoproctus gigantus (Weygoldt, 1971)

1009 bearing a spine close to the tip of the fixed finger of the pedipalpal claw, not present in females.

1010 The sexually dimorphic pedipalps of Thelyphonidae are hypothesized to play a role in

1011 male-male contest over prospective females (Watari \& Komine, 2016). Fighting includes a phase

1012 of grappling, where males face each other and fight using their pedipalps, and a tackling phase,

1013 during which males try to overturn their opponent using the pedipalps (Watari \& Komine, 2016).

1014 Numerous publications report that males also use the pedipalps in mating, typically grabbing the 
1015 first legs of the female with the pedipalps and manipulating her until they are face-to-face

1016 (Weygoldt, 1971, 1972).

1017 Further work is needed to determine the underlying drivers of SD in the Uropygi. As

1018 many species are known from only a small number of individuals (Gravely, 1916; Huff \&

1019 Prendini, 2009), a concerted collecting effort will be required before any broad scale patterns in

1020 SSD may be distinguished in whip scorpions.

1021

1022 Discussion

1023 Trends in SD across Arachnida

1024 When SD is considered across Arachnida as a whole, general trends become apparent (Table 1).

1025 The lack of current consensus regarding phylogenetic relationships between arachnid orders

1026 precludes us from deriving the ancestral condition of dimorphism, with only Arachnopulmonata

1027 (containing Scorpiones, Araneae, Amblypygi, Schizomida and Uropygi; Figure 17) and its

1028 internal relationships being consistently recovered (Giribet, 2018). However, a current consensus

1029 phylogeny is included to allow readers to gain an insight into the distribution of sexual

1030 dimorphism across the group (Figure 17).

1031 Firstly, though generally not as pronounced as in Araneae, female-biased SSD in overall

1032 body size is present across much of Arachnida: female-biased SSD has also been reported in

1033 mites, amblypygids, harvestmen, pseudoscorpions, scorpions and solifuges. Whilst some species

1034 are known to subvert the general trend, we note that there is no evidence of male-biased SSD

1035 being dominant across an order. 

scorpions, solifuges, spiders, Ricinulei and harvestmen. This trait is seemingly driven by behavioural factors, although the precise mechanism differs between groups (see below). Additionally, the majority of arachnid orders exhibit dimorphism in either size or shape of the pedipalps. When present, SSD in the pedipalps typically favours males, which often possess

1041 additional spurs or other accessories to the appendage. In the most extreme examples, spiders 1042 have modified their pedipalps to transfer spermatophores directly. However, in the majority of 1043 cases, the pedipalp does not play a direct role in sperm transfer and is instead involved in female 1044 mate choice or intraspecific male contest. SSD in chelicerae is also observed in a number of arachnid orders (Acari, Araneae,

1046 Opiliones and Solifugae), though the direction of dimorphism can differ. When dimorphism is 1047 male-biased, the chelicerae tend to be under the influence of sexual selection. For example, 1048 Opiliones chelicerae are used in male-male contest (Willemart et al., 2006), spider chelicerae are 1049 thought to be used for intersexual agonistic displays (Faber, 1983) and nuptial gift giving (Costa1050 Schmidt \& Araújo, 2008). Female-biased dimorphism, on the other hand, appears to be related to 1051 increased feeding due to the high energetic costs of produding eggs. Female biased intersexual 1052 difference in the number of prey captured has been empirically demonstrated in spiders that 1053 exhibit female-biased cheliceral SSD (Walker \& Rypstra, 2002). Differences in cheliceral wear 1054 patterns suggest this is also the case in solifuge (Fitcher, 1940). Several orders also show male-bias in the number of sensory structures (Amblypygi, Solifugae and Scorpiones). In solifuges and scorpions, the co-occurrence of larger sensory

1057 structures and longer leg length (Melville, 2000; Peretti \& Willemart, 2007; Punzo, 1998b) may

1058 be tied to the selective pressures of mate searching (Punzo, 1998a; Melville, 2000). In Opiliones, 
1059 male and females have different sensory anatomy (Wijnhoven, 2013) though there is no clear

1060 indication as to whether one sex has increased sensory capabilities relative to the other.

1061

1062 Selective pressures for SD in Arachnida

1063 Weapons and ornaments

1064 When sexually dimorphic structures appear better developed in males, they are often found to

1065 play a role in male-male contests or male-female courtship. The degree to which these intra- or

1066 intersexual selection pressures are most prevalent has yet to be discussed for Arachnida as a

1067 whole however. Here we find evidence for male-male contests driving the evolution of sexually

1068 dimorphic structures in Acari, Amblypygi, Araneae, Opiliones, Pseudoscorpiones and Uropygi.

1069 In mites, male C. berlesei use enlarged third legs to kill rival males (Radwan, 1993), whilst male

1070 amblypygids 'fence' each other using their sexually dimorphic antenniform 'whip' legs

1071 (Weygoldt, 2000). The hyperallometric chelicerae of male Areneae are known to be used in

1072 male-male contests (Funke \& Huber, 2005), and the enlarged fourth leg of male Opiliones is

1073 used in contests between males of the 'major' morph (Zatz et al., 2011). Finally, the sexually

1074 dimorphic pedipalps of Pseudoscorpiones (Weygoldt, 1966; Thomas \& Zeh, 1984) and Uropygi

1075 (Watari \& Komine, 2016) are involved in grappling during male-male aggression.

1076 Yet in the instances outlined above, the male-biased sexually dimorphic structures have

1077 also been found to function during courtship and mating. Elaborations on the enlarged third legs

1078 of mites may assist males in aligning with the female spermaduct opening (Gaud \& Atyeo,

1079 1979), and the sexually dimorphic antenniform 'whips' of amblypygids are also used to display

1080 to and rub females prior to mating (Weygoldt, 2000). The enlarged chelicerae of some male 
1081 spiders are thought to play a role in courtship displays (Faber, 1983), whilst the pedipalps of

1082 pseudoscorpions are also involved in a ritualised dance prior to mating (Weygoldt, 1966). There

1083 are several instances therefore of both intra- and intersexual selection pressures acting on a given

1084 sexually dimorphic structure.

1085 Arguably, however, examples of courtship and female choice driving the evolution of

1086 sexually dimorphic structures are even more widespread. Of those groups considered in the

1087 present study, evidence of intersexual selection driving SSD is lacking for only Uropygi. In

1088 addition to the examples listed above, the cheliceral horns of Opiliones are placed on the female

1089 dorsum after copulation (Willemart et al., 2006), and the longer male legs of Ricinulei are

1090 engaged in 'leg play’ prior to mating (Cooke, 1967; Legg, 1977). In schizomids, the female

1091 chelicerae grip the male flagellum during mating (Sturm, 1958, 1973), whereas the dimorphic

1092 chelicerae of solifuge are used by the male to grip the female and transfer spermataphores

1093 (Peretti \& Willemart, 2007). The dimorphic pedipalp of scorpions has also been hypothesised to

1094 play a role in the 'courtship dance', as males and females grasp chelae prior to mating (e.g.

1095 Alexander, 1959; Polis \& Farley, 1979a). Indeed, in four orders (Ricinulei, Schizomida,

1096 Solifugae, and Scorpiones), courtship and mating appear to be the primary drivers of male-biased

1097 SSD in the appendages. 


\section{Scramble competition}

1100 The scramble competition hypothesis posits that the most mobile males within a population will

1101 reach and copulate with a greater number of females (Ghiselin, 1974). Male traits conferring an

1102 advantage in locating a receptive female, such as sensory and locomotor adaptations, may

1103 therefore become sexually dimorphic under the selective pressure of scramble competition

1104 (Andersson, 1994). This is well-supported in the case of Araneae, with decreased male body size

1105 and increased leg length in spiders being linked to improved climbing ability (Moya-Laraño et

1106 al., 2002), bridging ability (i.e. walking upside-down on silk bridges; Corcobado et al., 2010) and

1107 locomotor speed (Grossi \& Canals, 2015). Here we also identify instances of male-biased SSD in

1108 leg length in Acari, Scorpiones, Solifugae, Ricinulei and Opiliones, and reduced total body size

1109 in male Acari, Amblypygi, Pseudoscorpions, Scorpiones and Solifugae. Within scorpions,

1110 decreased body mass and elongate legs have been correlated to increased sprint speed in male $C$.

1111 vitttus (Carlson et al., 2014), and the increased size of pectines (sensory organs) in males has

1112 been hypothesised to play a role in mate searching (Melville, 2000). Elsewhere, smaller body

1113 size and increased leg length in male Solifugae may also be related to mate searching (Peretti \&

1114 Willemart, 2007), with male Metasolpuga picta typically covering much greater straight-line

1115 distances than females (Wharton, 1987). The chemosensing racquet organs of male solifuges are

1116 also enlarged (Peretti \& Willemart, 2007). The case for scramble competition driving some

1117 aspects of SD in both Scorpiones and Solifugae is therefore convincing. Yet within Ricinulei and

1118 Opiliones, male-biased SSD in leg length appears better explained by their role in mating (Legg,

1119 1977) and male-male contests (Willemart et al., 2009; Buzatto et al., 2014), respectively. As will

1120 be discussed below, further experimental work focusing on the biomechanical and physiological 
1121 implications of body size and leg length dimorphism would be particularly insightful in this

1122 respect.

\section{Fecundity selection}

1124 Fecundity selection is a well-documented driver of female-bias body size dimorphism within

1125 Araneae (Head, 1995; Coddington et al., 1997). In females of the wolf spider Donacosa merlini

1126 the disproportionately large opisthosoma of females has been correlated to egg production and

1127 storage, for example (Fernández-Montraveta \& Marugán-Lobón, 2017). Under laboratory

1128 conditions, female body mass in the ant-eating spider Zodarion jozefienae has been found to

1129 tightly correlate to number of eggs present within the egg sack (Pekár et al., 2011). More broadly

1130 across Araneae, body size dimorphism has been explained by female size increase via fecundity

1131 selection (Prenter, 1999; Huber, 2005). Yet despite this wealth of data pertaining to Araneae,

1132 relatively little is known of the role of fecundity selection across the smaller arachnid orders.

1133 Within scorpions, the carapace length of females is correlated to increased litter size (e.g.

1134 Outeda-Jorge et al., 2009), and female-biased dimorphism in prosoma length has therefore been

1135 taken as evidence of fecundity selection (Fox et al., 2015); similar patterns can also be seen in

1136 solifuges (Punzo, 1998a). Beyond this, female-biased SSD has been identified in other metrics of

1137 'total body size' in harvestmen (Pinto-da-Rocha et al., 2007; Zatz, 2010), pseudoscorpions (Zeh,

1138 1987a) and amblypygids (McArthur et al., 2018). Whilst the degree to which such dimensions

1139 correspond to potential fecundity in these groups has remained largely unexplored. At least in

1140 one species of amblypygid, for instance, female carapace size does appear to be correlated to

1141 brood size (Armas, 2005).

1142

\section{Niche partitioning}


1144 Males and females may also diverge in their energetic requirements due to their different

1145 reproductive or social roles, resulting in different trait optima between the sexes (Statkin, 1984).

1146 Here we highlight examples of niche partitioning within Acari and Araneae, although

1147 unequivocal examples are limited across Arachnida. Due to the increased energetic demands of

1148 reproduction, female ant-eating spiders (Z. jozefienae) have been found to consume larger prey

1149 items using their enlarged chelicerae compared to males (Pekár et al., 2011). In such instances,

1150 fecundity selection (as discussed above) can be thought of as driving niche partitioning. The

1151 increased reproductive output of females can necessitate habitat or dietary divergence, resulting

1152 in morphological dimorphism beyond that of total body size. Trophic dimorphism has also been

1153 reported in the nymphal stages of Kiwi bird feather mite Kiwialges palametrichus (Gaud \&

1154 Atyeo, 1996), with males and females diverging in their preferred microhabitat in and around the

1155 feather. In this instance, however, SD and niche partitioning is also compounded by ontogenetic

1156 nymphal stages. Hence, whilst there is some evidence that niche partitioning promotes sexual

1157 dimorphism in arachnids, it does not currently appear to be a major driving force. The relative

1158 lack of examples of niche partitioning (in comparison to male contests, for example) may partly

1159 reflect the paucity of information relating to the discrete dietary and habitat preferences of each

1160 sex, however. In some instances, our understanding of the differing morphology between sexes

1161 far exceeds that of their potential dietary and habitat niches.

1162

\section{Conclusion}

1164 In conclusion, we believe that a key endeavour for future work should be to trace the evolution

1165 of SD across Arachnida more broadly, extending work that has thus far predominantly been

1166 restricted to Araneae. For example, the frequency with which pedipalp SSD occurs across 
1167 arachnids (7 out of 11 orders) may point towards an early origin within the group. Alternatively,

1168 given that arachnid pedipalps appear to be involved in numerous different courting, mating and

1169 other related tasks, and show many different types of SD, it is equally possible pedipalp

1170 dimorphism may have evolved independently several times. Such analyses will prove extremely

1171 informative with regards to the origin of SD in the group, but necessarily must overcome issues

1172 regarding phylogenetic uncertainty. In arachnids as a whole, there is little congruence between

1173 recent morphological and molecular phylogenies (Sharma et al., 2014; Garwood et al., 2017;

1174 Giribet, 2018); this issue is often replicated within individual arachnid orders. Furthermore, there

1175 is a general paucity of information on the phylogenetic relationships within smaller arachnid

1176 orders. For example, just one molecular phylogenetic study of Palpigradi has been published to

1177 date (Giribet et al. 2014). In Amblypygi, limited morphological phylogenies have been published

1178 (Weygoldt, 1996, Garwood et al., 2017) and no molecular phylogenetic study of the order as a

1179 whole has ever been conducted. Therefore, ideally future analyses of SSD should be

1180 accompanied by improved phylogenies, or else account for current uncertainty in phylogeny.

1181 Furthermore, we note that basic data pertaining to the biology and life history of many

1182 arachnid orders are still lacking, particularly in the smaller groups. For example, information on

1183 courtship displays in Schizomida are limited to anecdotal evidence, and there is no published

1184 data on mating in Palpigradi. An improved understanding of ontogenetic scaling in the size and

1185 shape of arachnids is also a priority. In particular, the ability to better identify discrete

1186 ontogenetic stages and the onset of sexual maturity will prove useful, as dimorphism frequently

1187 becomes more pronounced beyond this point.

$1188 \quad$ Future research efforts should also exploit recent advances in the fields of

1189 morphometrics, statistics, experimental physiology and biomechanics. Some progress has been 
1190 made in this direction concerning Araneae SD: for example, recent studies have employed

1191 geometric morphometric to quantify shape dimorphism amongst $D$. merlini (Fernández-

1192 Montraveta \& Marugán-Lobón, 2017). In contrast, potential shape dimorphism amongst the

1193 smaller arachnid orders is typically quantified using ratios of linear metrics (e.g. Weygoldt,

1194 2000; Vasconcelos et al., 2014; Santos et al., 2013), and may therefore fail to capture finer-scale

1195 shape change between sexes. Furthermore, statistical hypothesis testing remains limited amongst

1196 the smaller orders. Whilst limited sample sizes are both frequent and undoubtedly a problem,

1197 other studies comprising a larger number of samples continue to eschew statistical testing, and

1198 further work is needed to statistically corroborate previously published qualitative observations.

1199 Finally, field and lab-based experimental studies are uncommon outside of spiders (Moya-

1200 Laraño et al., 2002; Grossi \& Canals, 2015). This work is, however, imperative, as an improved

1201 understanding of form-function relationships will provide further insights into the life history of

1202 both sexes, and the potential evolutionary drivers behind SD within arachnids.

1203

\section{Acknowledgments}

1205

1206 We thank the editor, Glaucho Machado and one other anonymous reviewer, whose comments

1207 greatly improved this manuscript

\section{References}

1210 Abouheif E., Fairbairn DJ. 1997. A comparative analysis of allometry for sexual size

1211 dimorphism: assessing Rensch's rule. The American Naturalist 149:540-562. 
1212 Aisenberg A., Costa FG., González M., Postiglioni R., Pérez-Miles F. 2010. Sexual dimorphism

1213 in chelicerae, forelegs and palpal traits in two burrowing wolf spiders (Araneae: Lycosidae)

1214 with sex-role reversal. Journal of Natural History 44:1189-1202.

1215 Alexander AJ. 1959. Courtship and mating in the buthid scorpions. Journal of Zoology 133:145$1216 \quad 169$.

1217 Amitai P., Levy G., Shulov A. 1962. Observations on mating in a solifugid Galeodes sulfuripes

1218 Roewer. Bulletin of the Research Council of Israel, Section B, Zoology 11:156-159.

1219 Andersson, M. 1994. Sexual selection. Princeton University Press, Princeton. 624pp.

1220 Angermann H. 1955. Indirekte Spermatophorenübertragung bei Euscorpius italicus (Hbst.)

1221 (Scorpiones, Chactidae). Naturwissenschaften 42:303.

1222 Angermann H. 1957. Über verhalten, spermatophorenbildung und sinnesphysiologie von

1223 Euscorpius italicus Hbst. und verwandten arten (Scorpiones, Chactidae). Ethology 14:276-

1224302.

1225 Armas, L.F.D., 2005. Notas sobre la biología reproductiva del amblipígido partenogenético

1226 Charinus acosta (Quintero, 1983) (Amblypygi: Charinidae). Boletín de la Sociedad

1227 Entomológica Aragoneza 36:271-273.

1228 Ax P. 2000. Palpigradi-Holotracheata. In: Multicellular Animals. Springer, 120-122.

1229 Baker RH., Wilkinson GS. 2001. Phylogenetic analysis of sexual dimorphism and eye-span

$1230 \quad$ allometry in stalk-eyed flies (Diopsidae). Evolution 55:1373-1385.

1231 Barnes RD. 1982. Invertebrate Zoology. Philadelphia, PA: Holt-Saunders International.

1232 Barranco P., Mayoral JG. 2007. A new species of Eukoenenia (Palpigradi, Eukoeneniidae) from

1233 Morocco. Journal of Arachnology 35:318-324. 
1234 Behan-Pelletier VM. 2015a. Sexual dimorphism in Autogneta, with description of three new

1235 species from North America and new diagnosis of the genus (Acari, Oribatida,

$1236 \quad$ Autognetidae). Zootaxa 3946:55-78.

1237 Behan-Pelletier VM. 2015b. Review of sexual dimorphism in brachypyline oribatid mites.

$1238 \quad$ Acarologia 55:127-146.

1239 Behan-Pelletier VM., Eamer B. 2010. The first sexually dimorphic species of Oribatella (Acari,

1240 Oribatida, Oribatellidae) and a review of sexual dimorphism in the Brachypylina. Zootaxa

$1241 \quad 2332: 1-20$.

1242 Beier M. 1961. Über Pseudoscorpione aus sizilia-nischen Höhlen. Bolletino Accademia Gioenia 1243 di Scienze Naturali in Catania 4:89-96.

1244 Bernini F., Avanzati AM. 1983. Notulae Oribatologicae XXIX. Le Oribatellidae (Acarida, 1245 Oribatida) viventi sul massiccio sardo-corso. Biogeographia 8 (1): 347-410

1246 Bertani R., Guadanucci, JPL. 2013. Morphology, evolution and usage of urticating setae by 1247 tarantulas (Araneae: Theraphosidae). Zoologia 30:403-418.

1248 Bird TL. 2015. Cheliceral morphology of Solifugae (Arachnida): Primary homology,

1249 terminology, and character survey. $\mathrm{PhD}$ Thesis, Colorado State University.

1250 Bonduriansky, R. 2007. Sexual selection and allometry: A critical reappraisal of the evidence $1251 \quad$ and ideas. Evolution 61: 838-849.

1252 Booncham, U. 2007. Sexual dimorphism in the Asian Giant Forest Scorpion, Heterometrus 1253 laoticus Couzijn, 1981. Naresuan University Science Journal 4:42-52.

1254 Brookhart JO., Muma MH. 1981. The pallipes species-group of Eremobates Banks (Solpugida:

1255 Arachnida) in the United States. Florida Entomologist 64: 283-308. 
1256 Bulbert MW., O’Hanlon JC., Zappettini S., Zhang S., Li D. 2015. Sexually selected UV signals

1257 in the tropical ornate jumping spider, Cosmophasis umbratica may incur costs from

$1258 \quad$ predation. Ecology and Evolution 5:914-920.

1259 Buzatto BA., Machado G. 2008. Resource defence polygyny shift to female polygyny over the

1260 course of the reproductive season of a Neotropical harvestman. Behavioural Ecology and

$1261 \quad$ Sociobiology 63:85-94.

1262 Buzatto BA., Machado G. 2014. Male dimorphism and alternative reproductive tactics in

1263 harvestmen (Arachnida: Opiliones). Behavioural Processes 109:2-13.

1264 Buzatto BA., Requena GS., Lourenço RS., Munguía-Steyer R., Machado G. 2011. Conditional

1265 male dimorphism and alternative reproductive tactics in a Neotropical arachnid (Opiliones).

1266 Evolutionary Ecology 25:331-349.

1267 Buzatto BA., Tomkins JL., Simmons LW., Machado G. 2014. Correlated evolution of sexual

1268 dimorphism and male dimorphism in a clade of neotropical harvestmen. Evolution 68:1671-

$1269 \quad 1686$.

1270 Carlson BE., McGinley S., Rowe MP. 2014. Meek males and fighting females: sexually-

1271 dimorphic antipredator behavior and locomotor performance is explained by morphology in

$1272 \quad$ bark scorpions (Centruroides vittatus). PloS One 9:e97648.

1273 Carrera PC., Mattoni CI., Peretti A V. 2009. Chelicerae as male grasping organs in scorpions:

1274 sexual dimorphism and associated behaviour. Zoology 112:332-350.

1275 Chapin KJ., Reed-Guy S. 2017. Territoriality mediates atypical size-symmetric cannibalism in

1276 the Amblypygi Phrynus longipes. Ethology 123:772-777. 
1277 Clark, D.L., Uetz, G.W. 1993. Signal efficacy and the evolution of male dimorphism in the

1278 jumping spider, Maevia inclemens. Proceedings of the National Academy of Sciences of

$1279 \quad$ United States of America, 90:11954-11957.

1280 Coddington JA., Hormiga G., Scharff N. 1997. Giant female or dwarf male spiders? Nature

$1281 \quad 385: 687$.

1282 Cokendolpher JC., Enríquez T. 2004. A new species and records of Pseudocellus (Arachnida:

1283 Ricinulei: Ricinoididae) from caves in Yucatán, Mexico and Belize. Texas Memorial

1284 Museum, Speleological Monographs 6:95-99.

1285 Condé B. 1991. Le dimorphisme sexuel des Palpigrades. Bulletin de la Société Neuchâteloise des

$1286 \quad$ Sciences Naturelles 116:67-73.

1287 Condé B. 1996. Les Palpigrades, 1885-1995: acquisitions et lacunes. Revue Suisse de Zoologie,

$1288 \quad$ hors série 1:87-106.

1289 Cooke JAL. 1967. Observations on the biology of Ricinulei (Arachnida) with descriptions of two 1290 new species of Cryptocellus. Journal of Zoology 151:31-42.

1291 Cooke JAL., Shadab MU. 1973. New and little known ricinuleids of the genus Cryptocellus

1292 (Arachnida, Ricinulei). American Museum Novitates 2530

1293 Costa-Schmidt LE., Araújo AM. 2008. Sexual dimorphism in chelicerae size in three species of

1294 nuptial-gift spiders: a discussion of possible functions and driving selective forces. Journal 1295 of Zoology 275:307-313.

1296 Cox RM., Butler MA., John-Alder HB. 2007. The evolution of sexual size dimorphism in

1297 reptiles. In: Sex, size and gender roles: evolutionary studies of sexual size dimorphism.

1298 Oxford: Oxford University Press, 38-49.

1299 Cracraft J., Donoghue MJ. 2004. Assembling the tree of life. Oxford: Oxford University Press. 
1300 Elgar MA. 1991. Sexual cannibalism, size dimorphism, and courtship behavior in orb-weaving $1301 \quad$ spiders (Araneidae). Evolution 45:444-448.

1302 Elgar MA., Ghaffar N., Read AF. 1990. Sexual dimorphism in leg length among orb-weaving 1303 spiders: a possible role for sexual cannibalism. Journal of Zoology 222:455-470.

1304 Emlen DJ., Hunt J., Simmons LW. 2005. Evolution of sexual dimorphism and male dimorphism 1305 in the expression of beetle horns: phylogenetic evidence for modularity, evolutionary 1306 lability, and constraint. The American Naturalist 166:S42-S68.

1307 Faber DB. 1983. Sexual differences in body proportions of Zygoballus rufipes Peckham and

1308 Peckham (Araneae, Salticidae): an effect of cheliceral and leg allometry. Journal of $1309 \quad$ Arachnology 11:385-391.

1310 Fernández-Montraveta C., Marugán-Lobón J. 2017. Geometric morphometrics reveals sex1311 differential shape allometry in a spider. PeerJ 5:e3617.

1312 Fitcher E. 1940. Studies of North American Solpugida, I. The true identity of Eremobates 1313 pallipes. American Midland Naturalist 24:351-360.

1314 Foellmer MW., Moya-Larano J. 2007. Sexual size dimorphism in spiders: patterns and

1315 processes. In: Sex, size and gender roles: Evolutionary studies of sexual size dimorphism.

1316 Oxford: Oxford University Press Oxford, 71-81.

1317 Fox GA., Cooper AM., Hayes WK. 2015. The dilemma of choosing a reference character for 1318 measuring sexual size dimorphism, sexual body component dimorphism, and character 1319 scaling: cryptic dimorphism and allometry in the scorpion Hadrurus arizonensis. PloS One $1320 \quad 10: \mathrm{e} 0120392$. 
1321 Framenau VW. 2005. Gender specific differences in activity and home range reflect

1322 morphological dimorphism in wolf spiders (Araneae, Lycosidae). Journal of Arachnology

$1323 \quad 33: 334-346$.

1324 Francke OF. 1979. Observations on the reproductive biology and life history of Megacormus

1325 gertschi Diaz (Scorpiones: Chactidae; Megacorminae). Journal of Arachnology, Vol7 (3)

$1326 \quad 223-230$.

1327 Franklin D., Oxnard CE., O’Higgins P., Dadour I. 2007. Sexual dimorphism in the subadult

1328 mandible: quantification using geometric morphometrics. Journal of Forensic Sciences

$1329 \quad 52: 6-10$.

1330 Funke S., Huber BA. 2005. Allometry of genitalia and fighting structures in Linyphia

1331 triangularis (Araneae, Linyphiidae). Journal of Arachnology 33:870-872.

1332 Garcia LF., Gonzalez-Gomez JC., Valenzuela-Rojas JC., Tizo-Pedroso E., Lacava M. 2016. Diet

1333 composition and prey selectivity of Colombian populations of a social pseudoscorpion.

1334 Insectes sociaux 63:635-640.

1335 Garwood RJ., Dunlop J. 2014. Three-dimensional reconstruction and the phylogeny of extinct

1336 chelicerate orders. PeerJ 2:e641.

1337 Garwood RJ., Dunlop JA., Knecht BJ., Hegna TA. 2017. The phylogeny of fossil whip spiders.

1338 BMC Evolutionary Biology 17:105.

1339 Gaud J., Atyeo WT. 1979. Co-évolution des acariens sarcoptiformes plumicoles et de leurs hôtes.

$1340 \quad$ Acarology 21:291-306.

1341 Gaud, J. \& Atyeo, W.T. (1996) Feather mites of the world (Acarina, Astigmata): The

1342 supraspecific taxa. Annales du Musée royale de l'Afrique centrale, Série in-80, Sciences

1343 zoologiques, 277, (Part I, Text) 1-193, (Part II, Illustrations of feather mite taxa) 1-436. 
1344 Gertsch WJ. 1971. Three new ricinuleids from Mexican caves (Arachnida, Ricinulei). Bulletin of 1345 the Association for Mexican Cave Studies 4:127-135.

1346 Girard MB., Endler JA. 2014. Peacock spiders. Current Biology 24:R588-R590.

1347 Giribet, G., 2018. Current views on chelicerate phylogeny-A tribute to Peter Weygoldt. $1348 \quad$ Zoologischer Anzeiger, 273:7-13.

1349 Giribet G., Edgecombe GD., Wheeler WC., Babbitt C. 2002. Phylogeny and systematic position 1350 of Opiliones: a combined analysis of chelicerate relationships using morphological and 1351 molecular data. Cladistics 18:5-70.

1352 Giribet G., McIntyre E., Christian E., Espinasa L., Ferreira RL., Francke ÓF., Harvey MS., Isaia

1353 M., Kováć Ĺ., McCutchen L. 2014. The first phylogenetic analysis of Palpigradi

1354 (Arachnida)-the most enigmatic arthropod order. Invertebrate Systematics 28:350-360.

1355 Giupponi APL., Kury AB. 2013. Two new species of Heterophrynus Pocock, 1894 from

1356 Colombia with distribution notes and a new synonymy (Arachnida: Amblypygi: Phrynidae). $1357 \quad$ Zootaxa 3647:329-342.

1358 Gravely FH. 1916: The evolution and distribution of the Indo-Australian Thelyphonidae, with 1359 notes on distinctive characters of various species. Records of the Indian Museum. 12:59-86

1360 Grossi B., Canals M. 2015. Energetics, scaling and sexual size dimorphism of spiders. Acta $1361 \quad$ Biotheoretica $63: 71-81$.

1362 Van der Hammen L. 1989. An introduction to comparative arachnology. The Hague; The 1363 Netherlands: SPB Academic Publishing.

1364 Harvey MS. 1992. The Schizomida (Chelicerata) of Australia. Invertebrate Systematics 6:77$1365 \quad 129$. 
1366 Harvey MS. 2001. New cave-dwelling schizomids (Schizomida: Hubbardiidae) from Australia. 1367 Records of the Western Australian Museum, Supplement 64:171-185.

1368 Harvey MS. 2003. Catalogue of the smaller arachnid orders of the world: Amblypygi, Uropygi, 1369 Schizomida, Palpigradi, Ricinulei and Solifugae. Collingwood, Victoria, Australia: CSIRO $1370 \quad$ Publishing.

1371 Head G. 1995. Selection on fecundity and variation in the degree of sexual size dimorphism 1372 among spider species (class Araneae). Evolution 49:776-781.

1373 Heinemann S., Uhl G. 2000. Male dimorphism in Oedothorax gibbosus (Araneae, Linyphiidae): 1374 a morphometric analysis. Journal of Arachnology 28:23-28.

1375 Heymons R. 1902. Biologische Beobachtungen an asiatischen Solifugen, nebst Beitragen zur

1376 Systematik derselben. Abhandlungen der Königlich Preus- sischen Akademie der 1377 Wissenschaftern 1901:1-65.

1378 Hormiga G., Scharff N., Coddington JA. 2000. The phylogenetic basis of sexual size

1379 dimorphism in orb-weaving spiders (Araneae, Orbiculariae). Systematic Biology 49:435$1380 \quad 462$.

1381 Hrušková-Martišová M., Pekár S., Bilde T. 2010. Coercive copulation in two sexually 1382 cannibalistic camel-spider species (Arachnida: Solifugae). Journal of Zoology 282:91-99.

1383 Huber BA. 1995. The retrolateral tibial apophysis in spiders_-shaped by sexual selection?

1384 Zoological Journal of the Linnean Society 113:151-163.

1385 Huber BA. 2005. Sexual selection research on spiders: progress and biases. Biological Reviews $1386 \quad 80: 363-385$. 
1387 Huff JC., Prendini L. 2009. On the African whip scorpion, Etienneus africanus (Hentschel, 1388 1899) (Thelyphonida: Thelyphonidae), with a redescription based on new material from 1389 Guinea-Bissau and Senegal. American Museum Novitates 3658:1-16.

1390 Humphreys WF., Adams M., Vine B. 1989. The biology of Schizomus vinei (Chelicerata:

1391 Schizomida) in the caves of Cape Range, Western Australia. Journal of Zoology 217:177$1392 \quad 201$.

1393 Igelmund P. 1987. Morphology, sense organs, and regeneration of the forelegs (whips) of the 1394 whip spider Heterophrynus elaphus (Arachnida, Amblypygi). Journal of Morphology $1395 \quad 193: 75-89$.

1396 Junqua C. 1962. Biologie-Donnees sur la Reproduction dun Solifuge-Othoes Saharae Panouse.

1397 Comptes rendus Hebdomadaires des Seances de la Acadmie des Sciences 255:2673-5.

1398 Kaliontzopoulou A., Carretero MA., Llorente GA. 2007. Multivariate and geometric

1399 morphometrics in the analysis of sexual dimorphism variation in Podarcis lizards. Journal $1400 \quad$ of Morphology 268:152-165.

1401 Kauri H. 1989. External ultrastructure of sensory organs in the subfamily lrumuinae (Arachnida, 1402 Opiliones, Assamiidae). Zoologica Scripta 18:289-294.

1403 Kern WHJ., Mitchell RE. 2011. Giant whip scorpion Mastigoproctus giganteus giganteus 1404 (Lucas, 1835) (Arachnida: Thelyphonida (= Uropygi): Thelyphonidae). Institute of Food 1405 and Agricultural Sciences, University of Florida.

1406 Kjellesvig-Waering EN. 1966. The scorpions of Trinidad and Tobago. Caribbean Science 6:1231407 135. 
1408 Klußmann-Fricke B., Wirkner CS. 2016. Comparative morphology of the hemolymph vascular

1409 system in Uropygi and Amblypygi (Arachnida): Complex correspondences support

$1410 \quad$ Arachnopulmonata. Journal of morphology 277:1084-1103.

1411 Koch LE. 1977. The taxonomy, geographic distribution and evolutionary radiation of Australo-

1412 Papuan scorpions. Records of the Western Australian Museum 5:83-367.

1413 Kovarik F. 2009. Illustrated catalog of scorpions, part 1. Clarion Productions, Prague. 650pp.

1414 Kronestedt T. 1990. Separation of two species standing as Alopecosa aculeata (Clerck) by

1415 morphological, behavioural and ecological characters, with remarks on related species in

1416 the pulverulenta group (Araneae, Lycosidae). Zoologica Scripta 19:203-225.

1417 Kruyt JW., Quicazán-Rubio EM., van Heijst GF., Altshuler DL., Lentink D. 2014. Hummingbird

1418 wing efficacy depends on aspect ratio and compares with helicopter rotors. Journal of The

$1419 \quad$ Royal Society Interface 11:20140585.

1420 Kury AB. 2013. Order Opiliones Sundevall, 1833. In: Zhang, Z.-Q.(Ed.) Animal Biodiversity:

1421 An Outline of Higher-level Classification and Survey of Taxonomic Richness (Addenda

1422 2013). Zootaxa 3703:27-33.

1423 Lamoral BH. 1975. The structure and possible function of the flagellum in four species of male

1424 solifuges of the family Solpugidae. In: Proceedings of the 6th international arachnological

1425 congress. 136-141.

1426 Lang G. 2001. Sexual size dimorphism and juvenile growth rate in Linyphia triangularis

1427 (Linyphiidae, Araneae). Journal of Arachnology 29:64-71.

1428 Lawrence RF. 1954. Some Solifugae in the collection of the British Museum (Natural History).

1429 Journal of Zoology 124:111-124. 
1430 Legg DA, Sutton MD, Edgecombe GD. 2013. Arthropod fossil data increase congruence of

1431 morphological and molecular phylogenies. Nature Communications 4:2485.

1432 Legg G. 1976. The external morphology of a new species of ricinuleid ( Arachnida ) from Sierra

1433 Leone. Zoological Journal of the Linnean Society 59:1-58.

1434 Legg G. 1977. Sperm transfer and mating in Ricinoides hanseni (Ricinulei : Arachnida). Journal 1435 of Zoology 182:51-61.

1436 Legrand RS., Morse DH. 2000. Factors driving extreme sexual size dimorphism of a sit-and-wait 1437 predator under low density. Biological Journal of the Linnean Society 71:643-664.

1438 Legrende P. 1998. Model II regression user's guide, R edition. R Vignette 14.

1439 Lim M.L., Li D. 2006. Extreme ultraviolet sexual dimorphism in jumping spiders (Araneae:

$1440 \quad$ Salticidae). Biological Journal of the Linnean Society, 89:397-406.

1441 Lindenfors P., Gittleman JL., Jones KE. 2007. Sexual size dimorphism in mammals. In: Sex, size

1442 and gender roles: evolutionary studies of sexual size dimorphism. Oxford: Oxford

$1443 \quad$ University Press, 16-26.

1444 Lindquist EE. 1984. Current theories on the evolution of major groups of Acari and on their

1445 relationships with other groups of Arachnida, with consequent implications for their

1446 classification. Acarology VI/editors, DA Griffiths and CE Bowman.

1447 Lipke E., Hammel JU., Michalik P. 2015. First evidence of neurons in the male copulatory organ 1448 of a spider (Arachnida, Araneae). Biology Letters 11:20150465.

1449 Logunov D V. 2011. Sexual size dimorphism in burrowing wolf spiders (Araneae: Lycosidae).

1450 In: Proceedings of Zoological Institute of the Russian Academy of Sciences: 315(3): 2741451288. 
1452 Lourenço WR, Duhem B. 2010. The genus Chaerilus Simon, 1877 (Scorpiones, Chaerilidae) in 1453 the Himalayas and description of a new species. Zootaxa 37:13-25.

1454 Machado G., Buzatto BA., García-Hernández S., Macías-Ordóñez R. 2016 Macroecology of

1455 sexual selection: a predictive conceptual framework for large-scale variation in reproductive $1456 \quad$ traits. The American Naturalist 188: S8-S27.

1457 Magalhaes ILF., Santos AJ. 2012. Phylogenetic analysis of Micrathena and Chaetacis spiders 1458 (Araneae: Araneidae) reveals multiple origins of extreme sexual size dimorphism and long 1459 abdominal spines. Zoological Journal of the Linnean Society 166:14-53.

1460 Mattoni CI. 2005. Tergal and sexual anomalies in bothriurid scorpions (Scorpiones,

1461 Bothriuridae). Journal of Arachnology 33:622-628.

1462 Maury EA. 1975. La estructura del espermatóforo en el género Brachistosternus (Scorpiones, 1463 Bothriuridae). Physis 34:179-182.

1464 McArthur IW, Silva de Miranda G., Seiter M., Chapin, KJ. 2018. Global patterns of sexual 1465 dimorphism in Amblypygi. Zoologischer Anzeiger 273:56-64.

1466 van der Meijden A., Langer F., Boistel R., Vagovic P., Heethoff M. 2012. Functional

1467 morphology and bite performance of raptorial chelicerae of camel spiders (Solifugae).

$1468 \quad$ Journal of Experimental Biology 215:3411-3418.

1469 Melville JM. 2000. The pectines of scorpions: analysis of structure and function. Oregon State $1470 \quad$ University.

1471 Monjaraz-Ruedas R., Francke OF. 2015. Taxonomic revision of the genus Mayazomus Reddell 1472 \& Cokendolpher, 1995 (Schizomida: Hubbardiidae), with description of five new species 1473 from Chiapas, Mexico. Zootaxa 3915:451-490. 
1474 Montaño-Moreno H., Francke OF. 2013. Observations on the life history of Eukoenenia chilanga

1475 Montaño (Arachnida: Palpigradi). Journal of Arachnology 41:205-212.

1476 Moya-Laraño J., Halaj J., Wise DH. 2002. Climbing to reach females: Romeo should be small.

$1477 \quad$ Evolution 56:420-425.

1478 Muchmore WB. 1990. A pseudoscorpion from arctic Canada (Pseudoscorpionida, Chernetidae).

1479 Canadian Journal of Zoology 68:389-390.

1480 Muma MH. 1966. Mating behaviour in the solpugid genus Eremobates Banks. Animal Behaviour $1481 \quad 14(2): 346-350$

1482 Munguía-Steyer R., Buzatto BA, Machado G. 2012. Male dimorphism of a neotropical arachnid:

1483 harem size, sneaker opportunities, and gonadal investment. Behavioural Ecology 23:827-

$1484 \quad 835$.

1485 Muniz DG, Machado G. 2015. Devoted fathers or selfish lovers? Conflict between mating effort

1486 and parental care in a harem-defending arachnid. Animal Behaviour 109:23-31.

1487 Murayama GP., Willemart RH. 2015. Mode of use of sexually dimorphic glands in a Neotropical

1488 harvestman (Arachnida: Opiliones) with paternal care. Journal of Natural History 49:1937-

$1489 \quad 1947$.

1490 Murienne J., Harvey MS., Giribet G. 2008. First molecular phylogeny of the major clades of

1491 Pseudoscorpiones (Arthropoda: Chelicerata). Molecular Phylogenetics and Evolution

$1492 \quad 49: 170-184$.

1493 Norton RA., Alberti G. 1997. Porose integumental organs of oribatid mites (Acari, Oribatida). 3.

1494 Evolutionary and ecological aspects. Zoologica 146:115-143. 
1495 Outeda-Jorge S., Mello T., Pinto-da-Rocha R. 2009. Litter size, effects of maternal body size,

1496 and date of birth in South American scorpion (Arachnida: Scorpiones). Zoologia 26(1): 43-

$1497 \quad 53$

1498 Owens IPF., Hartley IR. 1998. Sexual dimorphism in birds: why are there so many different

1499 forms of dimorphism? Proceedings of the Royal Society of London B: Biological Sciences

$1500 \quad 265: 397-407$.

1501 Painting CJ., Probert AF, Townsend DJ, Howell GI. 2015. Multiple exaggerated weapon

1502 morphs: a novel form of male polymorphism in harvestmen. Scientific Reports 5:16368.

1503 Peaslee AG., Wilson G. 1989. Spectral sensitivity in jumping spiders (Araneae, Salticidae).

1504 Journal of Comparative Physiology A: Neuroethology, Sensory, Neural, and Behavioral

1505 Physiology 164:359-363.

1506 Peckham G., Peckham E. 1889. Observations on sexual selection in the family of spiders

1507 Attidae. Occasional Papers of the Wisconsin Natural History Society. 1:3-60.

1508 Pekár S., Martišovà M., Bilde, T. 2011. Intersexual trophic niche partitioning in an ant-eating

1509 spider (Araneae: Zodariidae). PLoS One 6:e14603.

1510 Pepato AR., da Rocha CEF., Dunlop JA. 2010. Phylogenetic position of the acariform mites:

1511 sensitivity to homology assessment under total evidence. BMC Evolutionary Biology

$1512 \quad 10: 235$.

1513 Peretti AV., Acosta LE., Benton TG. 1999. Sexual cannibalism in scorpions: fact or fiction?

1514 Biological Journal of the Linnean Society 68:485-496.

1515 Peretti AV., Willemart RH. 2007. Sexual coercion does not exclude luring behavior in the

1516 climbing camel-spider Oltacola chacoensis (Arachnida, Solifugae, Ammotrechidae).

$1517 \quad$ Journal of Ethology 25:29-39. 
1518 Pinto-da-Rocha R., Machado G., Giribet G. 2007. Harvestmen: the biology of Opiliones.

1519 Harvard University Press.

1520 Pittard K. 1970. Comparative external morphology of the life stages of Cryptocellus pelaezi

1521 (Arachnids, Ricinulei). Texas Tech University.

1522 Pittard K., Mitchell RW. 1972. Comparative Morphology of the Life Stages of Cryptocellus 1523 pelaezi (Arachnid, Ricinulei). PhD Thesis, Texas Tech.

1524 Platnick NI., Raven RJ. 2013. Spider systematics: past and future. Zootaxa 3683:595-600.

1525 Polis GA. 1990. The biology of scorpions. Stanford University Press.

1526 Polis GA., Farley RD. 1979a. Behavior and ecology of mating in the cannibalistic scorpion,

1527 Paruroctonus mesaensis Stahnke (Scorpionida: Vaejovidae). Journal of Arachnology

$1528 \quad 7(1): 33-46$.

1529 Polis GA., Farley RD. 1979b. Characteristics and environmental determinants of natality, growth

1530 and maturity in a natural population of the desert scorpion, Paruroctonus mesaensis

1531 (Scorpionida: Vaejovidae). Journal of Zoology 187:517-542.

1532 Polis GA., Sissom WD. 1990. Life history. In: The biology of scorpions. Stanford University

1533 Press Stanford, California, 161-223.

1534 Pollard SD. 1994. Consequences of sexual selection on feeding in male jumping spiders

1535 (Araneae: Salticidae). Journal of Zoology 234:203-208.

1536 Prendini L. 2001. Further additions to the scorpion fauna of Trinidad and Tobago. Journal of

1537 Arachnology 29:173-188.

1538 Prendini L. 2011. Order Ricinulei Thorell, 1876. Zootaxa 1876:122.

1539 Prenter J., Elwood RW., Montgomery WI. 1999. Sexual size dimorphism and reproductive

1540 investment by female spiders: a comparative analysis. Evolution 53:1987-1994. 
1541 Proctor H. 2003. Feather mites (Acari: Astigmata): ecology, behavior, and evolution. Annual 1542 Review of Entomology 48:185-209.

1543 Proctor H, Knee W. 2018. Asymmetry and polymorphism in males of the feather mite Michaelia 1544 neotropica Hernandes and Mironov (Acariformes: Astigmata: Freyanidae). Zoologischer $1545 \quad$ Anzeiger 273:226-230.

1546 Proud DN., Felgenhauer BE. 2013 Ultrastructure of the sexually dimorphic tarsal glands and 1547 tegumental glands in gonyleptoid harvestmen (Opiliones, Laniatores). Journal of $1548 \quad$ Morphology 274:1203-1215.

1549 Punzo F. 1998a. Natural history and life cycle of the solifuge Eremobates marathoni Muma \& 1550 Brookhart (Solifugae, Eremobatidae). Bulletin of the British Arachnological Society $1551 \quad 11: 111-118$

1552 Punzo F. 1998b. The biology of camel spiders: Arachnida, Solifugae. Boston: Kluwer Academic 1553 Publishing.

1554 Ra'Anan Z., Sagi A. 1985. Alternative mating strategies in male morphotypes of the freshwater 1555 prawn Macrobrachium rosenbergii (De Man). The Biological Bulletin 169:592-601.

1556 Radwan J. 1993. The adaptive significance of male polymorphism in the acarid mite 1557 Caloglyphus berlesei. Behavioral Ecology and Sociobiology 33:201-208.

1558 Rahmadi C., Harvey MS., Kojima J-I. 2010. Whip spiders of the genus Sarax Simon 1892 1559 (Amblypygi: Charinidae) from Borneo Island. Zootaxa 2612:1-21.

1560 Rajashekhar KP., Bali G. 1982. Sexual dimorphism in a whipscorpion, Thelyphonus indicus 1561 Stoliczka (Arachnida, Uropygi). Bulletin-British Arachnological Society 5(7): 330-331

1562 Reddell JR., Cokendolpher JC. 1991. Redescription of Schizomus crassicaudatus (Pickard1563 Cambridge) and diagnoses of Hubbardia Cook, Stenochrus Chamberlin, and 
1564 Sotanostenochrus new genus, with description of a new species of Hubbardia from

1565 California (Arachnida: Schizomida: Hubbardiidae). Texas Memorial Museum, The

1566 University of Texas at Austin.

1567 Reddell JR., Cokendolpher JC. 1995. Catalogue, bibliography, and generic revision of the order

1568 Schizomida (Arachnida). Texas Memorial Museum, College of Natural Sciences, University 1569 of Texas at Austin.

1570 Regier JC., Shultz JW., Zwick A., Hussey A., Ball B., Wetzer R., Martin JW., Cunningham CW.

15712010 . Arthropod relationships revealed by phylogenomic analysis of nuclear protein-coding $1572 \quad$ sequences. Nature 463:1079-1083.

1573 Rensch B. 1950. Die Abhangigkeit der relativen sexualdifferenz von der Korpergroße. Bonner $1574 \quad$ Zoologische Beiträge 1:58-69.

1575 Rovner JS. 1968. Territoriality in the Sheet-Web Spider Linyphia triangularis (Clerck)(Araneae, 1576 Linyphiidae. Ethology 25:232-242.

1577 Rowland JM. 1975. Classification, phylogeny and zoogeography of the American arachnids of 1578 the order Schizomida. Texas Tech University.

1579 Rowland JM., Reddell JR. 1979a. American Arachnological Society The Order Schizomida

1580 (Arachnida) in the New World. I. Protoschizomidae and dumitrescoae Group (Schizomidae:

1581 Schizomus). American Arachnological Society 6:161-196.

1582 Rowland JM., Reddell JR. 1979b. American Arachnological Society The Order Schizomida

1583 (Arachnida) in the New World. II. Simonis and brasiliensis Groups (Schizomidae:

1584 Schizomus). American Arachnological Society 7:89-119. 
1585 Rowland JM., Reddell JR. 1980. American Arachnological Society The Order Schizomida

1586 (Arachnida) in the New World. III. Mexicanus and Pecki Groups (Schizomidae:

1587 Schizomus). American Arachnological Society 8:1-34.

1588 Rowland JM., Reddell JR. 1981. American Arachnological Society The Order Schizomida

1589 (Arachnida) in the New World. IV. goodnightorum and briggsi Groups and Unplaced

$1590 \quad$ Species (Schizomidae: Schizomus). American Arachnological Society 9:19-46.

1591 Sánchez-Quirós C., Arévalo E., Barrantes G. 2012. Static allometry and sexual size dimorphism

1592 in Centruroides margaritatus (Scorpiones: Buthidae). Journal of Arachnology 40:338-344.

1593 Santos AJ., Ferreira RL., Buzatto BA. 2013. Two New Cave-Dwelling Species of the Short-

1594 Tailed Whipscorpion Genus Rowlandius (Arachnida: Schizomida: Hubbardiidae) from

1595 Northeastern Brazil, with Comments on Male Dimorphism. PLoS One 8:1-12.

1596 Scheffer SJ., Uetz GW., Stratton GE. 1996. Sexual selection, male morphology, and the efficacy

1597 of courtship signalling in two wolf spiders (Araneae: Lycosidae). Behavioral Ecology and

$1598 \quad$ Sociobiology 38:17-23.

1599 Schembri PJ., Baldacchino AE. 2011. Ilma, blat u hajja: is-sisien ta'l-ambjent naturali Malti.

$1600 \quad$ Malta University Services.

1601 Schmidt JO., Dani FR., Jones GR., Morgan ED. 2000. Chemistry, ontogeny, and role of pygidial

1602 gland secretions of the vinegaroon Mastigoproctus giganteus (Arachnida: Uropygi). Journal 1603 of Insect Physiology 46:443-450.

1604 Schütz D., Taborsky M. 2003. Adaptations to an aquatic life may be responsible for the reversed 1605 sexual size dimorphism in the water spider, Argyroneta aquatica. Evolutionary Ecology $1606 \quad$ Research 5:105-117. 
1607 Seiter M., Wolff J., Hoerweg C. 2015. A new species of the South East Asian genus Sarax

1608 Simon, 1892 (Arachnida: Amblypygi: Charinidae) and synonymization of Sarax

1609 mediterraneus Delle Cave, 1986. Zootaxa 4012:542-552.

1610 Sentenská L., Graber F., Richard M., Kropf C. 2017. Sexual dimorphism in venom gland

1611 morphology in a sexually stinging scorpion. Biological Journal of the Linnean Society

$1612 \quad 122: 429-443$.

1613 Sharma PP., Kaluziak ST., Pérez-Porro AR., González VL., Hormiga G., Wheeler WC., Giribet

1614 G. 2014. Phylogenomic interrogation of Arachnida reveals systemic conflicts in

1615 phylogenetic signal. Molecular Biology and Evolution 31:2963-2984.

1616 Shine, R. 1989. Ecological causes for the evolution of sexual dimorphism: a review of the

1617 evidence. The Quarterly Review of Biology 64:419-461.

1618 Shultz JW. 1990. Evolutionary morphology and phylogeny of Arachnida. Cladistics 6:1-38.

1619 Shultz JW. 2007. A phylogenetic analysis of the arachnid orders based on morphological

$1620 \quad$ characters. Zoological Journal of the Linnean Society 150:221-265.

1621 da Silva Fernandes N., Willemart RH. 2014. Neotropical harvestmen (Arachnida, Opiliones) use

1622 sexually dimorphic glands to spread chemicals in the environment. Comptes Rendus

1623 Biologies 337:269-275.

1624 Smuts BB., Smuts RW. 1993. Male aggression and sexual coercion of females in nonhuman

1625 primates and other mammals: evidence and theoretical implications. Advances in the Study

1626 of Behavior 22:1-63.

1627 Souza MFVR., Ferreira RL. 2012. A new highly troglomorphic species of Eukoenenia

1628 (Palpigradi: Eukoeneniidae) from tropical Brazil. Journal of Arachnology 40:151-158. 
1629 Søvik G. 2004. The biology and life history of arctic populations of the littoral mite

1630 Ameronothrus lineatus (Acari, Oribatida). Experimental and Applied Acarology 34:3-20.

1631 Spicer GS. 1987. Scanning electron microscopy of the palp sense organs of the harvestman

1632 Leiobunum townsendi (Arachnida: Opiliones). Transactions of the American Microscopical

1633 Society:232-239.

1634 Stumpf H., Linsenmair KE. 1996. Observations on the mating systems of two spiders, Linyphia

1635 hortensis Sund. and L. triangularis (Cl.) (Linyphiidae: Araneae). Revue Suisse de Zoologie,

1636 vol. hors série (August 1996):627-634.

1637 Sturm H. 1958. Indirekte Spermatophorenübertragung bei dem Geißelskorpion Trithyreus sturmi

1638 Kraus (Schizomidae, Pedipalpi). Naturwissenschaften 45:142-143.

1639 Sturm H. 1973. Zur Ethologie von Trithyreus sturmi Kraus (Arachnida, Pedipalpi,

$1640 \quad$ Schizopeltidia). Ethology 33:113-140.

1641 Tallarovic SK., Melville JM., Brownell PH. 2000. Courtship and mating in the giant hairy desert 1642 scorpion, Hadrurus arizonensis (Scorpionida, Iuridae). Journal of Insect Behavior 13:8271643838.

1644 Taylor CK. 2004. New Zealand harvestmen of the subfamily Megalopsalidinae (Opiliones:

1645 Monoscutidae)-the genus Pantopsalis. Tuhinga 15:53-76.

1646 Teruel R., Schramm FD. 2014. Description of the adult male of Pseudocellus pachysoma Teruel 1647 \& Armas 2008 (Ricinulei: Ricinoididae). Revista Ibérica de Aracnología 24:75-79.

1648 Thomas RH., Zeh DW. 1984. Sperm transfer and utilization strategies in arachnids: ecological 1649 and morphological constraints. In R. L. Smith (ed.), Sperm Competition and the Evolution of 1650 Animal Mating Systems Academic Press, N.Y.:179-221. 
1651 Tourinho AL., Azevedo CS. 2007. A new Amazonian Cryptocellus Westwood (Arachnida,

1652 Ricinulei). Zootaxa 1540:55-60.

1653 Tsubaki Y. 2003. The genetic polymorphism linked to mate-securing strategies in the male

1654 damselfly Mnais costalis Selys (Odonata: Calopterygidae). Population Ecology 45:263-

266.

1656 Tuxen SL. 1974. The African genus Ricinoides (Arachnida, Ricinulei). Journal of Arachnology

$1657 \quad 1: 85-106$.

1658 Vacante V. 2015. The handbook of mites of economic plants: identification, bio-ecology and

1659 control. Wallingford: CABI.

1660 Vanacker D., Maes L., Pardo S., Hendrickx F., Maelfait JP. 2003. Is the hairy groove in the

1661 gibbosus male morph of Oedothorax gibbosus (Blackwall 1841) a nuptial feeding device?

1662 Journal of Arachnology 31:309-315.

1663 Vasconcelos ACO., Giupponi APL., Ferreira RL. 2014. A new species of Charinus from Minas

1664 Gerais State, Brazil, with comments on its sexual dimorphism (Arachnida: Amblypygi:

1665 Charinidae). Journal of Arachnology 42:155-162.

1666 Vollrath F. 1998. Dwarf males. Trends in Ecology \& Evolution 13:159-163.

1667 Walker SE., Rypstra AL. 2002. Sexual dimorphism in trophic morphology and feeding

1668 behaviour of wolf spiders (Araneae: Lycosidae) as a result of differences in reproductive

1669 roles. Canadian Journal of Zoology 80:679-688.

1670 Walter DE., Proctor HC. 1999. Mites: ecology, evolution and behaviour. Wallingford: CABI.

1671 Watari Y., Komine H. 2016. Field observation of male-male fighting during a sexual interaction

1672 in the whip scorpion Typopeltis stimpsonii (Wood 1862)(Arachnida: Uropygi). Acta

1673 Arachnologica 65:49-54. 
1674 Watson PJ. 1990. Female-enhanced male competition determines the first mate and principal sire 1675 in the spider Linyphia litigiosa (Linyphiidae). Behavioral Ecology and Sociobiology 26:77167690.

1677 Weckerly FW. 1998. Sexual-size dimorphism: influence of mass and mating systems in the most 1678 dimorphic mammals. Journal of Mammalogy 79:33-52.

1679 Weygoldt P. 1966. Mating behavior and spermatophore morphology in the pseudoscorpion 1680 Dinocheirus tumidus Banks (Cheliferinea, Chernetidae). The Biological Bulletin 130:4621681467.

1682 Weygoldt P. 1971. Notes on the life history and reproductive biology of the giant whip scorpion, 1683 Mastigoproctus giganteus (Uropygi, Thelyphonidae) from Florida. Journal of Zoology $1684 \quad 164: 137-147$.

1685 Weygoldt P. 1972. Spermatophorenbau und Samenübertragung bei Uropygen (Mastigoproctus 1686 brasilianus CL Koch) und Amblypygen (Charinus brasilianus Weygoldt und Admetus 1687 pumilio CL Koch) (Chelicerata, Arachnida). Zeitschrift für Morphologie der Tiere 71:23168851.

1689 Weygoldt P. 1978. Paarungsverhalten und Spermatophorenmorphologie bei Geißelskorpionen:

1690 Thelyphonellus amazonicus Butler undTypopeltis crucifer Pocock (Arachnida, Uropygi). $1691 \quad$ Zoomorphology 89:145-156.

1692 Weygoldt P. 1988. Sperm transfer and spermatophore morphology in the whip scorpion 1693 Thelyphonus linganus (Arachnida: Uropygi: Thelyphonidae). Journal of Zoology 215:189_1694196. 
1695 Weygoldt P. 1996. Evolutionary morphology of whip spiders: towards a phylogenetic system

1696 (Chelicerata: Arachnida: Amblypygi). Journal of Zoological Systematics and Evolutionary

$1697 \quad$ Research 34:185-202.

1698 Weygoldt P. 2000. Whip spiders (Chelicerata: Amblypygi): their biology, morphology and 1699 systematics, Whip spiders.

1700 Weygoldt P. 2003. Reproductive biology of two species of Phrynichus, P. exophthalmus

1701 Whittick, 1940 and P. deflersi arabicus nov. ssp.(Chelicerata: Amblypygi). Zoologischer

1702 Anzeiger-A Journal of Comparative Zoology 242:193-208.

1703 Wharton RA. 1986. Biology of the diurnal Metasolpuga picta (Kraepelin)(Solifugae,

1704 Solpugidae) compared with that of nocturnal species. Journal of Arachnology, 14:363-383.

1705 Wheeler WC., Hayashi CY. 1998. The phylogeny of the extant chelicerate orders. Cladistics

$1706 \quad 14: 173-192$.

1707 Wijnhoven H. 2013. Sensory structures and sexual dimorphism in the harvestman Dicranopalpus

1708 ramosus (Arachnida: Opiliones). Arachnologische Mitteilungen 46:27-46.

1709 Willemart RH., Chelini M. 2007. Experimental demonstration of close-range olfaction and

1710 contact chemoreception in the Brazilian harvestman, Iporangaia pustulosa. Entomologia

$1711 \quad$ Experimentalis et Applicata 123:73-79.

1712 Willemart RH., Farine J., Gnaspini P. 2009. Sensory biology of Phalangida harvestmen

1713 (Arachnida, Opiliones): a review, with new morphological data on 18 species. Acta

$1714 \quad$ Zoologica 90:209-227.

1715 Willemart RH., Farine J-P., Peretti A V., Gnaspini P. 2006. Behavioral roles of the sexually

1716 dimorphic structures in the male harvestman, Phalangium opilio (Opiliones, Phalangiidae).

1717 Canadian Journal of Zoology 84:1763-1774. 
1718 Willemart RH., Osses F., Chelini MC., Macías-Ordóñez R., Machado G. 2009. Sexually

1719 dimorphic legs in a neotropical harvestman (Arachnida, Opiliones): Ornament or weapon?

1720 Behavioural Processes 80:51-59.

1721 Willemart RH., Pérez-González A., Farine J., Gnaspini P. 2010. Sexually dimorphic tegumental

1722 gland openings in Laniatores (Arachnida, Opiliones), with new data on 23 species. Journal 1723 of Morphology 271:641-653.

1724 Williams SC. 1980. Scorpions of Baja California, Mexico, and adjacent islands. San Francisco:

1725 California Academy of Sciences.

1726 World Spider Catalog 2018. World Spider Catalog. Version 19.0. Natural History Museum Bern.

1727 Online at: https://wsc.nmbe.ch/. Accessed on $21^{\text {st }}$ June 2018.

1728 Yeh PD., Alexeev A. 2016. Effect of aspect ratio in free-swimming plunging flexible plates.

$1729 \quad$ Computers \& Fluids 124:220-225.

1730 Yoshikura M. 1973. Whip Scorpions of Japan. Kumamoto journal of science. Biology 11:81-93.

1731 Zatz C. 2010. Seleção sexual e evolução do dimorfismo sexual em duas espécies de opiliões

1732 (Arachnida: Opiliones). Masters Thesis, Universidade de São Paulo.

1733 Zatz C., Werneck RM., Macías-Ordóñez R., Machado G. 2011. Alternative mating tactics in

1734 dimorphic males of the harvestman Longiperna concolor (Arachnida: Opiliones).

1735 Behavioral Ecology and Sociobiology 65:995-1005.

1736 Zeh DW. 1986. Ecological Factors, Pleiotropy, and the Evolution of Sexual Dimorphism in

1737 Chernetid Pseudoscorpions (Phoresy, Quantitative Genetics, Sexual Selection). PhD Thesis,

$1738 \quad$ University of Arizona.

1739 Zeh DW. 1987a. Aggression, density, and sexual dimorphism in chernetid pseudoscorpions

$1740 \quad$ (Arachnida: Pseudoscorpionida). Evolution 41:1072-1087. 
1741 Zeh DW. 1987b. Life history consequences of sexual dimorphism in a chernetid pseudoscorpion.

1742 Ecology 68:1495-1501.

1743 Zhang Z-Q. 2011. Phylum Arthropoda von Siebold, 1848. In: Zhang, Z.-Q.(Ed.) Animal.

$1744 \quad$ Zootaxa 3148:99-103. 


\section{Figure Captions}

1747 Fig 1 - Patterns of SSD across Acari. See "Standard Figure Abbreviations" for labelling guide.

1748 Fig 2 - Patterns of SSD across Amblypygi. Though carapace has been found to be statistically

1749 wider in males in Charinus jibaossu relative to carapace length, suggesting a larger carapace

1750 overall, it is not highlighted here due its wide consideration as a reference character for overall

1751 body size, which is thought to favour females. See "Standard Figure Abbreviations" for labelling 1752 guide.

1753 Fig 3 - Relationship between log pedipalp tibia length and log carapace length (modified from

1754 Weygoldt, 2000). Regression analysis was carried out between the two vairables using a type-II

1755 regression. Against the null hypothesis that the allometric slopes between adult males and

1756 females and juvaniles are equal males were siginificantly different in both species, $\mathrm{p}=<0.001$

1757 for Damon gracilis $\mathrm{p}=0.031$ for Damon variegatus.

1758 Fig 4 - Patterns of SSD across Araneae. See "Standard Figure Abbreviations" for labelling 1759 guide.

1760 Fig 5 - Patterns of SSD across Palpigradi. See "Standard Figure Abbreviations" for labelling 1761 guide.

1762 Fig 6 - Patterns of SSD across Pseudoscorpiones. See "Standard Figure Abbreviations" for 1763 labelling guide.

1764 Fig 7 - Patterns of sex bias in pedipalpal claw SSD in chernetid pseudoscorpions, red dots 1765 indicate male bias, green is female-biased. Modified from Zeh (1987a). 
1766 Fig 8 - Patterns of SSD across Opiliones. See "Standard Figure Abbreviations" for labelling 1767 guide.

1768 Fig 9 - SEM images showing dimorphism in the chelicerae of Phalangium opilo, the male

1769 chelicerae are noted for the presence of a horn used in contest (modified from Willemart et al, 1770 2006) C Canadian Science Publishing or its licensors.

1771 Fig 10 - Patterns of SSD across Ricinulei. See "Standard Figure Abbreviations" for labelling 1772 guide, $\mathrm{Cuc}=$ cucullus.

1773 Fig 11 - Patterns of SSD across Schizomida. See "Standard Figure Abbreviations" for labelling 1774 guide.

1775 Fig 12 - Patterns of differences in pedipalp lengths denoting both sexual and male dimorphism.

1776 Top $=$ frequency histogram of pedipalp patella lengths, Bottom $=$ Relationship between pedipalp

1777 patella length and prosoma length for the two male morphs and female (modified from Santos et 1778 al., 2013).

1779 Fig 13 - Patterns of SSD across Scorpiones. See "Standard Figure Abbreviations" for labelling 1780 guide.

1781 Fig 14 - Sexually dimorphic differences in body plan in Centruroides vittatus, note the longer

1782 male legs and metasoma (modified from Carlson, McGinley \& Rowe, 2014).

1783 Fig 15 - Patterns of SSD across Solifugae. See "Standard Figure Abbreviations" for labelling 1784 guide. 
1785 Fig 16 - Patterns of SSD across Uropygi. See "Standard Figure Abbreviations" for labelling 1786 guide.

1787 Fig 17 - A broad consensus arachnid phylogeny encompassing a range of recent studies 1788 (modified from Giribet, 2018).

1789 Table 1 - Patterns of SSD across arachnid orders. $\sigma^{7} / \mathrm{red}=$ male biased, 우/green $=$ female1790 biased, symbols in brackets indicate rare reversals. 


\section{Table 1 (on next page)}

Patterns of SSD across arachnid orders

$\sigma^{7} /$ red $=$ male biased, $\mathrm{q} /$ green $=$ female-biased, symbols in brackets indicate rare reversals, * indicates antenniform legs. 


\begin{tabular}{|c|c|c|c|c|c|c|c|c|c|c|c|}
\hline & Acari & Amblypygi & Aranaea & Palpigradi & Pseudoscorpiones & Opiliones & Ricinulei & Schizomida & Scorpiones & Solifugae & Uropygi \\
\hline $\begin{array}{l}\text { Overall } \\
\text { body }\end{array}$ & $(9)$ & $q$ & $q(\hat{\jmath})$ & & $q(\hat{\jmath})$ & 90 & & & $q(\hat{0})$ & ? & ก \\
\hline Legs & & $\delta^{7 *}$ & $\pi$ & & & $\pi$ & 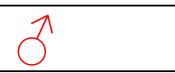 & & $\delta$ & $\pi$ & \\
\hline Chelicerae & $\pi$ & & $9 \pi$ & & & $\pi$ & $\delta$ & & & $(9)$ & \\
\hline Pedipalps & 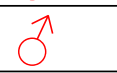 & $\hat{0}$ & & & 90 & $\pi$ & & $\delta^{1}$ & & 1 & $\pi$ \\
\hline
\end{tabular}


Figure 1

Patterns of SSD across Acari

See "Standard Figure Abbreviations" for labelling guide 


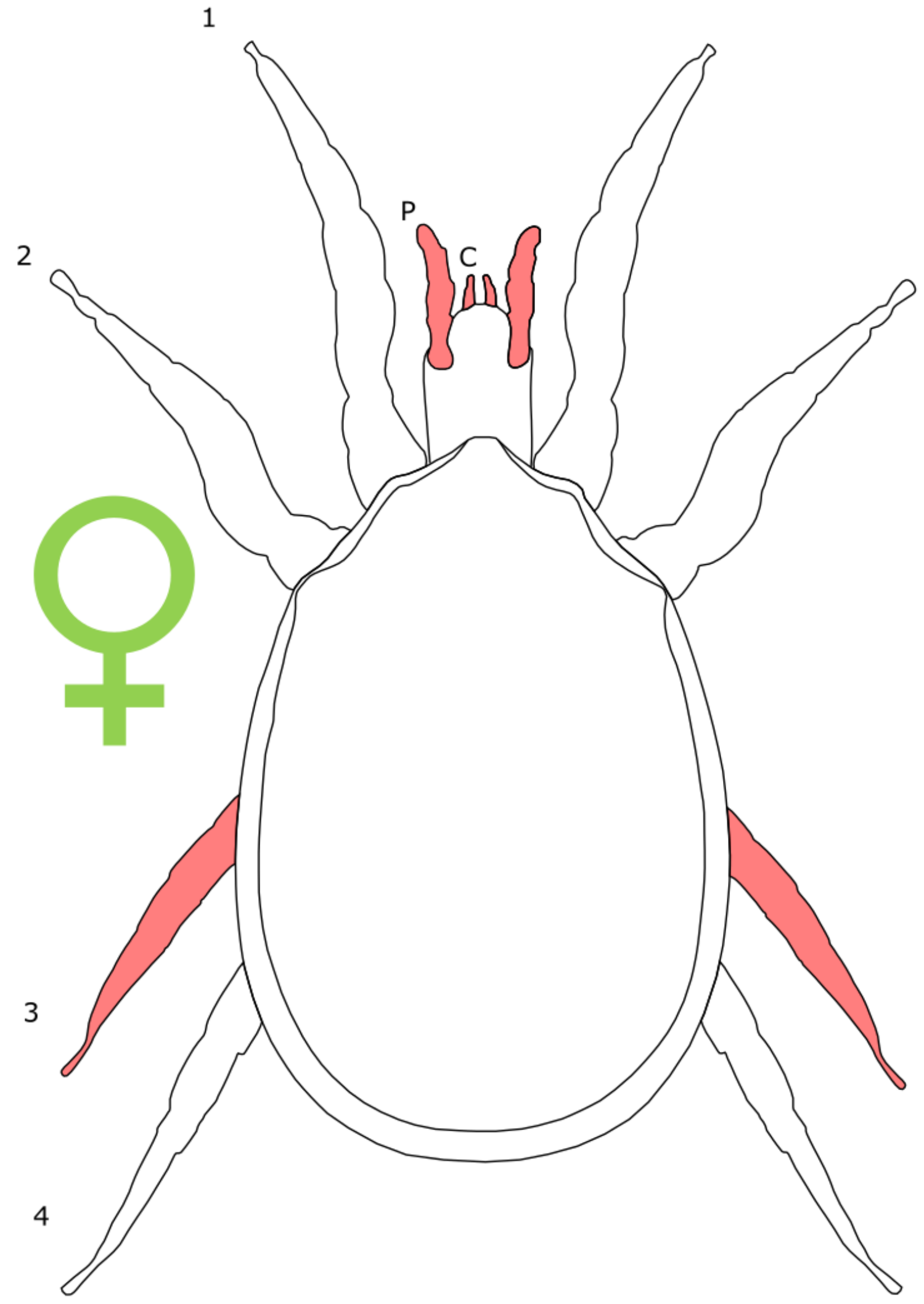


Figure 2

Patterns of SSD across Amblypygi

Though carapace has been found to be statistically wider in males in Charinus jibaossu relative to carapace length, suggesting a larger carapace overall, it is not highlighted here due its wide consideration as a reference character for overall body size, which is thought to favour females. See "Standard Figure Abbreviations" for labelling guide.

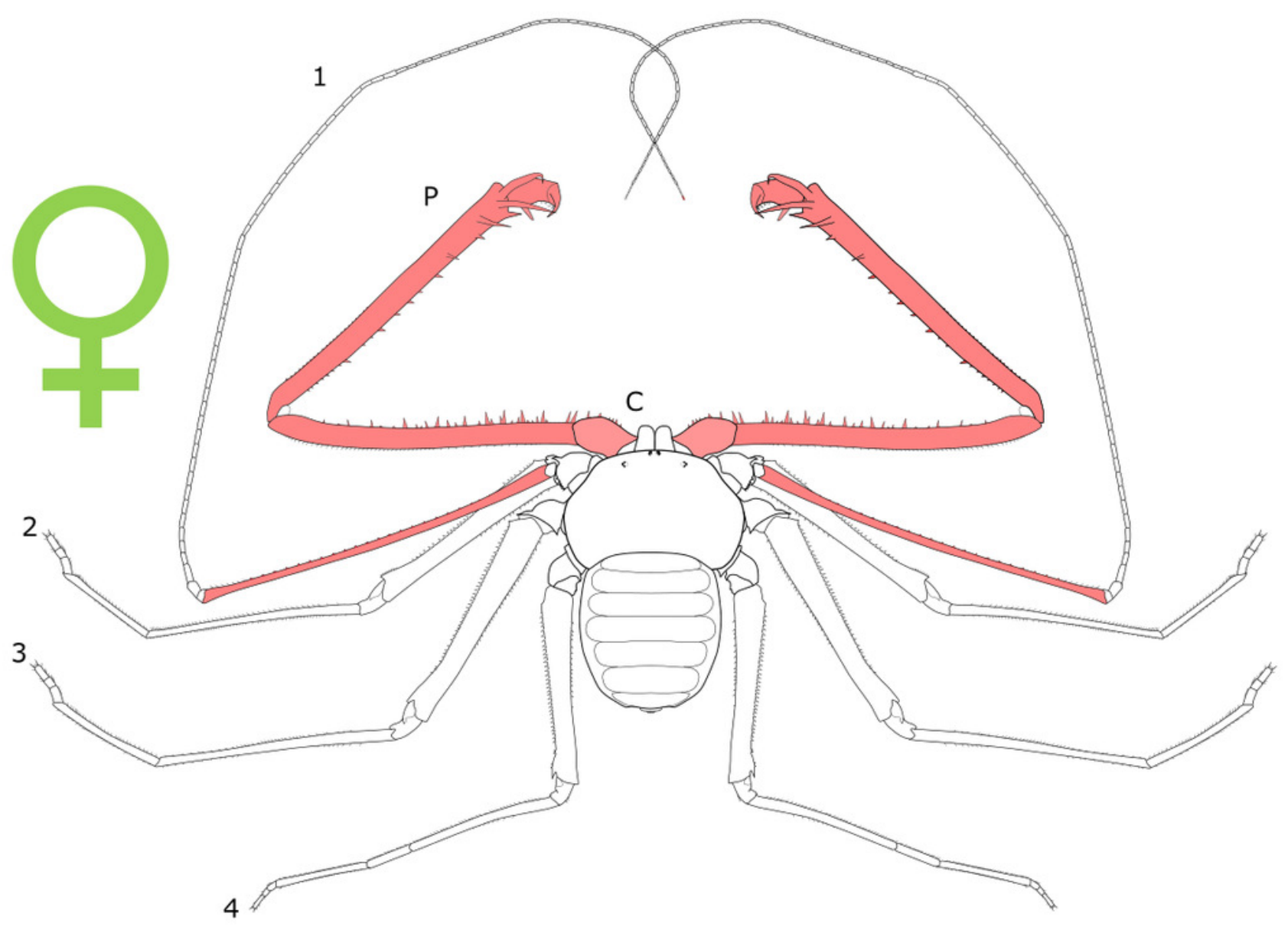


Figure 3

Relationship between log pedipalp tibia length and log carapace length

Relationship between log pedipalp tibia length and log carapace length (modified from Weygoldt, 2000). Regression analysis was re-run with a type two regression; against the HO that the two rates of allometric growth are equal $p=<0.001$ for Damon gracilis $(A), p=0.031$ for Damon variegatus (B).
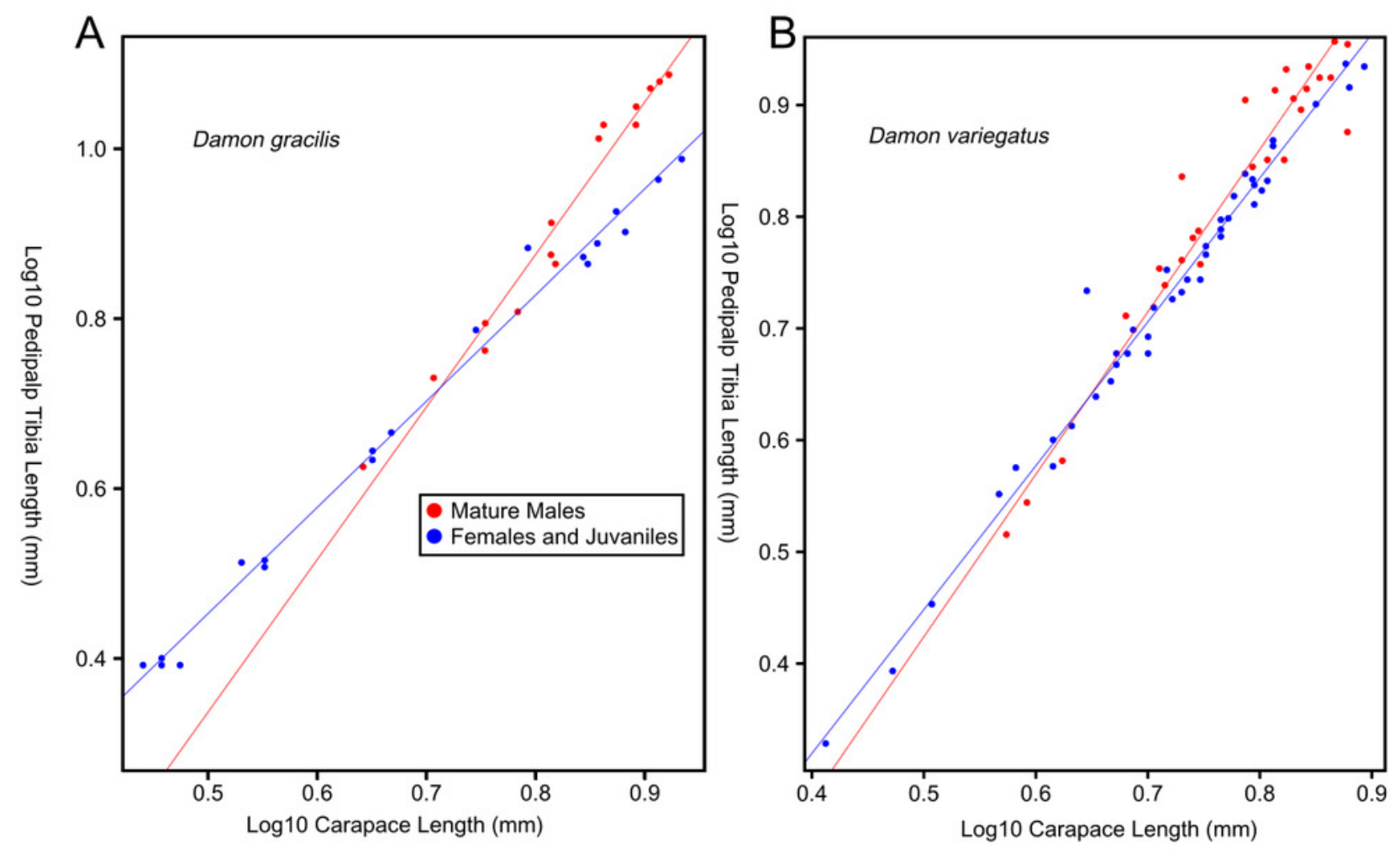
Figure 4

\section{Patterns of SSD across Araneae}

See "Standard Figure Abbreviations" for labelling guide. 


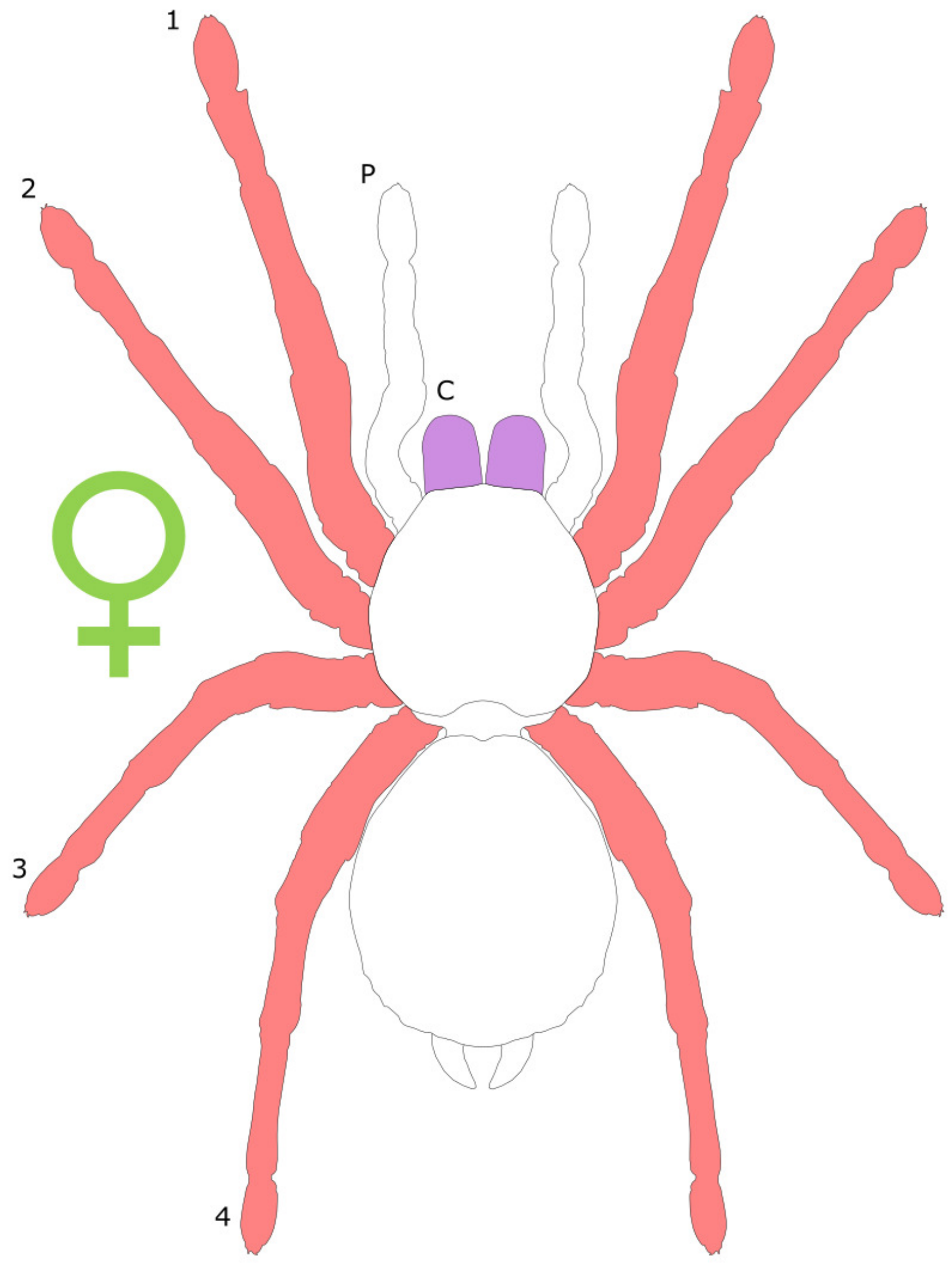


Figure 5

Patterns of SSD across Palpigradi

See "Standard Figure Abbreviations" for labelling guide. 


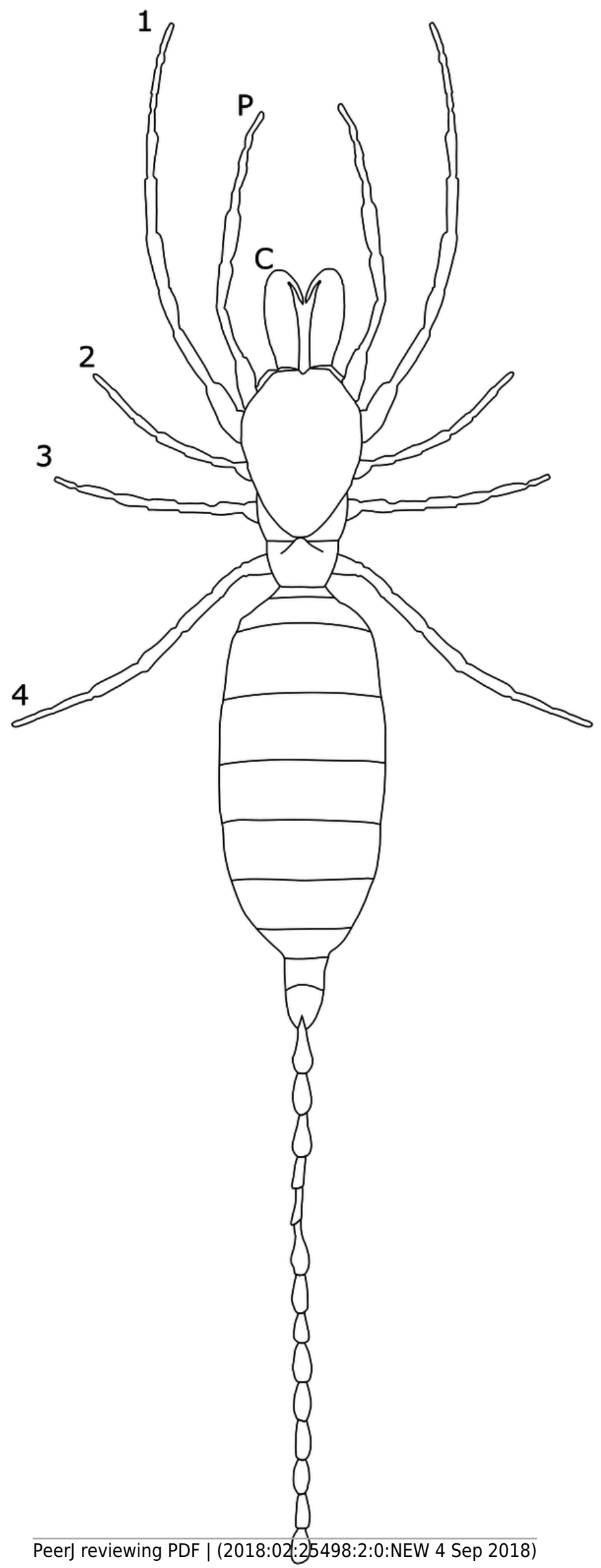


Figure 6

Patterns of SSD across Pseudoscorpiones

See "Standard Figure Abbreviations" for labelling guide.

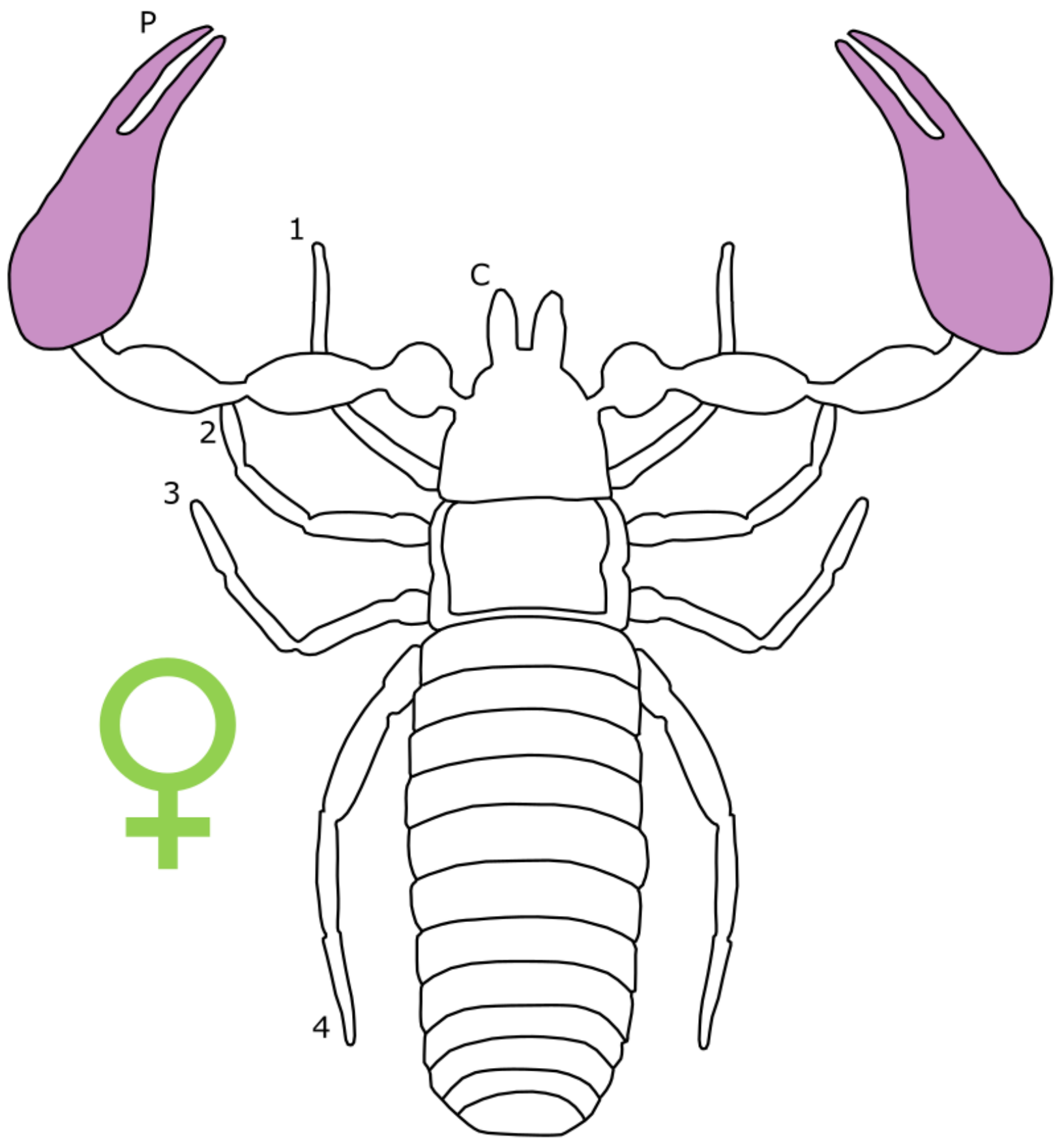


Figure 7

Patterns of sex bias in pedipalp claw SSD in Psuedoscorpions

Patterns of sex bias in pedipalp claw SSD in Psuedoscorpions, red dots indicate male bias, green is female-biased. Modified from Zeh (1987a).

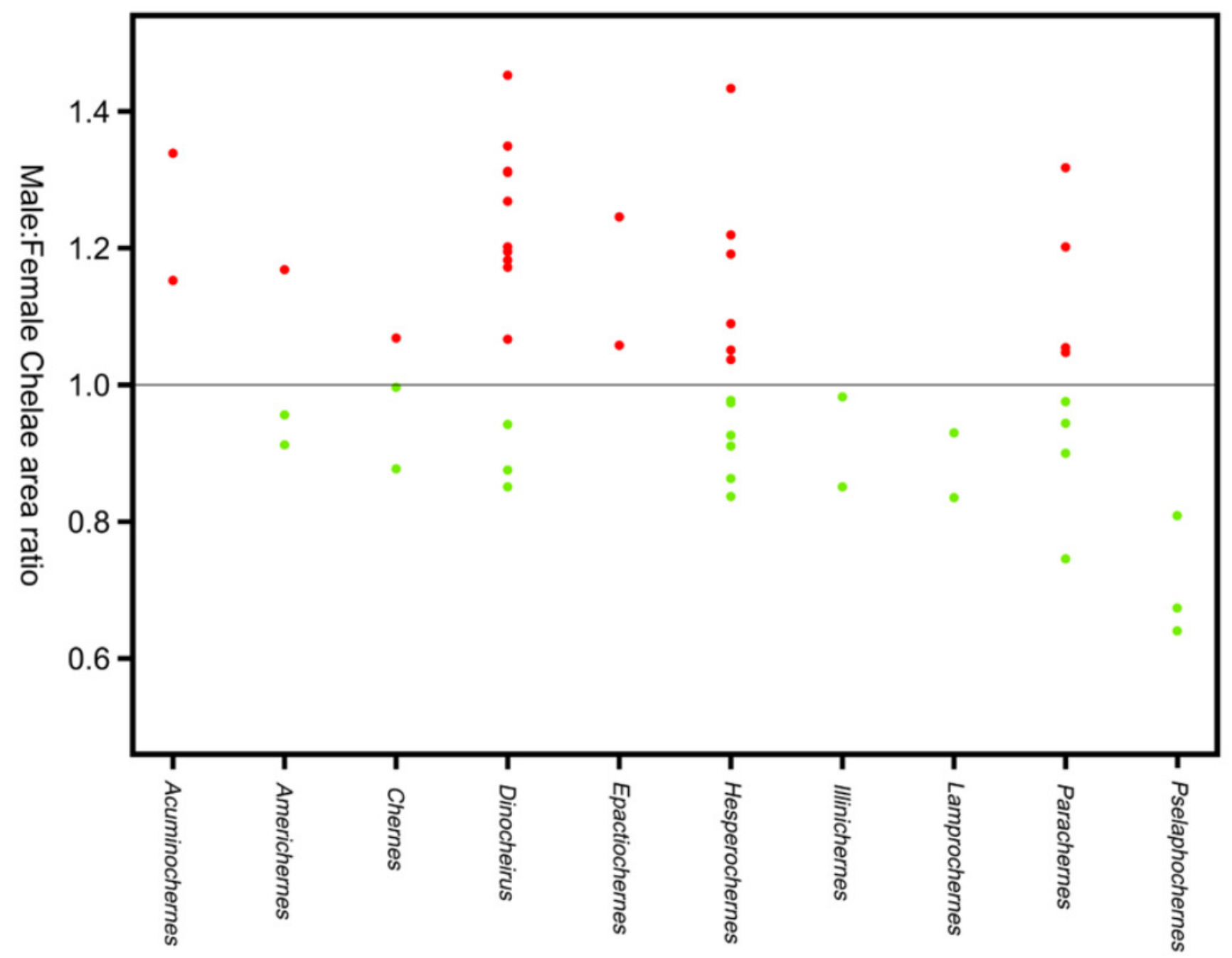

Genus 
Figure 8

Patterns of SSD across Opiliones

See "Standard Figure Abbreviations" for labelling guide.

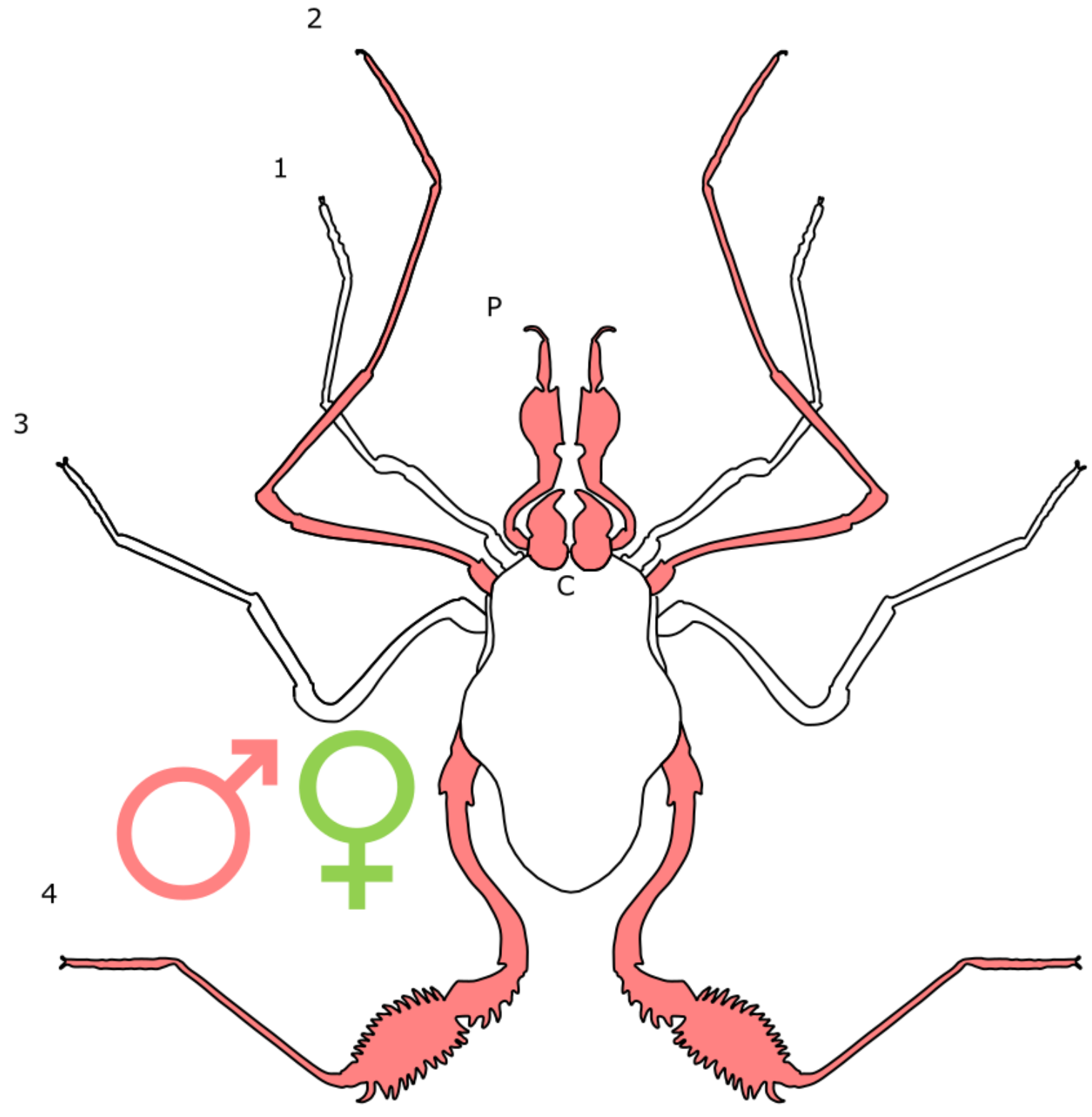




\section{Figure 9}

SEM images showing dimorphism in the chelicerae of P.opilo

The male chelicerae (B) are noted for the presence of a horn used in contest which is absent in the female (A, modified from Willemart et al, 2006) @ Canadian Science Publishing or its licensors.

*Note: Auto Gamma Correction was used for the image. This only affects the reviewing manuscript. See original source image if needed for review.
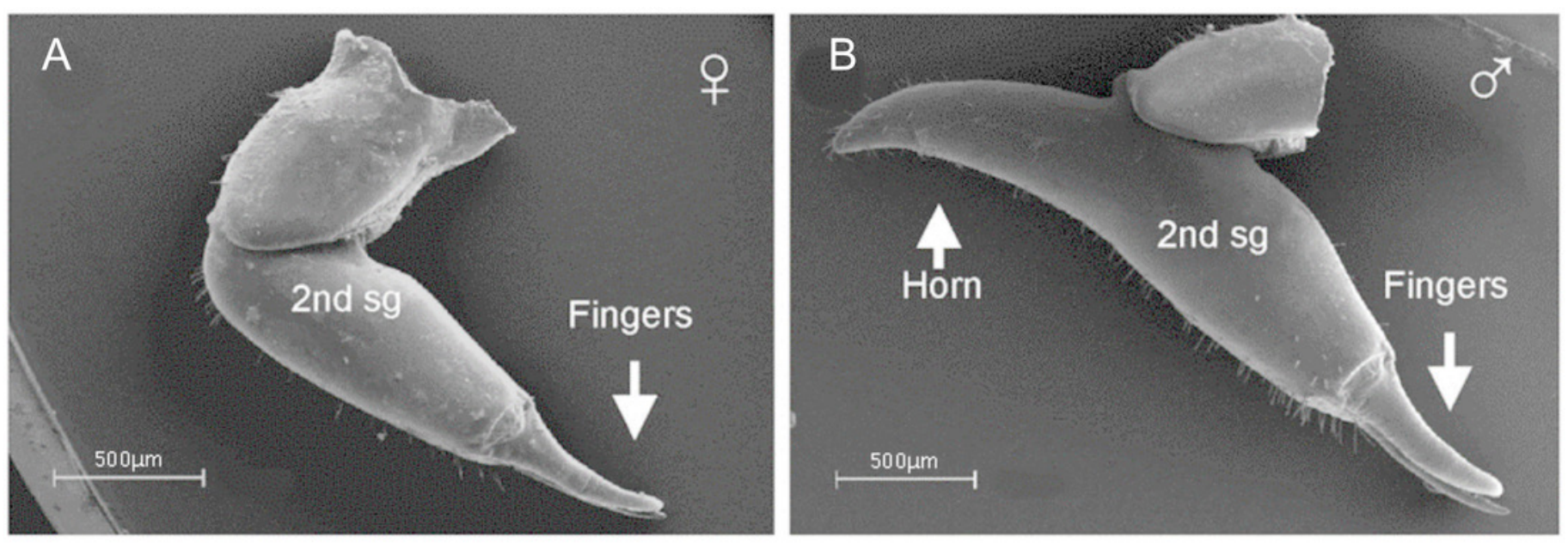
Figure 10

\section{Patterns of SSD across Ricinulei}

See "Standard Figure Abbreviations" for labelling guide, Cuc = cucullus

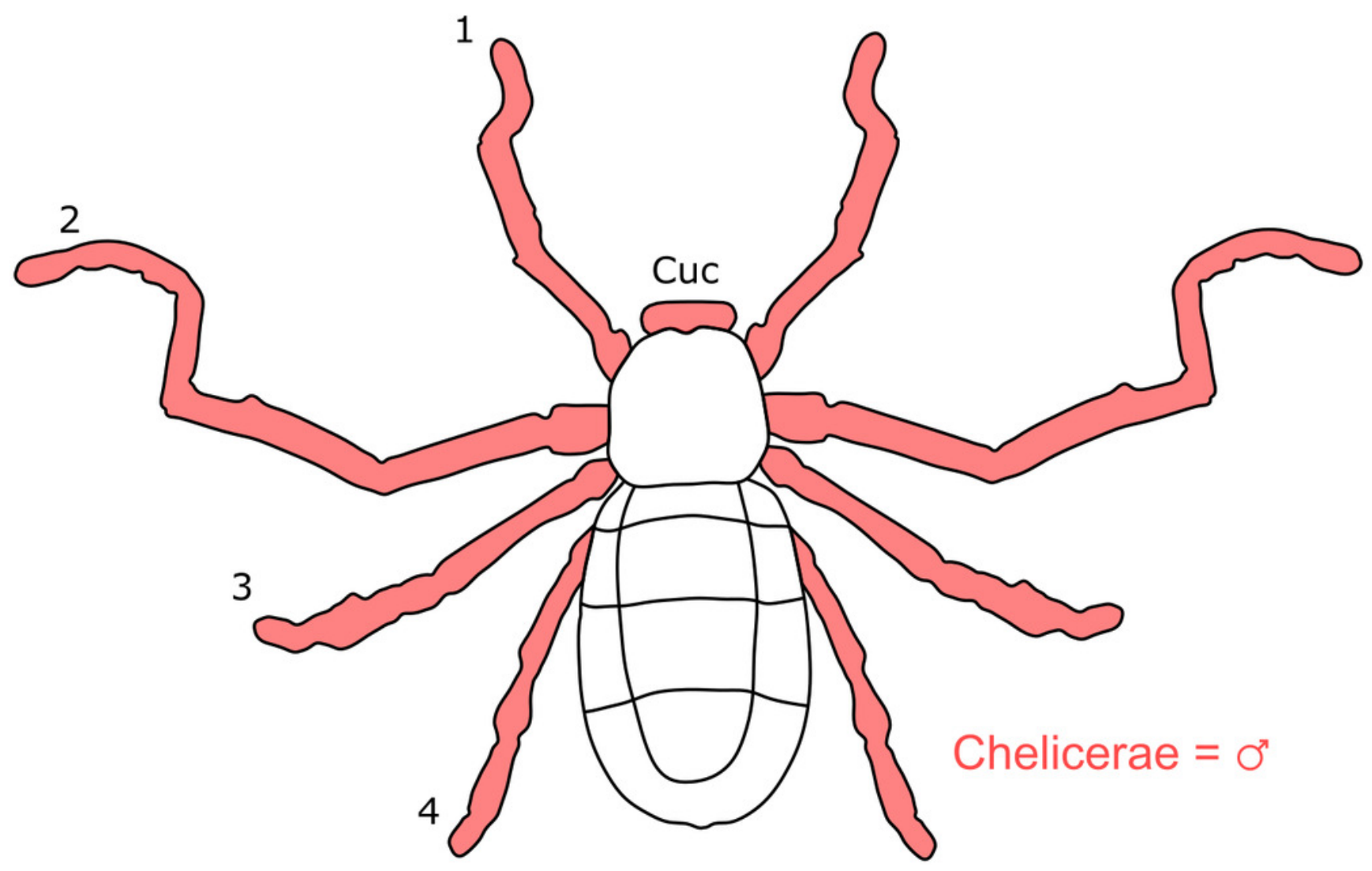


Figure 11

\section{Patterns of SSD across Schizomida}

See "Standard Figure Abbreviations" for labelling guide. 


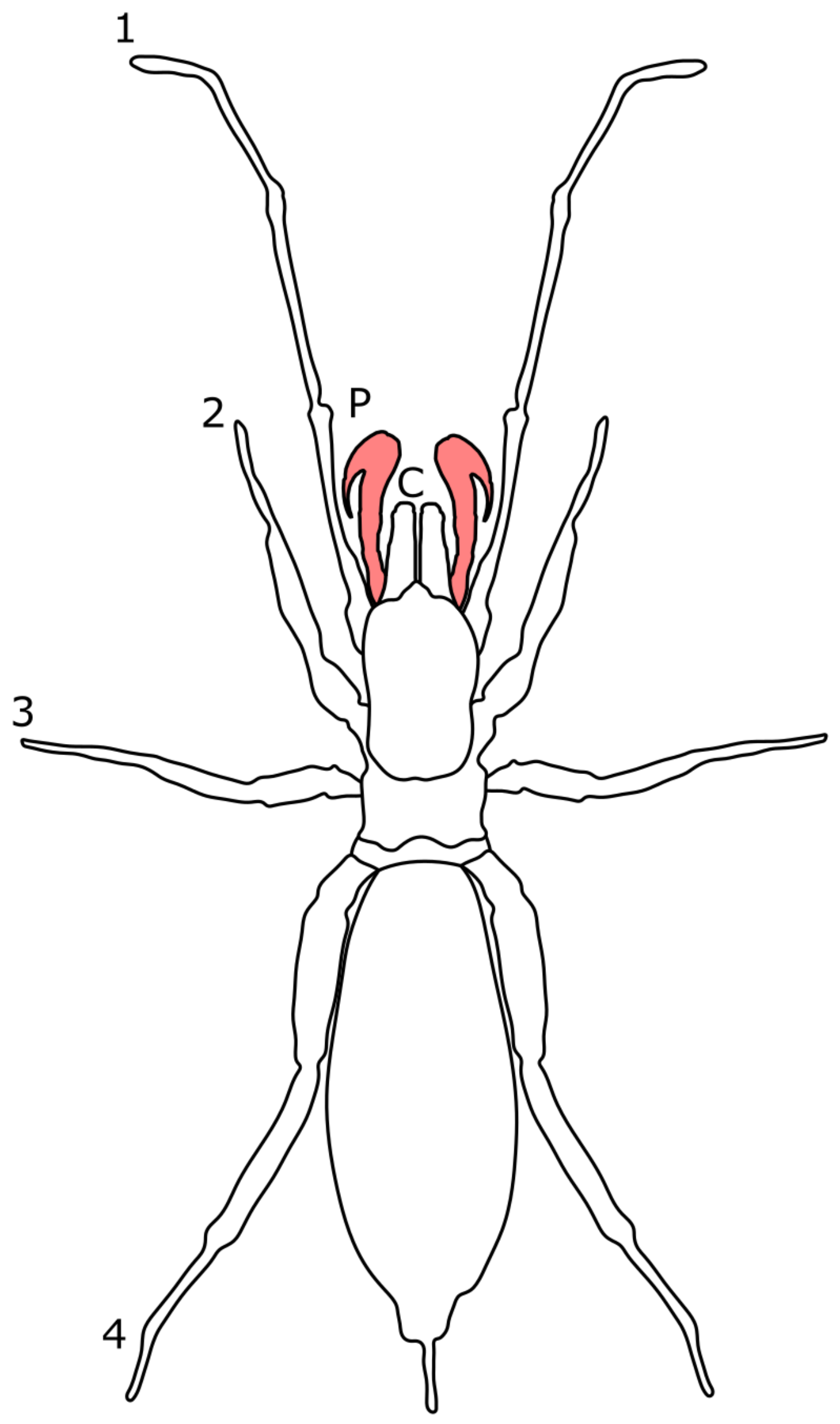




\section{Figure 12}

Patterns of differences in pedipalp lengths denoting both sexual and male dimorphism.

$A=$ frequency histogram of pedipalp patella lengths, $B=$ Relationship between pedipalp patella length and prosoma length for the two male morphs and female (modified from Santos et al, 2013). 


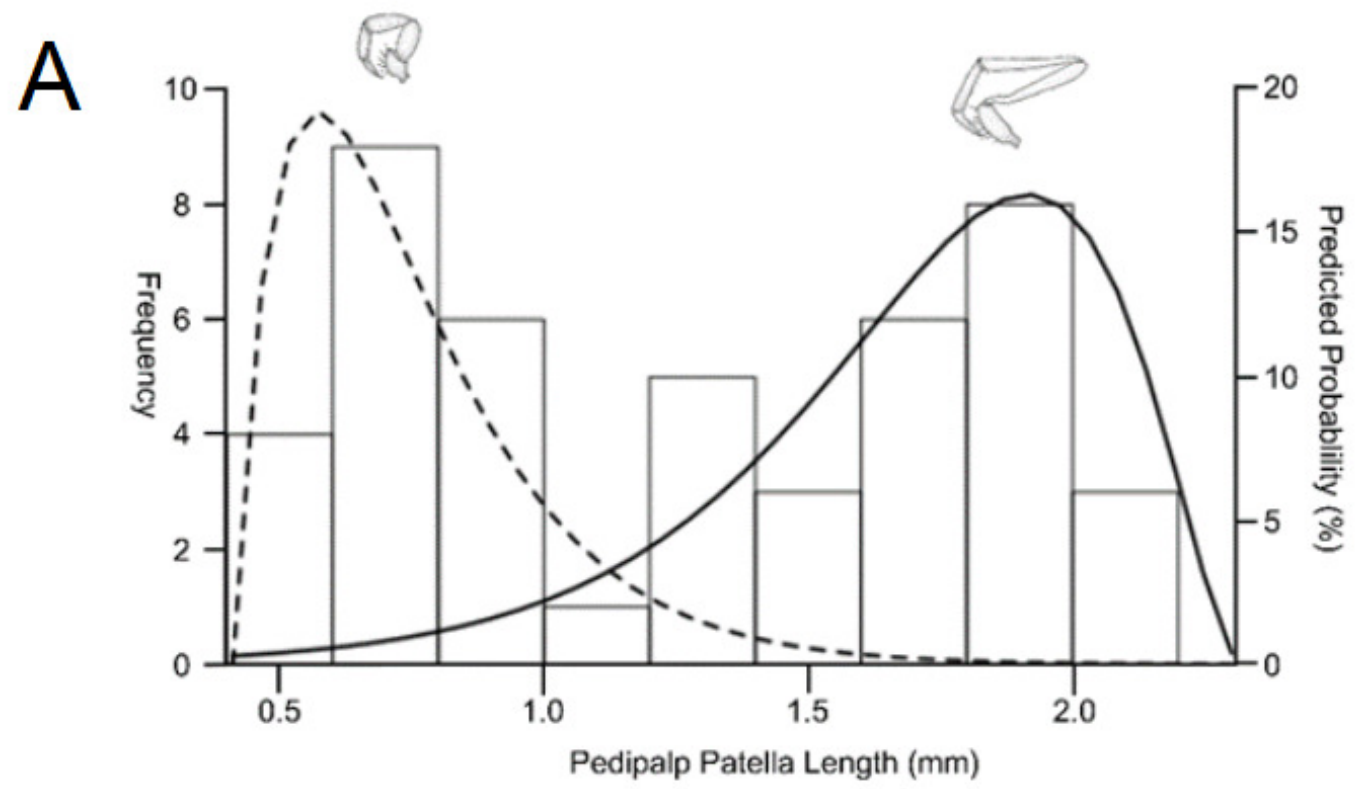

B

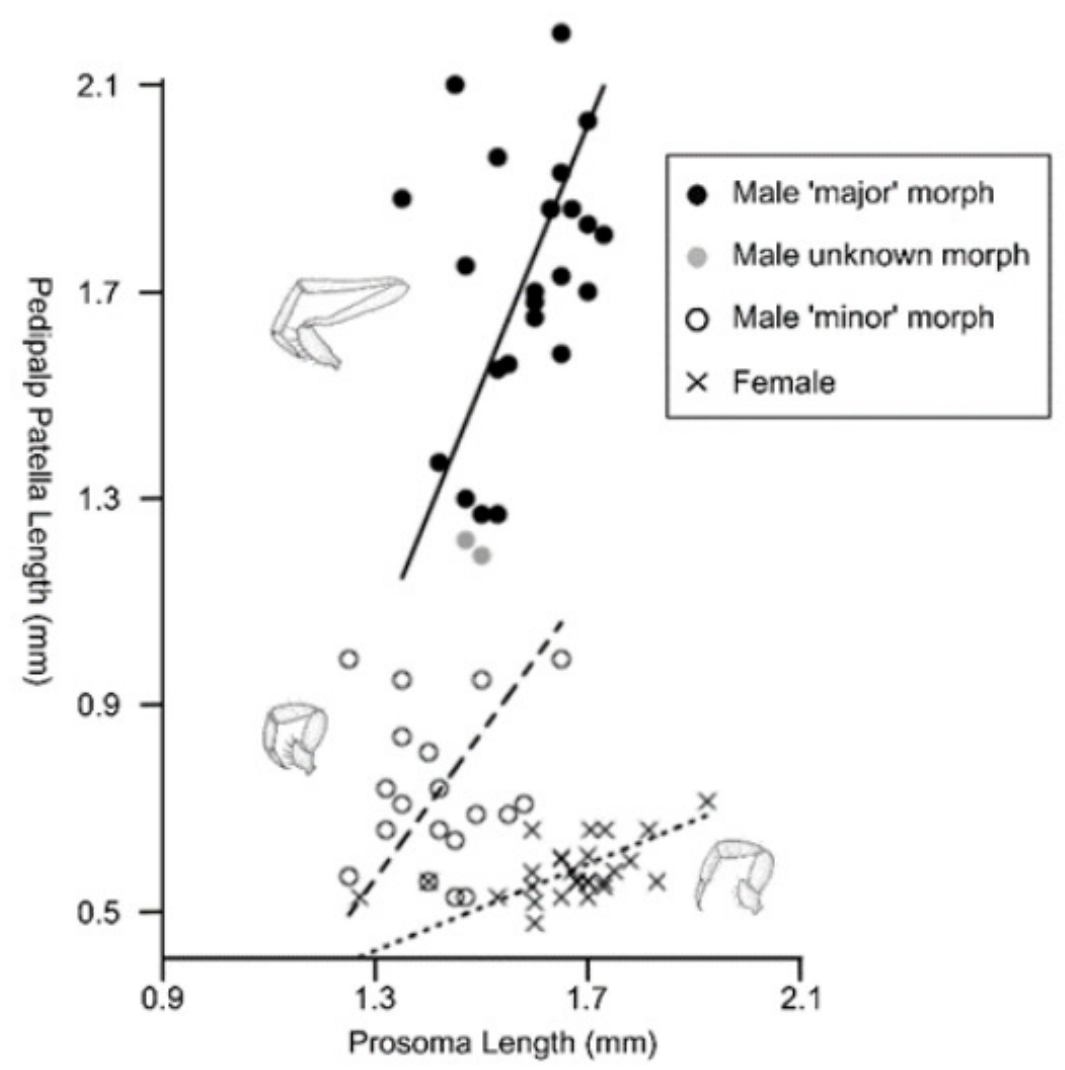


Figure 13

Patterns of SSD across Scorpiones

See "Standard Figure Abbreviations" for labelling guide.

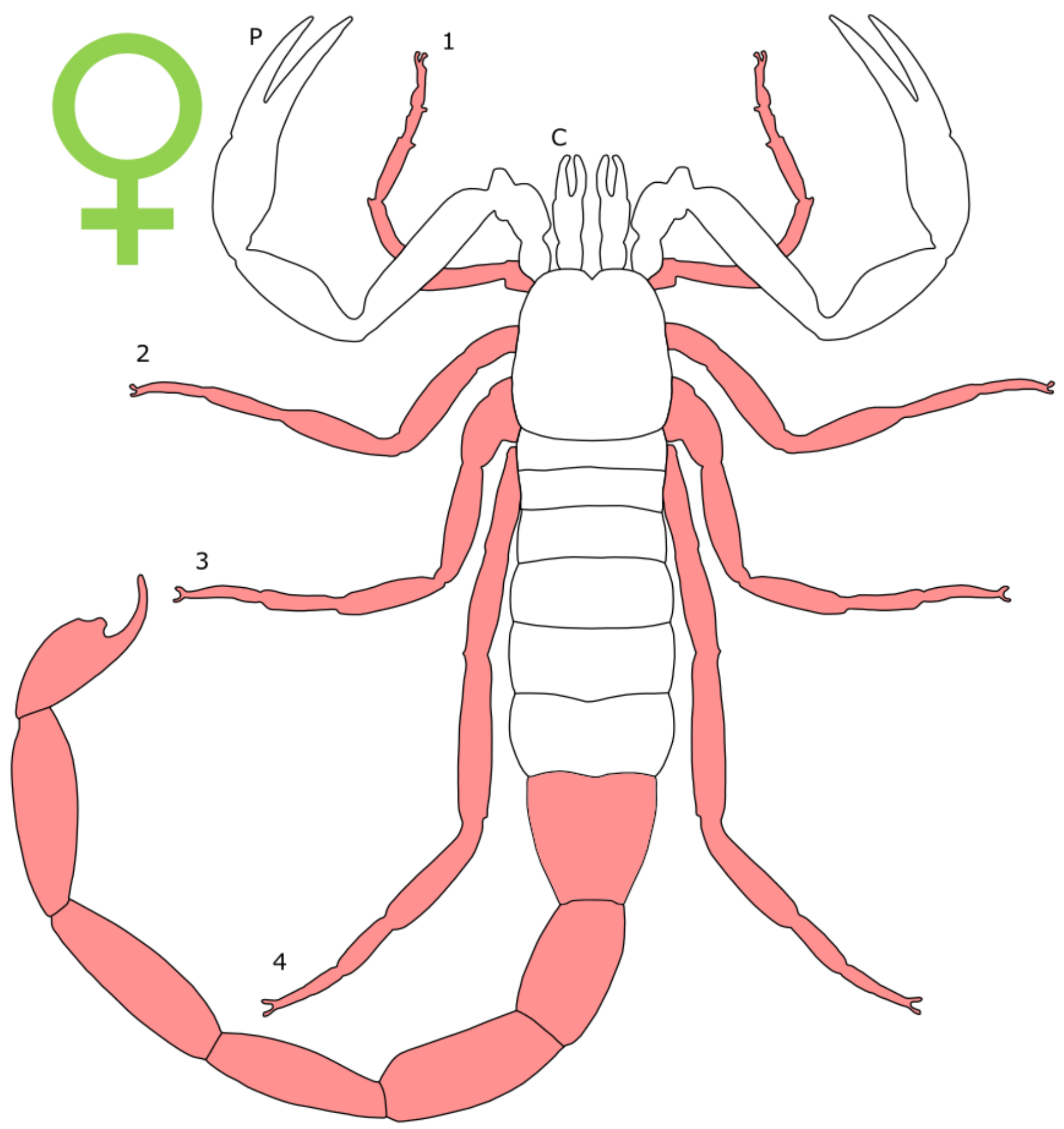




\section{Figure 14}

Sexually dimorphic body plan of Centruroides vittatus

Differences between the female (A) and male (B) body plan in Centruroides vittatus, note the longer metasoma and legs in the male.

O $A$

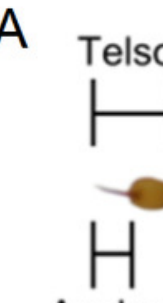

Aculeus
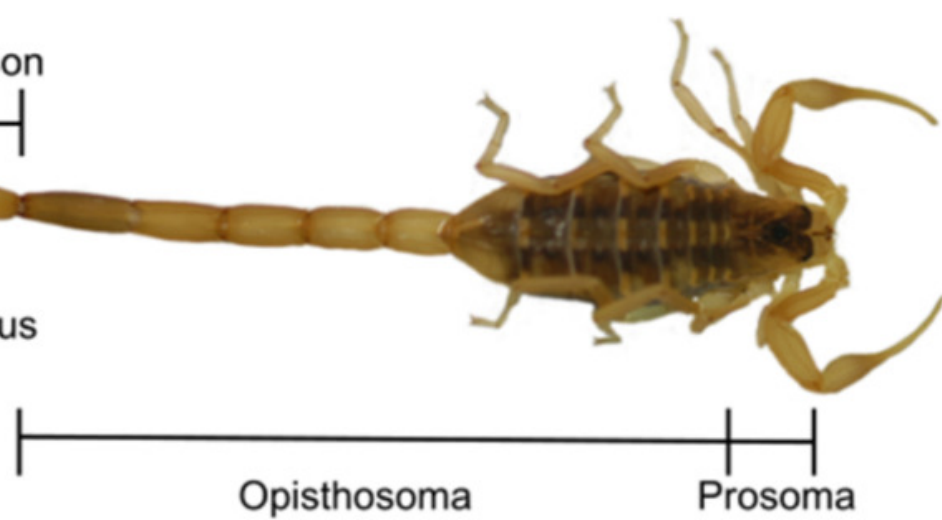

$\sigma^{7} B$

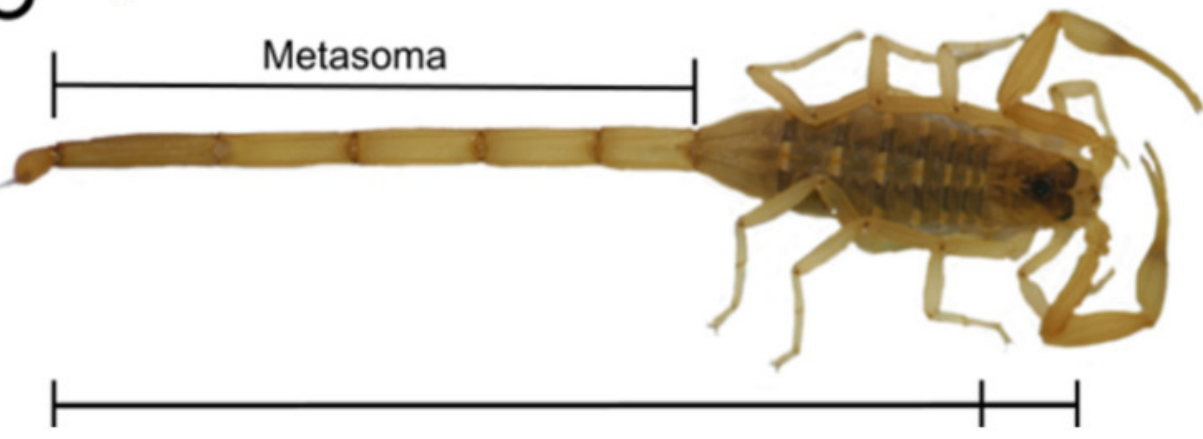

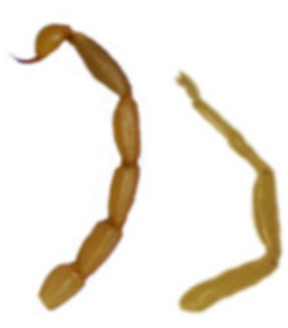

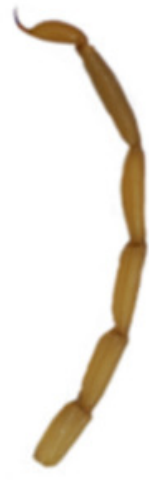

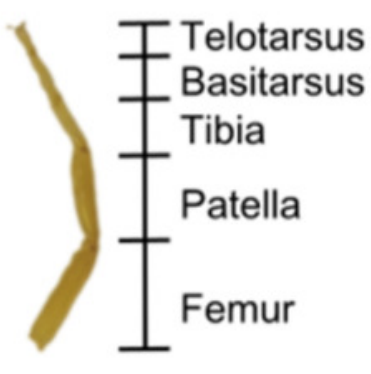


Figure 15

Patterns of SSD across Solifugae

See "Standard Figure Abbreviations" for labelling guide. 


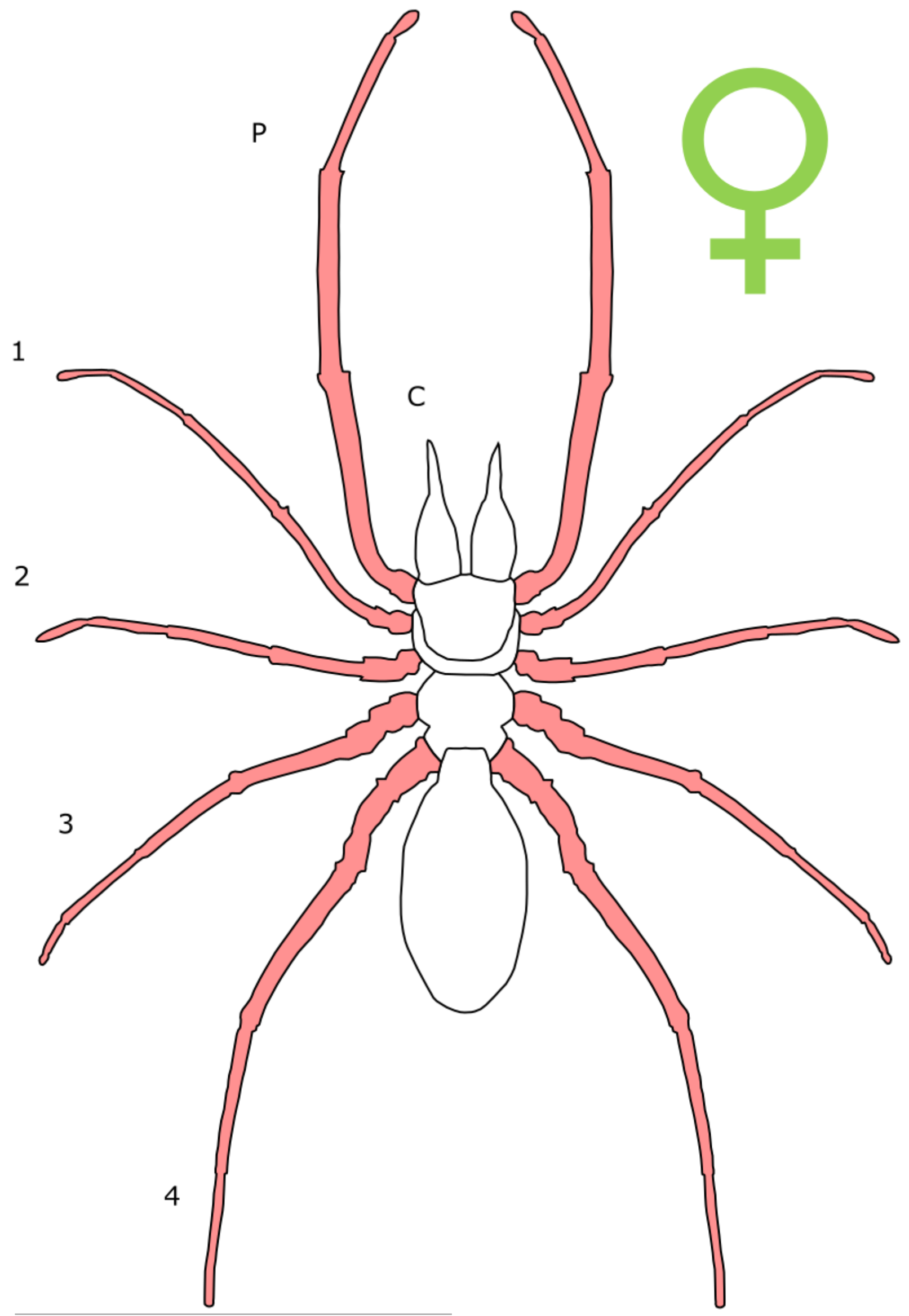


Figure 16

Patterns of SSD across Uropygi

See "Standard Figure Abbreviations" for labelling guide. 


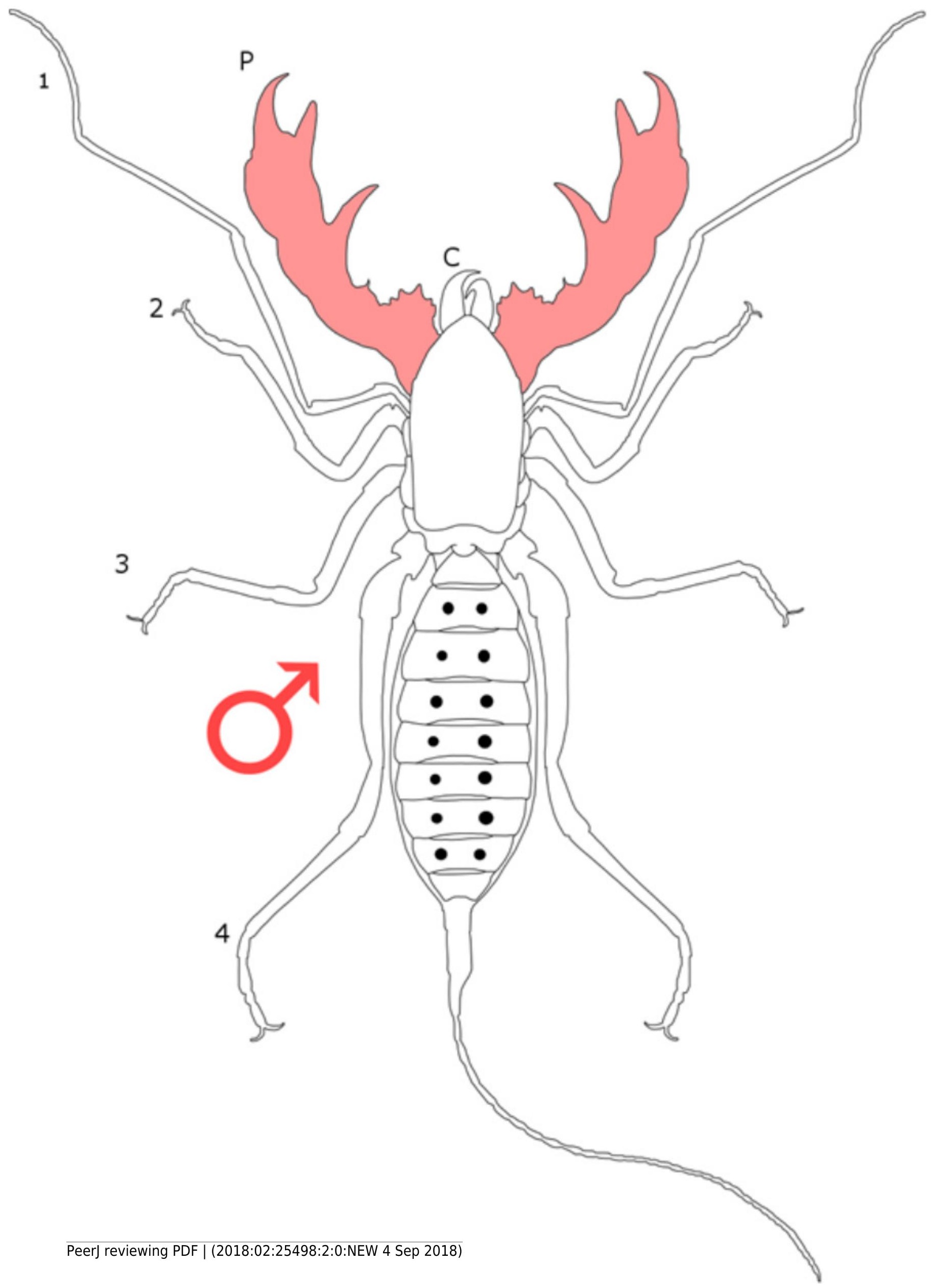




\section{Figure 17}

A broad consensus arachnid phylogeny encompassing a range of recent studies

A broad consensus arachnid phylogeny encompassing a range of recent studies (modified from Giribet, 2018). 


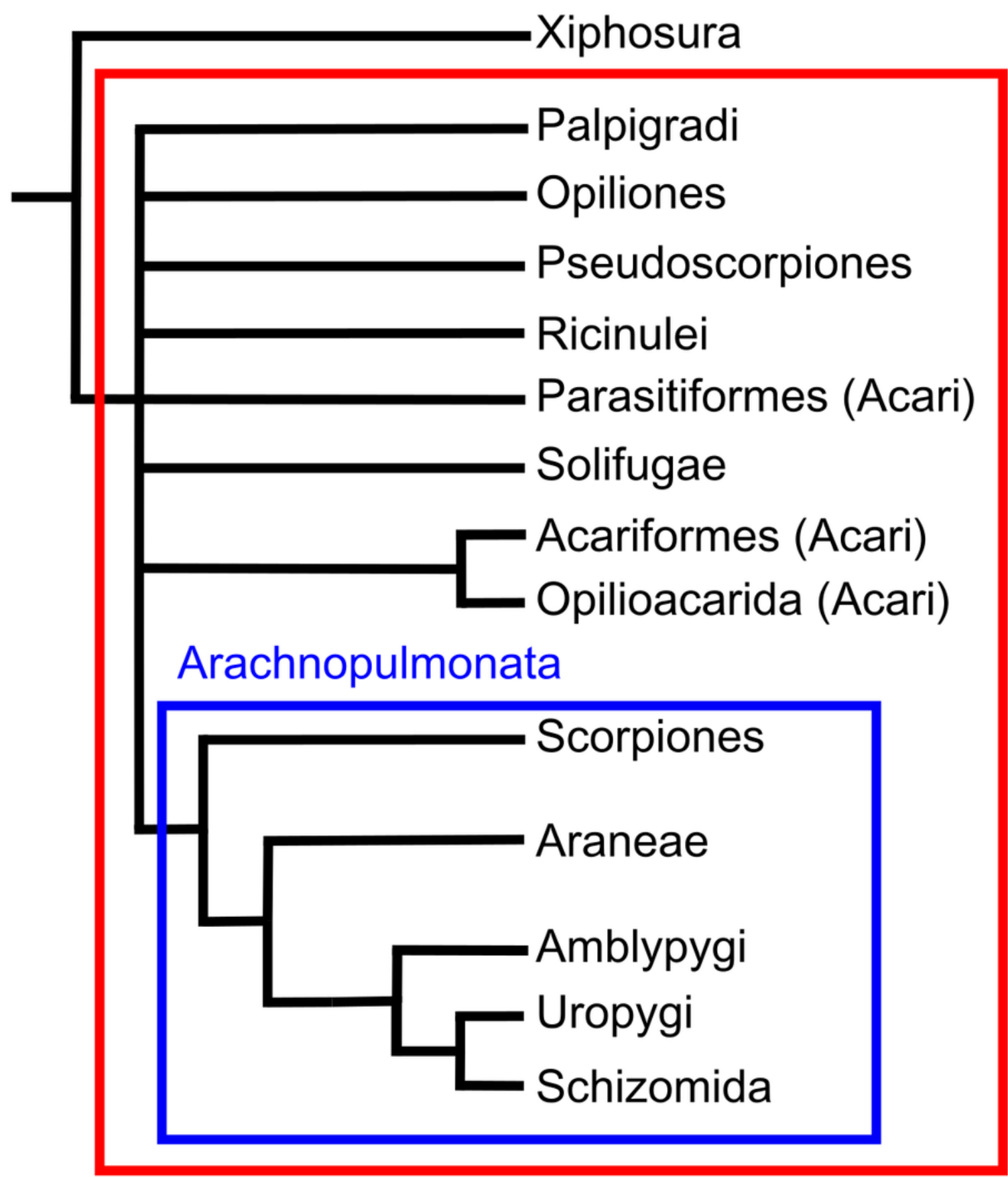

Arachnida 